\title{
The competition for supplier resources
}




\section{THE COMPETITION FOR SUPPLIER RESOURCES}

Niels J. Pulles 


\section{Promotion Committee:}

Chairman and Secretary:

Prof. dr. P.B. Boorsma

Promotor:

Prof. dr. habil. H. Schiele

Assistant Promotor:

Dr. J. Veldman

Members:

Prof. dr. C. Ellegaard

Prof. dr. ir. J.I.M Halman

Prof. dr. ir. J.J. Krabbendam

Prof. dr. J. Telgen

Prof. dr. A.J. van Weele
University of Twente

University of Twente

University of Groningen

Aarhus University

University of Twente

University of Twente

University of Twente

Eindhoven University of Technology

Printed by Ipskamp Drukkers

ISBN: 978-90-365-3733-9

DOI: $10.3990 / 1.9789036537339$

(C) 2014 Niels J. Pulles

All rights reserved. No part of this publication may be reproduced, stored in a database or retrieval system, or published in any form or in any way, electronically, mechanically, by print, photo print, microfilm, or any other means without prior written permission from the author. 


\section{THE COMPETITION FOR SUPPLIER RESOURCES}

\section{DISSERTATION}

to obtain

the degree of doctor at the University of Twente,

on the authority of the rector magnificus,

prof.dr. H. Brinksma,

on account of the decision of the graduation committee,

to be publicly defended

on day the $19^{\text {th }}$ of September 2014 at 12:45

by

\section{Niels J. Pulles}

Born on the $6^{\text {th }}$ of May 1984

in Scharsterland, The Netherlands 
This dissertation has been approved by:

Prof. dr. habil. H. Schiele Promotor

Dr. J. Veldman Assistant Promotor 


\section{Table of contents}

List of abbreviations

Chapter 1: Introduction 3

1.1. Research motivation 4

1.2. Literature background 5

1.3. Preferential resource allocation from suppliers 6

$\begin{array}{ll}\text { 1.4. Research focus and key objectives } & 7\end{array}$

1.5. Dissertation outline 10

1.6. Included publications 11

Chapter 2: Identifying innovative suppliers in business networks: 13 An empirical study

2.1. Introduction 14

2.2. Conceptual framework and hypotheses 15

2.3. Methodology 21

2.4. Results 25

2.5. Discussion and implications 27

Chapter 3: Obtaining better resources from a shared supplier network: 31

Customer attractiveness, supplier satisfaction, and their roles in attaining preferred customer status

3.1. Introduction $\quad 32$

3.2. Preferred customer status: obtaining preferential 33 resource allocation from suppliers

3.3. Customer attractiveness and supplier satisfaction and 34 their link to preferential resource allocation

3.4. The dimensions of customer attractiveness and 37 supplier satisfaction

3.5. Methodology for testing the hypotheses 40

3.6. Data analyses and results of hypotheses testing 45

3.7. Discussion and implications 46

Chapter 4: Winning competition for suppliers' resources: The role of 51 preferential resource allocation from suppliers

4.1. Introduction 52

4.2. The extended resource based view and the competition 53 for supplier resources

4.3. Indirect capabilities $\quad 54$

4.4. Conceptual model and hypotheses 55

4.5. Methodology 59

4.6. Results 64

4.7. Conclusions and discussion 67 
Chapter 5: Pressure or pamper? The effects of power and trust dimensions on supplier resource allocation

5.1. Introduction

5.2. Supply base rivalry

5.3. Theoretical background 74

5.4. Power, trust and supplier resource allocation 75

$\begin{array}{ll}\text { 5.5. Hypotheses } & 76\end{array}$

5.6. Methodology 83

5.7. Results $\quad 88$

5.8. Conclusions and discussion 91

5.9. Limitations and future research 94

Chapter 6: Summary and discussion $\quad 97$

6.1. Main findings 98

6.2. Implications and contributions 99

6.3. Limitations and future research 103

$\begin{array}{ll}\text { References } & 106\end{array}$

Appendix 1: Measures Chapter 2 122

Appendix 2: Measures Chapter $4 \quad 123$

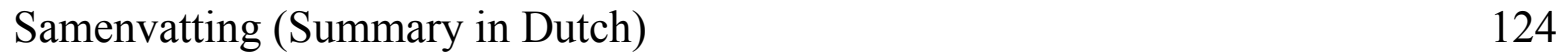

$\begin{array}{ll}\text { Acknowledgements } & 127\end{array}$ 


\section{List of abbreviations}

$\begin{array}{ll}\text { AVE } & \text { Average variance extracted } \\ \text { CFI } & \text { Comparative fit index } \\ \text { CL } & \text { Construct loading } \\ \text { CPO } & \text { Chief executive officer } \\ \text { CR } & \text { Composite reliability } \\ \text { ERBV } & \text { Extended resource-based view } \\ \text { GFI } & \text { Goodness-of-fit index } \\ \text { GM } & \text { General Motors } \\ \text { IMP } & \text { Industrial marketing and purchasing } \\ \text { IT } & \text { Information technology } \\ \text { MFL } & \text { Method factor loading } \\ \text { NPD } & \text { New product development } \\ \text { NS } & \text { Non-significant } \\ \text { PLS } & \text { Partial least squares } \\ \text { R\&D } & \text { Research and development } \\ \text { RBV } & \text { Resource-based view } \\ \text { RMSEA } & \text { Root mean square error of approximation } \\ \text { RO } & \text { Research objective } \\ \text { SCM } & \text { Supply chain management } \\ \text { SD } & \text { Standard deviation } \\ \text { SET } & \text { Social exchange theory } \\ \text { TLI } & \text { Tucker-Lewis index } \\ \text { UK } & \text { United Kingdom } \\ \text { US } & \text { United States } \\ \text { VIF } & \text { Variance inflation factor } \\ & \end{array}$





\section{Chapter 1}

\section{Introduction}

For many firms, leveraging the supplier base for competitive resources remains a key challenge. This is especially the case when competing firms seek to acquire similar resources from the same supplier base. This dissertation examines the competition between buying firms for supplier resources. Chapter 1 introduces the four chapters (Chapters 2, 3, 4 and 5) and the research objectives that form the core of this dissertation. 


\subsection{Research motivation}

In many industries, firms are highly dependent on their suppliers. The performance of these suppliers often have an impact the overall performance of the firm. For example, if suppliers deliver low quality components, this negatively affects the quality of the products a firm delivers to its customers. If a firm delivers low quality products, its customers are likely to take their business to firms that offer higher quality products. This also holds for other aspects that are valued by the firm's customers such as price, innovativeness and availability. Put simply, suppliers can have a major influence on the competitiveness of the firm. Therefore, firms that manage their supplies and suppliers effectively can gain competitive advantages over competitors that lack such capabilities.

There are several examples of firms that attained positions of competitive advantage by means of successful supply management strategies. For instance, Dell's supply management practices enable the firm to offer its customers flexible, fast and low priced deliveries and Walmart's supply management enables its low-price strategy. Dyer and Hatch (2006), provide an example of the effective incorporation of supplier management in Toyota's operations strategies. They describe how during the 1990s, Toyota relocated most of its car production for the U.S. market to the U.S. itself to meet local content requirements. As a consequence, Toyota entered the supply market in which its U.S. competitors were already active. When Toyota entered the U.S. market, it had less relative bargaining power than its U.S. competitors due to smaller volumes. Still it was able to create competitive advantage while retrieving supplies from the same supply base as its competitors. Toyota did so by sharing knowledge and building relationships with suppliers. These efforts lead to a situation in which Toyota's vehicles had roughly 40 percent fewer defects than their competitors and suppliers lowered their defects and inventories at a significantly higher rate for Toyota operations than for the U.S. manufacturers (Dyer \& Hatch, 2006). A different example by Terpend and Ashenbaum (2012) based on an article by Kelly and Kerwin (1993) shows how a firm's supply management practices can also lead to situations in which supplier have no inclination to help the firm beyond meeting basic performance expectations. They describe how in the beginning of the 1990s, GM's key suppliers became reluctant to share their latest technologies with GM and were shifting their brightest engineers to Chrysler and Ford, due to GM's aggressive supply chain practices.

The above examples demonstrate the strategic importance of the supply management function for firms. Because of Toyota's supply management practices it gained advantages over its competitors despite the fact that these competitors were sourcing from the same suppliers. On the contrary, GM's supply management practices lead to a situation in which its suppliers allocated their best resources to GM's competitors. These cases illustrate how a firm's supply management practices can be decisive in a situation where firms acquire the same inputs from the same suppliers as their competitors. Those firms that acquire better resources from shared suppliers can be said to obtain preferential resource allocation from their suppliers. However, as will be discussed in this dissertation, still little is known about the supply management practices that can actually influence suppliers to allocate better resources 
to a certain buying firm. Despite recent contributions in the literature (e.g., Hüttinger, 2014) many questions remain unanswered as to how firms can influence the resources allocation of suppliers. Therefore, a central question in this dissertation is:

How can buying firms obtain preferential resource allocation from suppliers?

\subsection{Literature background}

The concept of preferential resource allocation originates from the term preferred customer status which was originally defined by Steinle and Schiele $(2008$, p. 11) as:

"A firm has preferred customer status with a supplier, if the supplier offers the buyer preferential resource allocation. This can be accomplished in several ways. A supplier may dedicate its best personnel to joint new product development, customize its products according to the customer's wishes, offer innovations or even enter into an exclusivity agreement. The supplier might also ensure privileged treatment if bottlenecks occur due to constraints in production capacity."

This definition built on resource-based theories (Wernerfelt, 1984; Barney, 1991). Resources are defined as the tangible or intangible financial, human, intellectual, organizational, and physical entities available to the firm that enable it to increase its competitive advantage (Hunt \& Davis, 2008; Newbert, 2008). These resources are not necessarily housed within the firm, but can be exchanged between firms (Dyer \& Singh, 1998; Das \& Teng, 2000; Capron \& Chatain, 2008; Hunt \& Davis, 2012). Whereas the traditional resource-based theories mainly looked within the firm for resources (Barney, 1991; Peteraf, 1993), newer perspectives focused on the resources that are acquired external to the firm to explain competitive advantage (Dyer \& Singh, 1998; Das \& Teng, 2000; Steinle \& Schiele, 2008; Hunt \& Davis, 2012). According to these theories competitive advantage is derived from both internal and external resources (Mathews, 2003; Squire, et al., 2009; Lewis, et al., 2010). A firm's supply management can be seen as a mechanism to obtain supplier resources (Koufteros, Vickery \& Dröge, 2012).

Different perspectives emerged in the literature that address the notion of acquiring supplier resources. For example, Ellegaard and Koch (2012) discuss the concept of supplier resource mobilization, which can be understood as the supplying firm's activities of preparing, activating and deploying its resources for the buying firms. Hunt and Davis (2008) theorize that supply management practices can create a comparative advantage in a firm's resource position (relative to competitors) which enables the firm to more easily attain competitive advantages in its market position. Based on the concept of factor-market rivalry (i.e., rivalry over resource positions) Ellram et al. (2013) explain how ignoring the competition for supplier resources with (atypical) rivals can negatively affect the performance of the firm's supply management. These studies illustrate the increased attention in the literature for the impact of supplier resources on the buying firm's competitive advantage. Still, current research provides little insight into the mechanisms firms can apply to improve their resource allocation from suppliers. This is expressed in the calls of several authors for 
more research into this topic. For example, Peng et al. (2008, p. 744) conclude in their study that: "As competition is increasingly moving beyond a single firm, future research could study supply chain capabilities (...) used for integrating resources and competency across firm boundaries." Takeishi (2001, p. 403) questions: "How could a company outperform competitors who also have cooperative relations with their partners?" Weigelt (2013, p. 15) examines IT capabilities of suppliers and questions: "how can a firm improve its performance by using supplier IT capabilities that are also available to its competitors?" And Hüttinger et al. (2012) call for more research to identify drivers of preferential treatment of buyers by their suppliers.

This dissertation aims to contribute to this upcoming field in the literature by means of four research objectives. Before discussing these objectives, section 1.3 discusses the concept of preferential resource allocation from suppliers.

\subsection{Preferential resource allocation from suppliers ${ }^{1}$}

Competitive advantage is a relative notion. A firm can only gain competitive advantage if its resources are superior relative to those of rivals (Peteraf, 1993). This implies that the resources obtained from a supplier that is shared with competitors, will more likely result in competitive advantage if the buying firm obtains better resources than its competitors. For example, a collaboration with a supplier can lead to increased performance of a buying firm, but if this supplier is in a similar collaboration with the buying firm's competitor who attains similar benefits, neither of these buying firms will achieve a direct advantage over its competitor from the collaboration with this supplier. A firm that is not capable of attaining a superior position in competitive resource environments may therefore lose the ability to differentiate itself from competitors and thereby lower its competitive advantage (Gnyawali and Madhavan, 2001; Takeishi, 2001). Gulati and colleagues unveil the key challenge. Firms have limits to the resources they can devote and "may only have the time and resources to form and satisfy the expectations of a limited number of alliances. By making choices to ally with some partners, others are ipso facto excluded" (Gulati, Nohria \& Zaheer, 2000, p. 210). A study by Lavie (2007) indicates how an increase in the level of competition in resource environments is negatively associated with a firm's market performance. As a consequence, competitors acting in similar resource environments compete for resources and deploy strategies to degrade the resource position of their rivals (Capron \& Chatain, 2008).

Firms have to win the competition for supplier resources in order to gain advantages over their rivals by means of their supplier relationships. Following this theory, a central thesis in this dissertation is that if a firm obtains preferential resource allocation (e.g., the best ideas, newest technologies, preferential allocation of scarce materials) from suppliers that are shared with competitors, it will more easily attain competitive advantage through relationships with its suppliers. Figure 1.1 illustrates this.

\footnotetext{
${ }^{1}$ Section 1.3. partly builds on Pulles and Schiele (2013)
} 


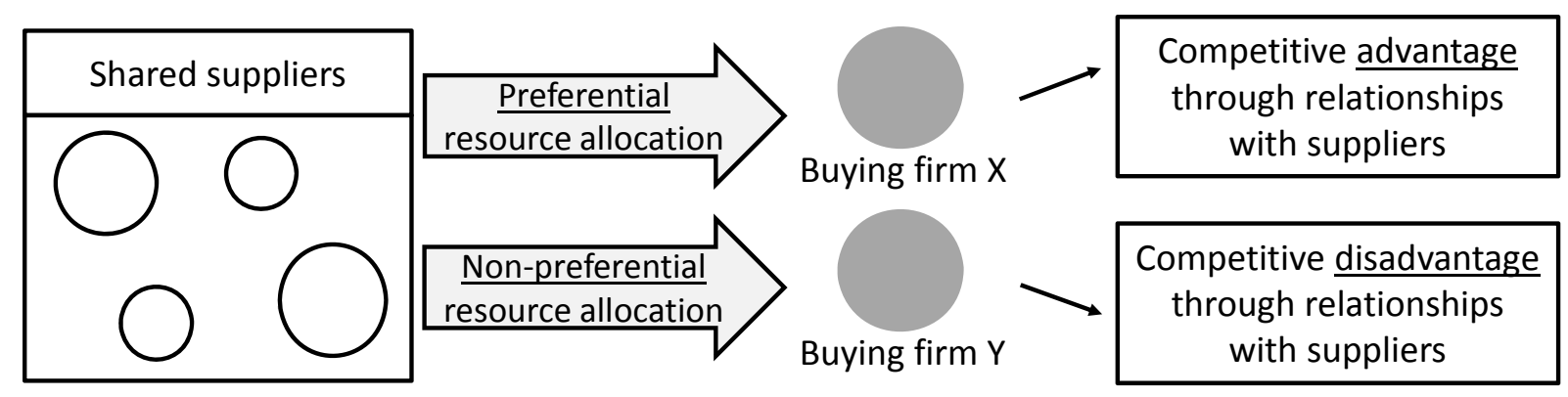

Fig. 1.1. The effect of resource allocation from shared suppliers on competitiveness

Of course, there are several ways in which buying firms can access supplier resources. For instance, mergers and acquisitions are often used practices to acquire external resources (Wernerfelt, 1984). However, to integrate the resources of a supplier a firm does not necessarily have to own the supplier. Instead, the integration of external resources can be achieved in relationships between an independent buyer and supplier (Heide \& John, 1992). In addition, in many situations acquiring a supplier is not desirable or feasible. This dissertation therefore focuses on the relational practices that firms can adopt in their relationships with suppliers. Firms typically have different relationships with many different suppliers. Buying firms that know how to adopt their behavior to gain better access to the resources of suppliers would enable themselves to more effectively utilize their supplier relationships to increase their competitiveness. The next section discusses the research objectives that examine the practices buying firms can apply to attain preferential resource allocation from suppliers.

\subsection{Research focus and key objectives}

Building on the model in Figure 1.1, this dissertation has four research objectives (ROs) that have one common focus: obtaining preferential resource allocation from suppliers. The first research objective (i.e., RO1) includes an examination of the preferred customer status construct as defined by Steinle and Schiele (2008). The subsequent ROs have a more theoretical focus in which the "preferential resource allocation from suppliers"-construct is introduced. The research that links to RO2-4 builds on the preferential resource allocation construct and theorizes on the construct's antecedents (RO2), the effects of the construct on the performance of the buying firm (RO3) and the dimensions of the construct itself (RO4). Gradually the ROs show a more detailed focus on the main construct of this dissertation: from examining the effect of preferred customer status only as a part of several characteristics by which buying firms can recognize innovative suppliers (RO1), to a detailed examination into how buying firms can influence supplier's allocation of different types of resources (RO4). Figure 1.2 gives an overview of this dissertation's research objectives. 


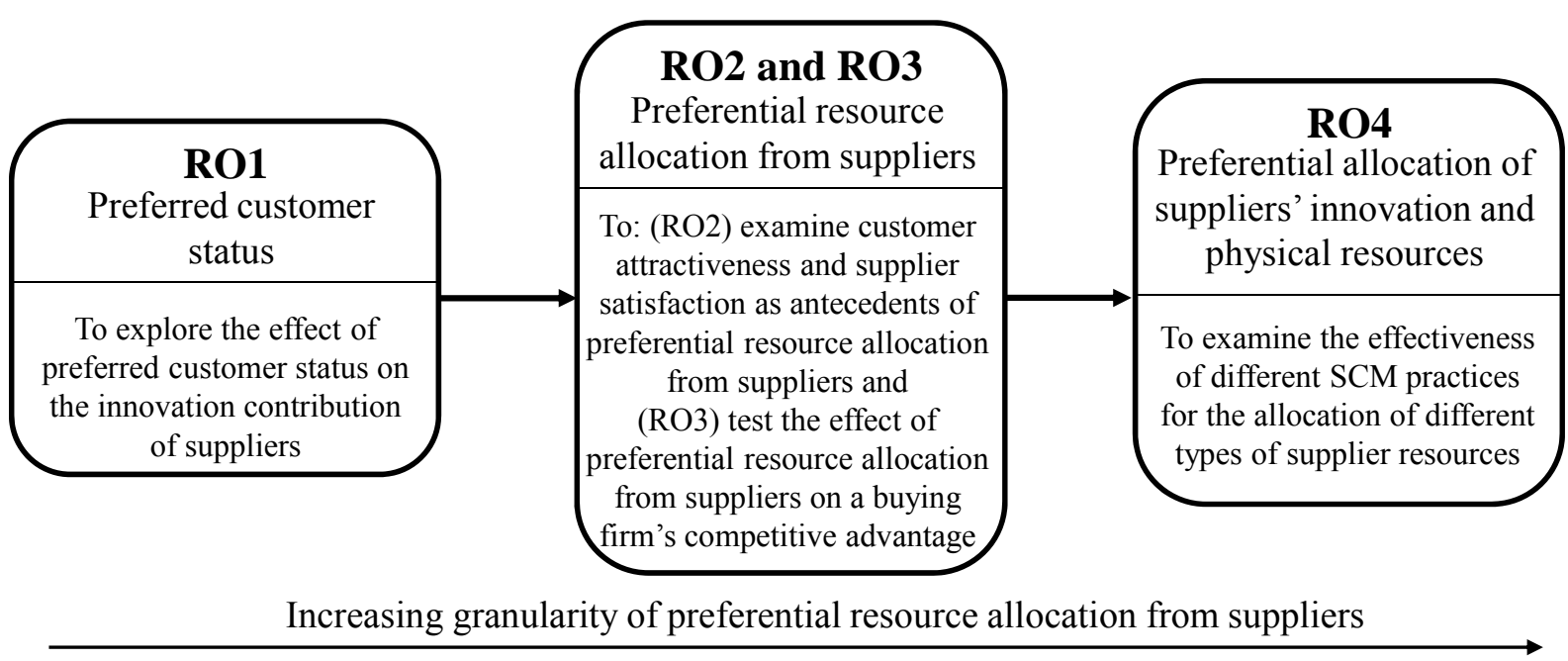

Fig. 1.2. Overview of research objectives

\subsubsection{Preferred customer status and identifying innovative suppliers}

The first research objective aims to explore preferred customer status and the context in which it can help buying firms. RO1 aims at clarifying how preferred customer status relates to other concepts that have been associated with successful buyer-supplier relationships. Because innovation is often the intended outcome of buyer-supplier relationships, RO1 focuses on examining the effect of preferred customer status to supplier contributions in buyer-supplier innovations. Not only preferred customer status is included in this research, also other characteristics of suppliers and buyer-supplier relationship characteristics that can contribute. Thus far, such a description of the nature of innovative suppliers was missing in the literature due to a lack of empirical evidence.

RO1. To examine those characteristics of suppliers and the characteristics of the buyer-supplier relationship, including preferred customer status, that significantly contribute to supplier contributions in buyer-supplier innovations.

\subsubsection{Preferential resource allocation and its antecedents}

The research relating to RO1 shows that preferred customer status positively links to supplier contributions in buyer-supplier innovations. This justifies a closer examination of the preferred customer status concept. Therefore, RO2 focuses on how firms can actually become a preferred customer. Chapter 3 presents this research. The research provides a closer examination of the preferred customer concept and introduces a new operationalization which builds on the resource-based literature: preferential resource allocation from suppliers. $\mathrm{RO} 2$ specifically focuses on the antecedents of preferential resource allocation from suppliers.

The literature reveals two concepts that play a crucial role for a firm aiming to obtain preferential resource allocation: (i) customer attractiveness (Christiansen \& Maltz, 2002; Ellegaard, Johansen \& Drejer, 2003; Hald, Cordón \& Vollmann, 2009; Ramsay \& Wagner, 2009; Mortensen \& Arlbjørn, 2012) and (ii) supplier satisfaction (Essig \& Amann, 2009; Ghijsen, Semeijn \& Ernstson, 2010; Nyaga, Whipple \& Lynch, 2010). However, the conceptual delineation between these constructs has proved to be challenging in the current literature (La Rocca, Caruana \& Snehota, 
2012). Consequently, the current literature still is ambiguous with regard to the relationships between these concepts. $\mathrm{RO} 2$ addresses these shortcomings.

RO2. To generate a comprehensive view on the dimensions of customer attractiveness and supplier satisfaction and to examine the relationship between these constructs as well as their effects on preferential resource allocation from suppliers.

\subsubsection{The effects of preferential resource allocation from suppliers}

Whereas RO2 addressed the antecedents of preferential resource allocation, RO3 aims at examining the effects of preferential resource allocation on the competitive advantage of the buying firm. In addition, RO3 addresses how the construct relates to supply chain management (SCM) capabilities that are often associated with higher buyer-supplier performance.

RO3 links to the ongoing debate in the literature whether the SCM function can have capabilities that lead to firm-level competitive advantages (e.g., Ramsay, 2001; Mol, 2003). Although recently scholars have begun to consider firm capabilities that can improve the outcome of inter-firm collaborations (e.g., Kale and Singh, 2007, Paulraj et al., 2008, Schilke and Goerzen, 2010), many questions remain as to how SCM capabilities relate to the competitive advantage of the buying firm. In addition, it remains unclear how preferential resource allocation from suppliers may affect the relationship between SCM capabilities and competitive advantage.

RO3. To identify SCM capabilities that have a positive effect on a buying firm's competitive advantage and to test how preferential resource allocation from suppliers affects this relationship.

\subsubsection{Preferential allocation of suppliers' innovation and physical resources}

$\mathrm{RO} 2$ and RO3 addressed preferential resource allocation as a single multidimensional construct. RO4 aims for a more detailed examination of preferential resource allocation and distinguishes between different types of resources. Generally, when applied to interorganizational studies, resources can be divided in two fundamental categories: tangible resources and intangible resources (Cropanzano \& Mitchell, 2005; Galbreath, 2005). It is likely that the practices to obtain these different types of supplier resources differ. Yet, the current literature provides only limited insights into how different types resources are exchanged in different types of relationship (Cropanzano \& Mitchell, 2005). To address this gap, the research linking to RO4 builds on social exchange theory (SET) to examine the effects of two core variables in this theory, power and trust, on suppliers' preferential allocation of different types of resources. This study combines the different dimensions of both power and trust in one empirical model.

RO4. To examine how the different dimensions of power and trust relate to suppliers' preferential allocation of different types of resources. 


\subsection{Dissertation outline}

The research that links to RO1-4 is presented in Chapters 2-5, respectively. The content of these chapters are briefly described below.

To address RO1, Chapter 2 develops and tests a framework to (1) empirically identify the supplier characteristics that explain the innovation potential of different suppliers, (2) examine the supplier's collaborative attitude and identify how a supplier's willingness to collaborate enables the buying firm to better exploit the innovation capabilities of the supplier, and (3) determine which relational characteristics lead to a stronger supplier commitment resulting in a greater innovation contribution from the supplier. This conceptual framework of this study is be based on previous studies in the Industrial Marketing and Purchasing literature. To test the framework, survey data from 121 respondents representing data for approximately 242 suppliers is analyzed. Partial least squares (PLS) structural equation modeling is employed to test the framework. The results provide a clearer empirical evaluation of the nature of innovative suppliers that allows managers to make better decisions with respect to sourcing suppliers with the highest expected innovation outcomes. In addition, Chapter 2 shows the relevance of preferred customer status for firms seeking for innovation contributions by their suppliers.

Chapter 3 refers to the resource-based literature to explain the relevance of the preferred customer construct. The study draws on social exchange theory to discuss the concepts of customer attractiveness and supplier satisfaction and to theorize on the relation of these constructs to preferential resource allocation from suppliers. Based on the notion that exchanges are not limited to material goods, but also include tangible value (Homans, 1958), attractiveness and satisfaction can explain the motivations of actors to initiate, intensify, or discontinue a relationship to attain additional value from exchange relationships (Thibaut \& Kelley, 1959; Blau, 1964). A customer is perceived as attractive if the supplier in question has a positive expectation towards the relationship with this customer (Schiele, Calvi \& Gibbert, 2012). Supplier satisfaction can be seen as a condition that is achieved if the quality of outcomes from a buyer-supplier relationship meets or exceeds the supplier's expectations (Schiele, Calvi \& Gibbert, 2012). Thus, whereas suppliers might be attracted to certain customers both $a$ priori and a posteriori a relationship, satisfaction can only occur a posteriori. Following this review, Chapter 3 builds on discussions with practitioners to generate customer attractiveness and supplier satisfaction dimensions that provide a comprehensive view on the different dimensions of these constructs. In addition, Chapter 3 follows the construct development framework by Diamantopoulos and Winklhofer (2001) to build measures of the customer attractiveness, supplier satisfaction, and preferential resource allocation constructs. These measures are used to test hypotheses on the relationships between the constructs using the data of 91 supply firms. The results provide a clearer view of the properties of customer attractiveness and supplier satisfaction and provide more consensus concerning their conceptual relationship with each other and with preferential resource allocation.

Chapter 4 addresses RO3 by examining two capabilities (linking to the conceptual work of Teece, 2007) that refer to a firm's capability to observe resource 
opportunities in its supply base (i.e., selection capability) and the ability to form an effective relation that facilitates resource exchange (i.e., relational capability). These capabilities are regarded as indirect capabilities (referring to a firm's ability to organize access to the complementary and dissimilar resources of other organizations). Both capabilities are hypothesized to have a positive effect on the competitive advantage of the buying firm. Also, the capabilities can help firms achieve preferential resource allocation from suppliers. Thus, because both the capabilities and preferential resource allocation relate to competitive advantage, and because the capabilities affect preferential resource allocation, a mediating effect of preferential resource allocation is hypothesized. In addition, it is examined how the impact of preferential resource allocation may differ for manufacturing and service firms. The resource-based literature is used to frame the relevance of this study's main variable: preferential resource allocation from suppliers. Data of 163 respondents from procurement functions were used to test the framework. The study in Chapter 4 advances the current literature because the findings (1) provide a fuller explanation of how capabilities within the SCM realm are linked to a firm's competitive advantages, (2) show the effect of preferential resource allocation from suppliers on the relationship between SCM capabilities and competitive advantage and (3) show the different effects of preferential resource allocation for manufacturing firms and service firms.

Chapter 5 links to RO4 and examines the effectiveness of different SCM practices on suppliers' preferential allocation of different types of resources. More specifically, Chapter 5 links dimensions of power and trust to supplier's allocation of (1) physical (tangible) and (2) innovation (intangible) resources. Also, it is examined how the effects of power and trust might change for differences in the buying firm's share in the supplier's turnover. This study analyzes survey data of 185 supplying firms using structural equation modeling. A multigroup analysis is conducted to test the effect of a buying firm's share in turnover. Chapter 5 contributes additional insights into the SCM strategies that can improve preferential resource allocation. In addition, it makes an empirical contribution to the SET literature by showing the different effects of power and trust on the preferential allocation of different types of supplier resources.

\subsection{Included publications}

Chapters 2-5 are based on four individual papers that have been either published in a peer-reviewed journal or in the proceedings of an international conference. The following papers serve as a basis of this dissertation:

Chapter 2. Pulles, N.J., Veldman, J. \& Schiele, H. (2014). Identifying innovative suppliers in business networks: An empirical study. Industrial Marketing Management, 43(3), 409-418.

A preliminary version of the paper was presented at the $20^{\text {th }}$ IPSERA conference, Maastricht, The Netherlands, April 2011. 
Chapter 3. Pulles, N.J., Schiele, H., Veldman, J. \& Hüttinger, L. Obtaining better resources from a shared supplier network: Customer attractiveness, supplier satisfaction, and their roles in attaining preferred customer status.

Currently in the second review round at an Industrial Marketing journal. A preliminary version of the paper was presented at the $21^{\text {st }}$ IPSERA conference, Naples, Italy, April 2012

Chapter 4. Pulles, N.J., Veldman, J. \& Schiele, H. Winning competition for suppliers' resources: The role of preferential resource allocation from suppliers.

Currently in the second review round at an Operations Management journal. A preliminary version of the paper was presented at the $21^{\text {st }}$ IPSERA conference, Naples, Italy, April 2012 and at the $10^{\text {th }}$ annual CAMS workshop, Skagen, Denmark, January 2012.

Chapter 5. Pulles, N.J., Veldman, J., Schiele, H. \& Sierksma, H. (2014). Pressure or Pamper? The Effects of Power and Trust Dimensions on Supplier Resource Allocation. Journal of Supply Chain Management, 50(3), 16-36.

A preliminary version of the paper was presented at the $24^{\text {th }}$ POMS conference, Denver, CO, the United States. 


\title{
Chapter 2
}

\section{Identifying innovative suppliers in business networks: An empirical study}

\begin{abstract}
In the literature, considerable attention has been given to the role of supplying firms in the context of innovation. However, not every supplier is capable of contributing to a buyer's innovation performance. In addition, the willingness and commitment of suppliers to collaborate with buyers is not always apparent. Thus far, the literature has not given a conclusive description of the nature of innovative suppliers due to a lack of empirical evidence. In this study, we seek to identify a set of characteristics that can identify those suppliers that can make significant contributions to a buyersupplier collaboration. Our statistical analysis of survey data shows that a supplier's technical characteristics and collaborative attitude, and the buyer-supplier relational characteristics on buyer- supplier relationships explain an important part of a supplier's contribution to buyer innovation. At a theoretical level, the findings of this study explain why some suppliers contribute more effectively than others to buyersupplier innovations. At a practical level, the findings provide managers with a more complete picture of those suppliers with the highest expected innovation contribution in their network.
\end{abstract}




\subsection{Introduction}

Business networks are an important source of the innovation performance of firms (Ahuja, 2000; Baum, Calabrese \& Silverman, 2000; Wilkinson \& Young, 2002; Corsaro, et al., 2012). Industrial Marketing and Purchasing (IMP) theory posits that the interactions among actors, resources, and relationships in networks form an important basis for the technological development of industries (Håkansson, 1987; Roy, Sivakumar \& Wilkinson, 2004). From this perspective, IMP researchers strive to better explain innovation in business networks (e.g., Hoholm \& Olsen, 2012). The interactions between firms enable the combination of existing ideas in new ways that are especially relevant to the creation of new ideas in the form of innovations (Romer, 1990; Ridley, 2010). The literature on network collaborations focuses increasingly on buyer-supplier relationships (e.g., Wynstra, Von Corswant \& Wetzels, 2010). Many of these studies describe the positive effect of supplier involvement on buyer innovation, which is defined as "the encouragement of improvement by the supplier with regard to how the buyer solves problems, develops ideas, and thinks of (process) improvements" (Mooi \& Frambach, 2012, p. 1025).

Although many scholars describe the positive effects of buyer- supplier relationships, merely involving any supplier in design programs does not guarantee direct improvements in innovation performance (Liker, et al., 1996; Freytag, Clarke \& Evald, 2012). Choosing a supplier with the wrong capabilities can lead to lower innovation performance or even project obstruction (Wognum, Fisscher \& Weenink, 2002; Zsidisin \& Smith, 2005). Buying firms can increase their innovative performance by collaborating with the most innovative suppliers. However, the most innovative supplier in a certain supply network cannot dedicate its best resources to every buyer (Gulati, Nohria \& Zaheer, 2000). Therefore, if competitive buying firms rely on the innovativeness of the same suppliers, then "it would be extremely difficult for a buyer to create competitive advantages through a shared supplier network" (Dyer \& Hatch, 2006, p. 703). Without the commitment of innovative suppliers to exclusive relationships with specific buyers, firms might fail to obtain innovation contributions from their suppliers and therefore lose the ability to differentiate themselves from their competitors (Takeishi, 2001). Thus, to obtain greater innovation value from their relationships with the suppliers in their networks, buying firms need to identify those suppliers that are both capable and willing to contribute to innovations for the buyers.

In the IMP literature, some theoretical frameworks that can be used to identify innovative suppliers have been proposed. For example, Rese (2006) introduces a decision model for selecting the 'right' supplier. Schiele (2006) proposes a framework in which he introduces supplier characteristics as well as relational characteristics that are argued to have a positive effect on buyer-supplier innovations. Even though early IMP studies empirically explored the different functions of buyersupplier relationships (e.g., Håkansson \& Snehota, 1995; Walter, Ritter \& Gemünden, 2001), the literature provides few empirical insights into the antecedents of buyersupplier innovation. Without a clear empirical indication of the nature of innovative suppliers, it would be very difficult for buying firms to fully benefit from the potential innovation value present in their supplier networks. In this study, we attempt to shed 
light on this issue by analyzing survey data in which the innovation contributions of 242 suppliers are evaluated by their buying firms. The main questions driving this paper are the following: What characteristics of suppliers might signal their high potential for making an innovative contribution to a buying firm, and how can a buying firm obtain an exclusive commitment from a supplier in order to achieve a better innovation contribution than their competitors?

To answer these questions, we develop and test a framework to (1) empirically identify the supplier characteristics that explain the innovation potential of different suppliers, (2) examine the supplier's collaborative attitude and identify how a supplier's willingness to collaborate enables the buying firm to better exploit the innovation capabilities of the supplier, and (3) determine which relational characteristics lead to a stronger supplier commitment resulting in a greater innovation contribution from the supplier.

\subsection{Conceptual framework and hypotheses}

The physical and social interactions in business networks enable firms to exchange and combine existing knowledge and create new knowledge (Romer, 1990; Mouzas \& Ford, 2009). Different types of network collaborations can provide firms with different types of knowledge, ultimately leading to higher innovation performance (Ahuja, 2000; Baum, Calabrese \& Silverman, 2000; Laursen \& Salter, 2006). Many potential innovation partners can be distinguished and different types of innovations can result from these collaborations. Von Hippel focused on the role of lead users in the innovation process (von Hippel, 1988; Thomke \& Von Hippel, 2002). Chesbrough (2003) identifies the advantages of involving other companies in "open innovation" processes, naming the growing competence of suppliers as one reason for the advent of open innovation. This paper focuses on buyer-supplier collaborations. Buyersupplier collaborations are important sources for innovation

(Walter, Ritter \& Gemünden, 2001; Young, Wiley \& Wilkinson, 2008) and have been shown to result in a wide range of innovation outcomes (Song \& Di Benedetto, 2008; Soosay, Hyland \& Ferrer, 2008).

\subsubsection{Characteristics of innovative suppliers}

In the literature that focuses on the characteristics of suppliers in buyer-supplier innovation, the characteristics of individual suppliers are assumed to be important factors. In particular, much attention has been paid to suppliers' technical characteristics, which are typically expressed in measurable terms (Park \& Krishnan, 2001; Ho, Xu \& Dey, 2010). However, as these technical characteristics are exploited by the buying firm, Croom (2001) argues that the effectiveness of the interaction between the buyer and supplier might be determined also by the collaborative attitude of the supplier.

A collaborative attitude is the cooperative propensity or external orientation embedded in a supplier's organization (Deshpandé, Farley \& Webster, 1993; Bidault, Despres \& Butler, 1998). A supplier might possess innovative capabilities, but without the willingness to collaborate, these capabilities might not be utilized effectively. Therefore, whereas much of the recent literature on supplier evaluation 
and selection focuses on so-called "hard facts" (i.e., the analysis of criteria such as certifications and $\mathrm{R} \& \mathrm{D}$ expenditures using multi-criteria approaches), recent conceptual works argue that not only these technical aspects but also aspects of the supplier's attitude towards the collaboration should be considered as well (Croom, 2001; Schiele, 2006). Therefore, to obtain a more complete picture of the characteristics of innovative suppliers, this study differentiates between the technical characteristics and the collaborative attitude of the supplier.

\subsubsection{Buyer-supplier relational characteristics}

To fully examine the characteristics of the supplier's contribution to buyer innovation, not only the supplier characteristics but also the relational characteristics of the buyer-supplier relationship are relevant (Croom, 2001; Schiele, 2006; Azadegan, et al., 2008). Collaborations with external partners have become important mechanisms for firms to enhance their innovation capabilities. Subsequently, the number of inter-firm collaborations has increased substantially over the past decades and these collaborations have become a central strategic component for many firms (Lavie, 2007). As more and more buying firms seek similar collaborations with the same innovative suppliers, it becomes increasingly difficult for these buyers to mobilize the supplier's resources and gain an advantage over competitors that are sourcing from the same supply base (Ellegaard \& Koch, 2012). This phenomenon, where more and more buying firms seek similar collaborations with the same suppliers, has been described mainly from a resource-based perspective, as innovative suppliers might have enough resources to satisfy only a limited number of buyers (Gulati, Nohria \& Zaheer, 2000). Therefore, suppliers must decide which buyer will receive their primary innovative resources and thereby benefit in terms of innovations.

To obtain a full understanding of the characteristics that play a distinguishing role in the contribution of a supplier to buyer-supplier innovation, a conceptual model is constructed in which three groups of constructs are identified: (1) supplier characteristics, (2) the supplier's collaborative attitude, and (3) the relational characteristics of the buyer-supplier relationship.

Fig. 2.1 shows the conceptual model used in this study.

\subsubsection{Conceptual model and hypotheses}

\subsubsection{Supplier characteristics: Professionalism}

A firm's internal innovation activities have been shown to influence their innovation collaborations with external partners (Cassiman \& Veugelers, 2006). For example, Salomo, Weise, and Gemünden (2007) show how process management capabilities directly improve a firm's innovation performance, whereas Naveh (2007) and Scott-Young and Samson (2008) focus on role process formalization, pre-defined milestones, and prioritized goals to explain innovation performance. Furthermore, higher levels of project management capabilities have been shown to lead to higher levels of new product development (NPD) performance (Ethiraj, et al., 2005).

Petroni and Panciroli (2002) link suppliers' project management competences to innovation and find that the best performing buyer- supplier relationships "show a distinctive profile in terms of project management competence" (p.146). In addition to the direct and indirect effects of these competences on innovation, the process and 
project management capabilities indicate a certain organizational maturity that are often used as prerequisites in audits used by buying firms to evaluate suppliers (Moultrie, Clarkson \& Probert, 2007). Suppliers that exhibit high levels of professionalism (i.e., skills, competence, and expertise) can be expected to make a greater contribution to an innovative collaboration than their peers with lower levels of professionalism. Consequently,

H2.1. Suppliers with higher levels of professionalism make a greater innovation contribution in a buyer-supplier relationship.

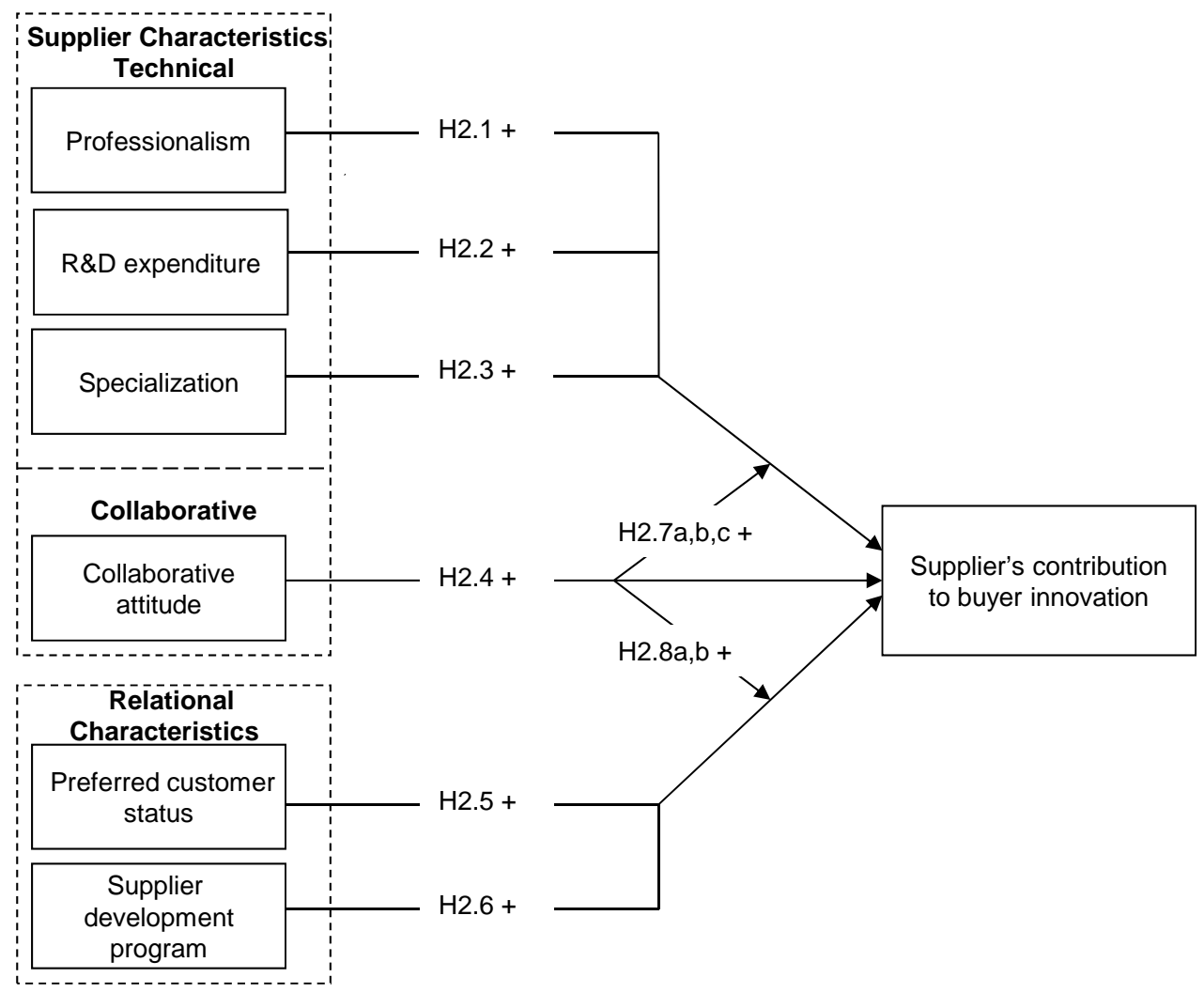

Fig. 2.1. Conceptual model for studying a supplier's contribution to buyer innovation.

\subsubsection{Supplier characteristics: $R \& D$ expenditure}

If the aim of a buyer-supplier collaboration is an innovative outcome, an important set of factors would be the so-called "hard facts" describing a supplier's innovative capabilities. Suppliers that have well developed innovation capabilities can be expected to make a greater contribution to the innovations of their buying firms. Expenditure on innovation is used often to assess this innovation capability. Firms with a higher R\&D investment per employee are more likely to be innovative (Griffith, et al., 2006). In an analysis of 170 UK firms during the period 19881992, Wakelin (2001) found that innovative firms have substantially higher R\&D expenditures than non-innovative firms.

Suppliers with higher levels of R\&D expenditures can be expected to be more innovative. Therefore, these suppliers might be more suitable partners for collaborating with buying firms in innovation programs. Azadegan et al. (2008), for instance, provide an example of how Dell relies more heavily on Tier 1 suppliers with 
larger R\&D expenditures than Dell itself for the design of new products. Because the R\&D expenditures of suppliers can be expected to increase a buyer's innovation performance, it is hypothesized that

H2.2. Suppliers with higher levels of R\&D expenditures make a greater innovation contribution in a buyer-supplier relationship.

\subsubsection{Supplier characteristics: Specialization}

An important reason for buyers to outsource certain activities is to access skills and knowledge that are not available in-house (Beaumont \& Sohal, 2004). Buyers compensate for their lack of internal knowledge by making use of external sources such as suppliers' areas of specialization. A broader set of specialized suppliers, therefore, provides the buyer with a broader knowledge base. Or, as Ahuja (2000, p. 429) states, "by tapping into the developed competencies of other firms, firms can enhance their own knowledge base and thereby improve their innovation performance." Specialization refers to a supplier's unique or differentiating capabilities (Dyer, 1996), which can be combined with the buying firm's own knowledge and expertise to lead to innovations.

In the literature on supplier selection, various supplier typologies link the level of supplier specialization to innovation. Kaufman, Wood, and Theyel (2000), for instance, classify specialized suppliers as "technology specialists" and associate specialization with innovativeness because of the design capabilities of these suppliers. Petroni and Panciroli (2002) describe how suppliers categorized as "despecialized" tend to be the least innovative suppliers in buyer-supplier relationships. Focusing on organizational innovation rather than collaborative innovation, Damanpour (1991) found that specialization tends to positively affect innovation. By sourcing technically specialized suppliers, buyers can obtain sophisticated and creative inputs (knowledge outside of their own core competences) for their projects. Thus,

H2.3. More highly specialized suppliers make a greater innovation contribution in a buyer-supplier relationship.

\subsubsection{Supplier characteristics: Collaborative attitude}

A main aim of innovation through buyer-supplier collaboration is the synergy that results from knowledge sharing. An important aspect of a successful buyer-supplier relationship is, therefore, that both parties have the capability to collaborate constructively (Allred, et al., 2011). Cabral and Traill (2001) describe how innovative suppliers tend to engage in several collaborative relationships. Past collaborations contribute to a better understanding of the partner firm (Andersen \& Christensen, 2000) and a higher level of collaborative experience. The experience that suppliers gain in previous collaborations contributes to their open attitude towards collaborations. This positive collaborative attitude enables interaction and collaboration between the buyer and supplier (Lockström, et al., 2010). Mishra and Shah (2009) show how a collaborative attitude and competences at a firm level lead to a higher performance outcome from a firm's alliances. 
A firm's attitude towards collaboration may relate to its experiences with collaboration. Therefore, firms develop different attitudes towards collaboration, and not all firms can be expected to have collaborative attitudes (Cagliano, et al., 2005). A collaborative attitude provides a greater opportunity for inter-firm relationships and renders better outcomes (Powell, Koput \& Smith-Doerr, 1996). A positive collaborative attitude entails a supplier's openness towards collaborative activity. A participative and collaborative organizational attitude has been shown to increase a firm's innovativeness (Hurley \& Hult, 1998). This attitude, for example, explains why some suppliers are more proactive than others in involving themselves in a buyer's development projects (von Corswant \& Tunälv, 2002). Therefore,

H2.4. Suppliers that have a collaborative attitude make a greater innovation contribution in a buyer-supplier relationship.

\subsubsection{Relational characteristics: Preferred customer status}

To increase innovation performance through collaboration, both the buyer and supplier must be willing to invest in their relationship. However, a supplier's willingness to collaborate is not always apparent (Essig \& Amann, 2009). Suppliers might become highly selective and may not allocate their resources equally to all of their customers (Mitsuhashi \& Greve, 2009). In these situations, the buying firms compete for the benevolence of their suppliers (Schiele, et al., 2012).

If a buying firm appears "attractive" to a supplier, then the latter is more likely to collaborate with this buyer rather than with the buyer's competitors (Ellegaard, Johansen \& Drejer, 2003; Ramsay \& Wagner, 2009). Therefore, a buying firm that becomes more attractive than their competitors to suppliers can be expected to obtain commitments with greater ease from their suppliers. Eventually, the buying firm may attain a preferred customer status. If a buying firm is a preferred customer, the supplier is more likely to, for example, allocate its best personnel to collaborative development or offer innovations that are not available to the buying firm's competitors (Hüttinger, Schiele \& Veldman, 2012). Therefore, a preferred customer status may result in better access to the supplier's innovative resources. Preferential resource allocation has, for example, been explained to be an important factor for the competitiveness of firms in regional clusters (Pulles \& Schiele, 2013). Consequently, it can be expected that a buyer's preferred customer status has a positive effect on the innovation performance of a buyer-supplier relationship. Therefore,

H2.5. Suppliers granting a buyer preferred customer status make a greater innovation contribution in a buyer-supplier relationship.

\subsubsection{Relational characteristics: Supplier development programs}

To attain high innovation performance through collaboration, it is important for the buying firms to have highly capable suppliers. Related to the exploitation-exploration dichotomy (Benner \& Tushman, 2003), firms can decide to develop the capabilities of existing suppliers (i.e., exploitation) rather than switching to another supplier (i.e., exploration) (Trent \& Monczka, 1999). Supplier development is the joint effort by the buyer and the supplier to improve the supplier's performance in order to meet the 
buyer's supply needs (Krause, 1999). In the process of supplier development, new ideas emerge through the intensive collaboration between buyer and supplier. In addition to the direct effect of these programs on suppliers' capabilities, supplier development programs may intensify the buyer-supplier relationship.

Supplier development involves close collaboration in which both parties must invest in knowledge transfer activities. This interaction has a positive effect on the relationship between the buyer and the supplier (Krause, 1997). The joint actions between firms and the trust resulting from the relationship "are the two most critical factors in supplier development to enhance competitive performance of the buyer." (Li, et al., 2007, p. 244). The mutual familiarity and trust resulting from cooperation in program development form an important starting point for collaborative innovations (Moran, 2005). The commitment of both the supplier and the buyer in supplier development has been shown to have a positive effect on the outcomes of the relationship (Krause, Handfield \& Tyler, 2007). Therefore,

H2.6. Suppliers taking part in supplier development programs make a greater innovation contribution in a buyer-supplier relationship.

\subsubsection{Moderating effects}

This paper's five main hypotheses describe a direct effects model in which all of the constructs relate directly to the supplier's contribution to buyer-supplier innovation processes. However, it can be argued that suppliers with strong collaborative attitudes are better able to utilize relational interfaces and exploit their innovative capabilities in collaborations with buyers. Following this argument, it can be expected that adding the moderating effects of the collaborative attitude construct to the direct effects model will increase the model's explanatory value. Therefore, five additional interactions have been specified in this study's conceptual model.

First, moderating effects are expected to exist between a supplier's collaborative attitude and its innovation characteristics (H2.7a, H2.7b, H2.7c). In order for buying firms to be effective in exploiting their suppliers' technical characteristics, effective knowledge sharing between the partners must take place. Innovation knowledge and best practices are transferred more easily when the supplier has a positive attitude towards collaboration (Hansen, 2002). Consequently, the collaborative attitude is an important enabler for interorganizational knowledge transfers (Cormican \& O'Sullivan, 2004). Suppliers with a collaborative attitude are better able to exploit their innovative capabilities within collaborations (Powell, Koput \& Smith-Doerr, 1996; Walter, 1999). Therefore, the more positive the supplier's collaborative attitude, the better the supplier can be expected to use its technical characteristics (i.e., professionalism, R\&D expenditure, and specialization) for the benefit of the buying firm. Therefore,

H2.7a. The supplier's collaborative attitude positively moderates the relationship between the supplier's professionalism and the supplier's innovation contribution in a buyer-supplier relationship. 
H2.7b. The supplier's collaborative attitude positively moderates the relationship between the supplier's R\&D expenditure and the supplier's innovation contribution in a buyer-supplier relationship.

H2.7c. The supplier's collaborative attitude positively moderates the relationship between the supplier's specialization and the supplier's innovation contribution in a buyer-supplier relationship.

Finally, moderating effects are expected to exist between a supplier's collaborative attitude and the buyer-supplier relational characteristics (H2.8a and H2.8b). The lack of a collaborative attitude makes it difficult for partners to exploit existing relations to share information and build trust (Spekman \& Carraway, 2006). Therefore, firms that have a strong commitment towards collaboration can be expected to better utilize the existing relational infrastructure between firms. Hult (1998) showed how organizational learning within collaborations leads to a greater relationship commitment and customer orientation in the supplying firm. According to BoschSijtsema and Postma (2009), partners with a collaborative attitude not only have access to each other's technological capabilities but also develop and share knowledge about organizational aspects. Because these studies suggest that the collaborative attitude is an important factor for the exploitation of buyer-supplier relationships, it can be expected that the collaborative attitude strengthens the effects mentioned in hypotheses 2.5 and 2.6. The following is hypothesized:

H2.8a. The supplier's collaborative attitude positively moderates the relationship between the preferred customer status and the supplier's innovation contribution in a buyer-supplier relationship.

H2.8b. The supplier's collaborative attitude positively moderates the relationship between the supplier's development programs and the supplier's innovation contribution in a buyer-supplier relationship.

\subsection{Methodology}

\subsubsection{Data}

To test these hypotheses, this study surveyed 121 firms to collect data. To prevent selection bias, it was necessary to not limit the study to only successful innovation collaborations. Therefore, to obtain a good distribution in terms of supplier contributions, this paper followed a suggestion made by Ulaga and Eggert (2006). The respondents assessed an excellent performing supplier and a disappointing supplier in terms of product and process innovation. The respondents were asked to write down the names of these two suppliers on separate sheets of paper. Then, they answered the questionnaire for both the suppliers. Therefore, the questionnaires from 121 respondents represented data for approximately 242 suppliers. The survey was pretested by five academic and seven practitioners, all knowledgeable in the field of buyer-supplier relations. 
Invitations to participate in the survey were distributed among members of the German and Austrian associations of materials management, purchasing, and logistics and to a list of contacts of a German business consulting firm that specialized in supply management. Respondents were invited to participate in the survey through email and newsletters that contained a link to a homepage with the questionnaire. This homepage was opened 440 times and 121 usable questionnaires were received. This response rate of $27.5 \%$ is comparable to other studies using online survey instruments (e.g., Briggs, Landry \& Daugherty, 2010). To test for non-response bias, we compared the data from early respondents to late respondents for the key variables in this study (Armstrong \& Overton, 1977). Respondents were found to differ significantly on only one of this study's variables (Supplier Specialization), which suggests that the threat of non-response bias is small. Comparative t-tests found no significant differences between respondents from the two associations and the consulting firm.

Among the respondents, $41.3 \%$ were purchasing managers, $34.7 \%$ were purchasers, and $24 \%$ served in other roles. Comparative t-tests showed no significant differences between respondents from purchasing functions and other functions with respect to this study's key variables. Legler and Frietsch (2007) defined medium- and high-tech sectors in German industry as sectors that invest between $2.5 \%$ and $7 \%$ and more than $7 \%$ of their turnover in $\mathrm{R} \& \mathrm{D}$, respectively. A substantial proportion of our respondents are in the medium-tech (e.g., automobile and mechanical engineering) and high-tech (e.g., electronic engineering) sectors of German industry. With an average R\&D expenditure of $7.9 \%$, our sample seems to be a reliable representation of Germany's medium- and high-tech sectors (Table 2.1).

Table 2.1.

Profile of the sample

\begin{tabular}{lr}
\hline & Frequency \\
\hline No. of employees & \\
$0-100$ & $10.7 \%$ \\
$101-500$ & $24.3 \%$ \\
$501-1000$ & $14.5 \%$ \\
$1001-10000$ & $37.9 \%$ \\
$>10000$ & $12.6 \%$ \\
& \\
Industry sector & \\
Electrical/electronic engineering & $21.5 \%$ \\
Mechanical engineering/machine building & $17.4 \%$ \\
Service & $10.7 \%$ \\
Chemicals, rubbers, and plastics & $10.7 \%$ \\
Automobile & $9.1 \%$ \\
Other manufacturing & $13.2 \%$ \\
Other & $17.4 \%$ \\
& \\
Annual sales ( $€$ ) & \\
$0-50$ Million & $24.0 \%$ \\
$51-100$ Million & $12.5 \%$ \\
$101-500$ Million & $20.8 \%$ \\
$501-1000$ Million & $13.5 \%$ \\
$>1000$ Million & $29.2 \%$ \\
\hline
\end{tabular}




\subsubsection{Measures}

Supplier contributions in buyer-supplier innovations were operationalized using items that reflect collaborative innovation (Krause, Pagell \& Curkovic, 2001). These items emphasize how the respondents experience the contribution of each supplier to their firm's innovation process by indicating the supplier's pro-activeness in approaching the buyer with innovative ideas, the capability and extent to which the supplier supports the buyer in collaborative product development and process improvement, and the supplier's willingness to share technological information. Supplier professionalism was measured with items based on a study by Petroni and Panciroli (2002), who mention the relevance of certifications and project management capabilities. The items for supplier specialization are based on a study by Wasti and Liker (1999), who found that specialized firms supply specific products to a limited market with a relatively small number of competitors. This study modeled the specialization construct in terms of formative indicators. This is consistent with Jarvis, MacKenzie, and Podsakoff (2003), who argue that the use of formative items is appropriate when all indicators have an impact on a construct and are, therefore, defining characteristics. For supplier R\&D expenditures, the respondents were asked to assess each supplier's R\&D expenditure as a percentage of the annual turnover. Suppliers' collaborative attitude was measured with three items, all reflecting the attitude of the supplier towards collaboration: (1) involvement in collaboration, (2) management focus, and (3) upstream collaboration initiatives. The buyer's preferred customer status was operationalized with items adopted from Ganesan (1994). The items measure preferential treatment, or 'vendor's benevolence', by evaluating a supplier's commitment and willingness to make additional efforts for the buyer. Finally, the development program construct was operationalized on the basis of a study by Kocabasoglu and Suresh (2006). The complete measurement instrument, is shown in Appendix 1.

\subsubsection{Control variables}

Several variables that could affect suppliers' innovation contributions were introduced as control variables in the analysis. First, because mutual dependency has been shown to influence relational behavior (Ganesan, 1994), this study controlled for buyer and supplier dependence terms of the difficulty of quickly replacing the partner (adopted from Corsten \& Felde, 2005). Second, because the physical distance between two firms might influence innovation contributions in different ways (Schiele, 2006), this study controlled for the proximity between buyer and supplier. Third, buyer turnover and R\&D expenditure were controlled because they may relate to the innovation performance of the organizations.

\subsubsection{Data analysis and validity}

Partial least squares (PLS) structural equation modeling was employed to test the hypotheses. PLS is a regression-based structural equation modeling (SEM) technique that does not make assumptions about data distributions. This study used PLS for three major reasons. First, PLS is ideally suited to test models with latent variables, especially during the early stages of theory development and in exploratory studies (Birkinshaw, Morrison \& Hulland, 1995). Second, unlike covariance based structural 
equation modeling, PLS allows for both formative and reflective indicators. Third, as Reinartz, Haenlein, and Henseler (2009) show PLS is recommended when the number of observations is less than 250. This study used SmartPLS 2.0 (Ringle, Wende \& Will, 2005) to obtain the estimates.

To test for the common method variance, Harman's single factor test (Podsakoff \& Organ, 1986) was used. In this test, all items used to construct the measures were entered into a principal component factor analysis with varimax rotation. A total of five components with eigenvalues greater than 1.0 were extracted; these components explained more than $68 \%$ of the total variance. The first factor accounted for $32 \%$ of the variance, which indicates that no single factor accounts for most of the covariance. These results suggest that common method variances do not pose a serious threat in this study.

Several study quality criteria were assessed. Composite reliability ranged between 0.72 and 0.93 , exceeding Nunnally's (1978) threshold of 0.7. An examination of the average variance extracted (AVE) revealed that all constructs exceeded the 0.50 cutoff (Fornell \& Larcker, 1981). Discriminant validity was tested using the Fornell and Larcker (1981). The correlation of the latent variables was compared to the square root of the average variance extracted. None of the correlations exceeded the value of the squared AVE, indicating a satisfactory level of discriminant validity. Finally, to examine whether observed correlations between multicollinearity test was conducted. The tolerance and corresponding Variance Inflation Factor (VIF) are commonly used measures to conduct collinearity diagnostics for independent variables (Miles \& Shevlin, 2001; O'Brien, 2007). (Miles \& Shevlin, 2001; O’brien, 2007). None of the tolerances are less than 0.2 (corresponding to a VIF of 5), which points to the absence of multicollinearity (MacCallum \& Browne, 1993). Together with the validity measures and correlations, the tolerance and VIF values are shown in Table 2.2.

Table 2.2.

Collinearity statistics and correlations

\begin{tabular}{ccccccccccc}
\hline & $\begin{array}{l}\text { Validity } \\
\text { Measures }\end{array}$ & \multicolumn{3}{c}{$\begin{array}{l}\text { Collinearity } \\
\text { Statistics }\end{array}$} & \multicolumn{3}{c}{ Correlations } \\
\hline Variables & CR & AVE & Tolerance & VIF & SP & SSP & SRD & SCA & PCS & SDP \\
\hline SIC & 0.93 & 0.78 & --- & -- & & & & & & \\
SP & 0.72 & 0.77 & 0.58 & 1.72 & --- & & & & & \\
SSP & --- & --- & 0.77 & 1.30 & $-0.05^{* *}$ & -- & & & & \\
SRD & --- & --- & 0.84 & 1.19 & $0.28^{* *}$ & 0.10 & -- & & & \\
SCA & 0.82 & 0.60 & 0.39 & 2.60 & $0.53^{* *}$ & 0.11 & 0.11 & --- & & \\
PCS & 0.93 & 0.74 & 0.40 & 2.51 & $0.43^{* *}$ & $0.22^{* *}$ & $0.18^{*}$ & $0.68^{* *}$ & --- & \\
SDP & 0.84 & 0.52 & 0.58 & 1.73 & $0.37^{* *}$ & $0.21^{* *}$ & $0.16^{*}$ & $0.57^{* *}$ & $0.51^{* *}$ & --- \\
\hline
\end{tabular}

** Pearson Correlations significant at the $p<0.01$ level, * significant at $p<0.05$ level $\mathrm{SIC}=$ Supplier Innovation Contribution, $\mathrm{SP}=$ Supplier Professionalism, SSP $=$ Supplier Specialization, SRD = Supplier R\&D Expenditure, SCA = Supplier Collaborative Attitude, PCS = Preferred Customer Status, SPD = Supplier Development Programs $\mathrm{AVE}=$ average variance extracted, $\mathrm{CR}=$ composite reliability. AVE and $\mathrm{CR}$ of the formative construct SSP cannot be given, SRD has only one item and, therefore, no AVE and CR are given. 


\subsection{Results}

To test the size and statistical significance of the hypothesized paths, a bootstrapping procedure using 1500 resamples was used. Because a main objective of this study is to test the influence of different factors on the innovation contributions of suppliers, the results are obtained for four different models. Model I tests the effects of the technical supplier characteristics, Model II adds the collaborative attitude as a supplier characteristic, and Model III also includes the relational characteristics testing H2.1-H2.6. Finally, Model IV tests the hypothesized interaction effects (H2.7a, H2.7b, H2.7c, H2.8a, and H2.8b).

Table 2.3.

PLS analyses (dependent variable: Supplier Innovation Contribution)

\begin{tabular}{|c|c|c|c|c|}
\hline Independent variables & PLS (Model I) & PLS (Model II) & PLS (Model III) & PLS (Model IV) \\
\hline \multicolumn{5}{|l|}{ Supplier Characteristics } \\
\hline Professionalism & $0.39(7.29)^{* *}$ & $0.22(3.99)^{* *}$ & $0.20(4.77)^{* *}$ & $0.19(3.99)^{* *}$ \\
\hline R\&D Expenditure & 0.02 (n.s) & 0.05 (n.s.) & 0.03 (n.s.) & 0.03 (n.s) \\
\hline Specialization & $0.39(7.13)^{* *}$ & $0.22(4.47)^{* *}$ & $0.14(2.55)^{* *}$ & $0.11(1.89)^{*}$ \\
\hline Collaborative Attitude & & $0.47(8.4)^{* *}$ & $0.27(4.57)^{* *}$ & $0.27(4.21)^{* *}$ \\
\hline \multicolumn{5}{|l|}{ Relational Characteristics } \\
\hline Preferred Customer Status & & & $0.24(4.78)^{* *}$ & $0.32(5.01)^{* *}$ \\
\hline Supplier Development Program & & & $0.18(3.52)^{* *}$ & $0.20(3.58)^{* *}$ \\
\hline \multicolumn{5}{|l|}{ Interaction of Collaborative } \\
\hline Professionalism & & & & $0.07(1.65)^{*}$ \\
\hline R\&D Expenditure & & & & 0.00 (n.s.) \\
\hline Specialization & & & & $-0.12(2.82) * *$ \\
\hline Preferred Customer Status & & & & 0.06 (n.s.) \\
\hline Supplier Development Program & & & & $0.08(1.90)^{*}$ \\
\hline \multicolumn{5}{|l|}{ Control variables } \\
\hline Buyer Dependency & $0.18(3.57)^{* *}$ & $0.09(2.05)^{*}$ & 0.04 (n.s.) & 0.01 (n.s.) \\
\hline Supplier Dependency & 0.04 (n.s.) & 0.04 (n.s.) & 0.01 (n.s.) & -0.01 (n.s.) \\
\hline Proximity & 0.01 (n.s.) & 0.03 (n.s.) & 0.03 (n.s.) & 0.03 (n.s.) \\
\hline R\&D Expenditure Buyer & -0.04 (n.s.) & -0.04 (n.s.) & -0.02 (n.s.) & -0.01 (n.s.) \\
\hline Turnover & 0.00 (n.s.) & 0.03 (n.s.) & 0.03 (n.s.) & 0.06 (n.s.) \\
\hline$R^{2}$ & 0.57 & 0.67 & 0.73 & 0.75 \\
\hline$f^{2}$ & - & 0.30 & 0.22 & 0.08 \\
\hline
\end{tabular}

Path coefficients $(t$-values) $* p<0.05, * * p<0.01$, n.s. $=$ non significant

\subsubsection{Direct effects}

As the left column of Table 2.3 shows, the technical supplier characteristics (Model I) account for $57 \%$ of the variance in a supplier's contribution to buyer-supplier innovations (i.e., $R^{2}=0.57$ ). When the collaborative attitude items are added (Model II), the $R^{2}$ increases to 0.67 . Finally, the relational characteristics are added (Model III), which increases the $R^{2}$ to 0.73 . The results show that the values of the suppliers' 
professionalism $(\beta=0.20 ; p<0.01)$, specialization $(\beta=0.14 ; p<0.01)$, and collaborative attitude $(\beta=0.27 ; p<0.01)$ are positively related to supplier innovation contribution, supporting $\mathrm{H} 2.1, \mathrm{H} 2.3$, and 2 2.4. The relationship between suppliers' R\&D expenditures is found to be not significant. Therefore, H2.2 is not supported. With regard to the relational characteristics, the results show that the preferred customer status $(\beta=0.24 ; p<0.01)$ and supplier development program $(\beta=0.18 ; p<$ 0.01 ) constructs have a significant positive effect, supporting H2.5 and H2.6.

\subsubsection{Interaction effects}

Next, the interaction variables are included in the model in addition to the main effects. Because the model contains formative measures for supplier specialization, the product terms of the variables were calculated using the latent variable scores (cf., Wynstra, Von Corswant \& Wetzels, 2010). The right column of Table 2.3 shows the results for the fourth model. The $R^{2}$ value of the model (including the interaction effects) is 0.75 . This result demonstrates that the interaction between a supplier's collaborative attitude and the other antecedents improves the explained variance in a supplier's contribution to buyer-supplier innovations. The paths of $\mathrm{H} 2.1-\mathrm{H} 2.6$ show slightly changing $\beta$ values, but all $\beta$ values remain significant.

The interactions between a supplier's collaborative attitude and supplier professionalism, and their supplier development programs are found to be significant ( $\beta=0.07$ with $p<0.05$ and $\beta=0.08$ with $p<0.05$, respectively). However, the positive interaction effect with the other variables was not significant. Moreover, a negative interaction is observed between collaborative attitude and supplier specialization. Hence, the results support $\mathrm{H} 2.7 \mathrm{a}$ and $\mathrm{H} 2.8 \mathrm{~b}$, but not $\mathrm{H} 2.7 \mathrm{~b}, \mathrm{H} 2.7 \mathrm{c}$, and H2.8a. In Model I and Model II, the buyer dependency variable was found to be significant. In the models that include all of the hypothesized effects (Model III and IV), no control variables were found to be significant. Fig. 2.2 shows this study's structural model.

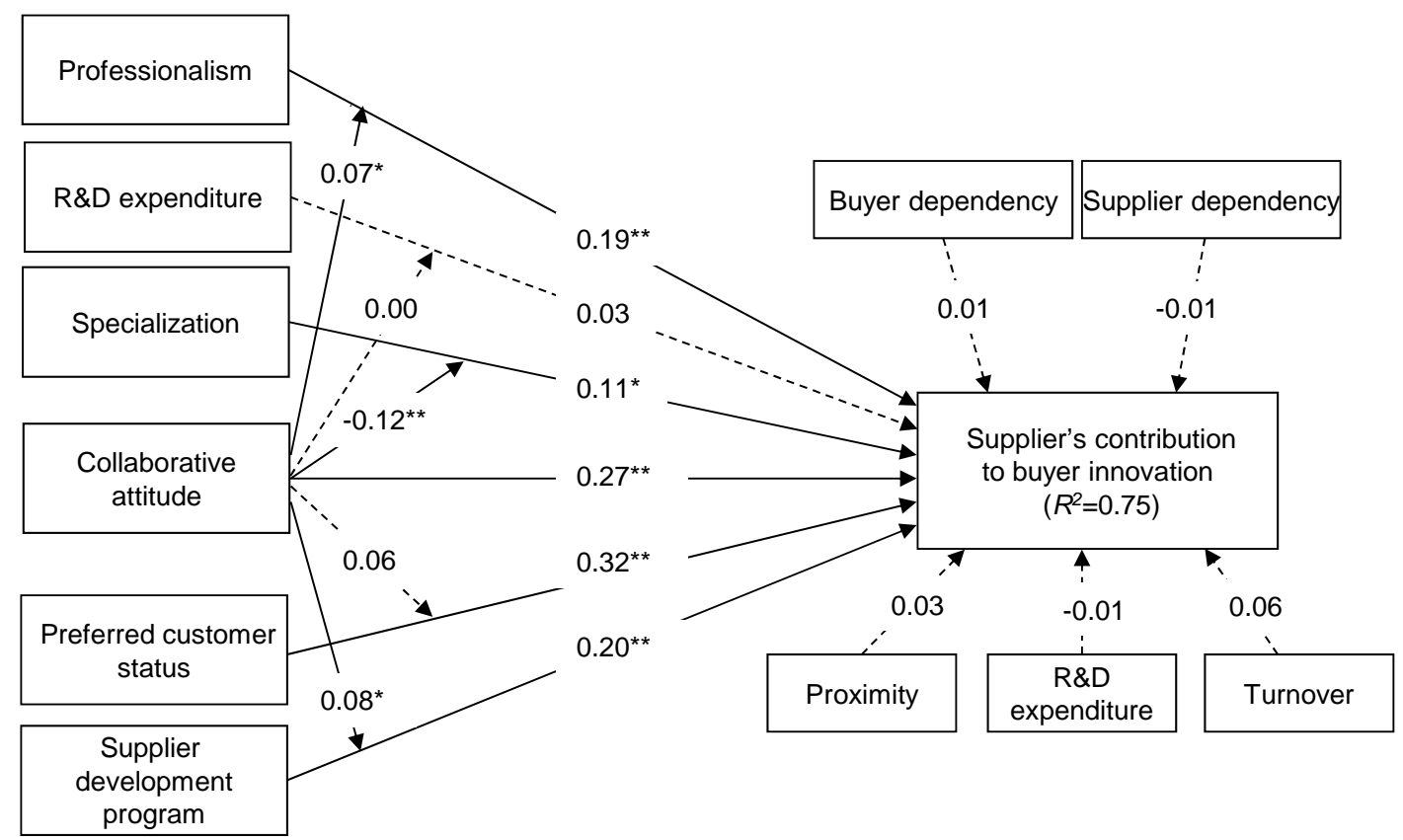

Fig. 2.2. Structural Model, ${ }^{*} p<0.05,{ }^{* *} p<0.01$, dashed arrows indicate non-significant relationships. 
Table 2.3 shows Cohen's (2001) $f^{2}$ statistic that indicates the size of the effect $(0.02,0.15$, and 0.35 are small, medium, and large effects, respectively) of the added variables. Adding the collaborative attitude (Model II) and, subsequently, the relational characteristics (Model III) account for medium-to-large size effects of 0.30 and 0.22 , respectively. To compare the effect sizes of supplier characteristics, collaborative attitude, and relational characteristics, two additional models were tested: one model with all variables except the technical supplier characteristics and interaction terms $\left(R^{2}=0.68\right)$, and another model with all of the variables except the collaborative attitude and interaction terms $\left(R^{2}=0.70\right)$. These results showed that the set of technical supplier characteristics has an effect size of 0.19 , the collaborative attitude has an effect size of 0.11 , and the relational characteristics have an effect size (as shown in Table 2.3) of 0.22. When the interaction terms are added to Model IV, the $R^{2}$ increases by 0.02 , which represents an $f^{2}$ of 0.08 and indicates a small-tomedium moderating effect (Cohen, 2001).

\subsection{Discussion and implications}

\subsubsection{Discussion of the results}

The supplier characteristics of professionalism and specialization are found to have a positive effect on suppliers' innovation contributions to the buyer-supplier relationship (H2.1 and H2.3). These findings are consistent with a body of literature that assumes that suppliers' specialization and professionalism positively relate to buyer-supplier innovativeness (e.g., Krause, Pagell \& Curkovic, 2001; Ragatz, Handfield \& Petersen, 2002). Interestingly, although firms with higher R\&D expenditures are found to be more innovative (Griffith et al., 2006), and large firms with low R\&D expenditures can, in some cases, rely on suppliers' expenditures (Azadegan, et al., 2008), this study found that a supplier's R\&D expenditure does not directly affect the supplier's innovation contribution in buyer-supplier relationships. These findings suggest that supplier professionalism and specialization (as well as relational characteristics, see below) might matter more for buyers seeking an innovative contribution from suppliers. The insignificance of the R\&D expenditure could indicate that suppliers do not always allocate their assets to the relationship with a particular buyer. In addition the results show that a supplier's collaborative attitude $(\mathrm{H} 2.4)$ represents a substantial fraction of the explained variance of the suppliers' innovative contribution, thereby indicating empirical evidence for several propositions made in earlier conceptual work (e.g., Rese, 2006; Schiele, 2006).

This study expected that a buying firm's preferred customer status and supplier development programs would have a positive effect on a supplier's contribution to the buying firm's innovations (H2.5 and H2.6). These expected effects were found to be significant. These results indicate that attaining an effective innovation contribution is not merely a matter of selecting the supplier with the right characteristics. Building a relationship through development programs and attaining a preferred customer status could, therefore, be considered at least equally important to, or, as Cohen's $f^{2}$ statistic indicates, even more important than the technical characteristics of the supplier with whom a buying firm is collaborating. 
Finally, this study investigated the moderating effect of a supplier's collaborative attitude on the supplier and relational characteristics $(\mathrm{H} 2.7 \mathrm{a}, \mathrm{H} 2.7 \mathrm{~b}, \mathrm{H} 2.7 \mathrm{c}, \mathrm{H} 2.8 \mathrm{a}$, and $\mathrm{H} 2.8 \mathrm{~b}$ ). The results show a positive moderating effect on supplier professionalism and supplier development programs. According to these results, supplier professionalism is exploited more easily when the supplier has a positive attitude towards collaboration. In addition, the results indicate that suppliers with a strong collaborative attitude are better able to utilize the buyer-supplier interface within development programs.

Although it was hypothesized that - similar to professionalism and development programs - a supplier's collaborative attitude would enable firms to better utilize the suppliers' specialization, the opposite was found to be true. Suppliers' collaborative attitude negatively moderates the effect of supplier specialization on innovative contribution. This negative interaction could possibly be explained by the fact that the specialization of the supplier might set clear boundaries between the buyer and the suppliers. Therefore, there might be relatively little overlap between the buyer and supplier, which was found to hamper collaboration in previous literature (Liker, Collins \& Hull, 1999). The negative moderation effect found in our study might therefore reflect the difficulties in the communication with highly specialized suppliers during innovation collaborations.

\subsubsection{Theoretical contributions and managerial implications}

This paper contributes to a better understanding of innovation in business networks. Whereas early IMP literature has explored innovation in buyer-supplier relationships (e.g., Håkansson \& Snehota, 1995; Walter, Ritter \& Gemünden, 2001), this paper provides a clearer empirical evaluation of the nature of innovative suppliers that enables buying firms to better grasp potential innovation value from their supplier networks. By doing so, this paper contributes to the IMP literature on obtaining innovation value from business networks in several ways. First, although already suggested by several researchers this paper provides the first empirical test of the relationship between supplier professionalism and specialization, and buyer-supplier innovation contribution. Second, this study shows the importance of a supplier's collaborative attitude in buyer-supplier collaborations. This study thereby provides amore exhaustive picture than is given in much of the current sourcing literature (Ho, $\mathrm{Xu} \&$ Dey, 2010) by showing that sourcing innovative suppliers is not merely a case of selecting suppliers with the "best" technical characteristics. Third, this study provides greater insight into the relational characteristics that influence buyersupplier innovation performance. It shows how a preferred customer status and supplier development programs are important facilitators of innovation collaborations between buyers and suppliers. Because of the intense character of innovation collaborations, a supplier cannot dedicate its resources equally among buyers. As the results of this study indicate, buyers can target a supplier's most innovative resources by pursuing a preferred customer status.

Also on a managerial level, this study has several important implications. In current practice, often the supplier with the highest technical performance in a firm's network is sourced (Kannan \& Tan, 2002). This study's results, however, suggest that the managerial decision-making framework for selecting the most innovative supplier 
should be extended to include the supplier's collaborative attitude and the relational aspects. If these aspects are taken into account, then a more complete picture emerges that allows managers to make better decisions with respect to sourcing suppliers with the highest expected innovation outcomes. Therefore, in selecting innovative suppliers, firms might want to move away from considering only "hard facts" on suppliers (e.g., R\&D expenditures and certificates) and give more consideration to the relational aspects in the buyer-supplier dyad and to suppliers' collaborative attitudes. Firms might reevaluate their supplier network knowing that the 'best' supplier may not be the best supplier for their firm. This study showed that focusing on these relational aspects better enables managers to select suppliers that have a high likelihood of performing well in buyer-supplier innovations.

\subsubsection{Limitations and future research}

The findings of this study should be interpreted in the light of some limitations. Because the results of this study are based on subjective data the ratings may reflect the respondents' rationalization and sense making (Rong \& Wilkinson, 2011). For example, an alternative explanation for the strong link between collaborative attitude and supplier contribution to buyer-supplier innovation, may be that if the supplier contributes to innovation, it is perceived to have a collaborative attitude. Future research should address this shortcoming by making use of objective data. Next to this, even though the results of this study support most of the hypotheses that are posed, it can be argued whether or not collaborative attitude is a cause or an effect of supplier contribution to innovation. Future research might take a longitudinal approach to address this shortcoming. Additionally, the dataset represents the buyer's perspective. The supplier's perspective might help to better understand the workings of the hypothetical supplier and relational characteristics. Therefore, examining the supplier perspective in the buyer-supplier relationship is a direction for future research. Furthermore, the findings on the relational characteristics are only applicable to suppliers within the current network of the buying firm. Consequently, an interesting question for future research is how firms can recognize innovative suppliers that are not within their current network.

Finally, this study showed how a buyer's preferred customer status has a positive effect on the supplier's contribution to the buying firm's innovations. However, what other benefits can be expected from being a preferred customer and how can buying firms become a preferred customer? Also, is it, for example, easier for larger firms to receive preferential treatment because they represent a higher potential share in turnover for the supplier compared to small and medium-sized companies? Addressing these types of questions in future research can lead to interesting insights into the role of the preferred customer construct. 

Chapter 3

\title{
Obtaining better resources from a shared supplier network: Customer attractiveness, supplier satisfaction, and their roles in attaining preferred customer status
}

\begin{abstract}
This paper discusses how a firm can become preferred customer, defined as a particular buyer to whom the supplier allocates better resources than less preferred buyers. Two concepts play a crucial role for a firm aiming to become preferred customer: (i) customer attractiveness and (ii) supplier satisfaction. However, the current literature still lacks a clear discussion on the conceptual differences between these constructs and their attributes and is ambiguous with regard to the relationships between the concepts. This study addresses these shortcomings in two ways. First, it builds upon practitioner input to generate a more comprehensive view of the construct dimensions than currently available in literature. Second, it uses survey data from 91 suppliers to examine the relationship between customer attractiveness and supplier satisfaction as well as their effects on preferential resource allocation from suppliers. Our analyses showed that the impact of customer attractiveness on preferential resource allocation is fully mediated by supplier satisfaction. These findings expand the current understanding of these concepts. In addition, our findings might help managers better evaluate their position in their supplier network and align their strategies accordingly to obtain better resources from their suppliers.
\end{abstract}




\subsection{Introduction}

It is well-known that relationships with suppliers offer many opportunities for firms. Previous research provides various examples of firms improving their performance through collaborations with suppliers (e.g., Krause, Handfield \& Tyler, 2007; Bernardes \& Zsidisin, 2008; Nyaga, Whipple \& Lynch, 2010). Suppliers can provide resources such as ideas, capabilities, and materials that build competitive advantages that might not be achieved otherwise (Koufteros, Vickery \& Dröge, 2012). However, competing firms may seek similar resources in the same supplier network (Takeishi, 2002; Dyer \& Hatch, 2006). Therefore, it is unclear whether firms that collaborate with their suppliers gain a competitive advantage through this collaboration because "other sharks in the water" might obtain better resources. Firms that are capable of obtaining better resources from their supplier network than their competitors have an advantage in resources and will therefore more easily attain a competitive advantage (Hunt \& Davis, 2008).

The observation that some buyers obtain better resources from a supplier network than their competitors (e.g., Takeishi, 2002; Dyer \& Hatch, 2006) shows that the allocation of supplier resources to relationships with buying firms is a selective process. A recent special issue in Industrial Marketing Management (Schiele, Calvi \& Gibbert, 2012) has emphasized the importance of being a preferred customer (i.e., a buyer to whom the supplier allocates better resources than less preferred buyers). Being a preferred customer leads to a variety of benefits (e.g., first access to new technology or the allocation of scarce materials in times of high demand; Ramsay, 2001b; Hüttinger, Schiele \& Veldman, 2012). Two concepts play a crucial role in becoming a preferred customer:

i. Customer attractiveness (Christiansen \& Maltz, 2002; Ellegaard, Johansen \& Drejer, 2003; Hald, Cordón \& Vollmann, 2009; Ramsay \& Wagner, 2009; Mortensen \& Arlbjørn, 2012)

ii. Supplier satisfaction (Essig \& Amann, 2009; Ghijsen, Semeijn \& Ernstson, 2010; Nyaga, Whipple \& Lynch, 2010)

As shown by the literature review of Hüttinger et al. (2012), customer attractiveness and supplier satisfaction are multidimensional constructs. That is, multiple characteristics of a buying firm can be attractive for suppliers (e.g., presence in growth markets, turnover, known for information sharing) and multiple relational benefits can lead to supplier satisfaction (e.g., large share in turnover, help with innovations, trust). However, many studies have taken a relatively narrow approach in the exploration of these concepts by only taking one or few dimensions into account (e.g., Ellegaard, Johansen \& Drejer, 2003; Baxter, 2012; Mortensen \& Arlbjørn, 2012). What is missing in the literature is an empirical exploration of the different dimensions of customer attractiveness and supplier satisfaction and a test on how these multidimensional constructs relate to each other and to preferred customer status. Our study addresses these gaps thereby responding to recent calls for theoretical conceptualizations (Schiele \& Krummaker, 2011; Mortensen \& Arlbjørn, 2012) and empirical evidence on the relationships between these concepts (Hüttinger, 
Schiele \& Veldman, 2012). More specifically, we draw on social exchange theory to discuss the concepts of customer attractiveness and supplier satisfaction and we build hypotheses on the links between these concepts and preferred customer status. We operationalize preferred customer status as preferential resource allocation from suppliers. In addition, we build on discussions with CPOs and managers by using a new World Café methodology to generate customer attractiveness and supplier satisfaction dimensions that provide more comprehensive views on the different dimensions of these constructs than currently reported in the literature. We use the construct development framework discussed by Diamantopoulos and Winklhofer (2001) to build measures of the customer attractiveness, supplier satisfaction, and preferential resource allocation constructs and test our hypotheses using the data of 91 supply firms.

Figure 3.1 shows the research approach of this study and the outline of this paper. In section 3.3 we theorize on the relationship between the customer attractiveness, supplier satisfaction and preferential resource allocation constructs. In section 3.4 we explore the different dimensions of customer attractiveness and supplier satisfaction. Section 3.5 builds the measures for these constructs and in section 3.6 we present the results of the hypotheses tests. This paper begins with a discussion of the preferred customer concept in section 3.2.

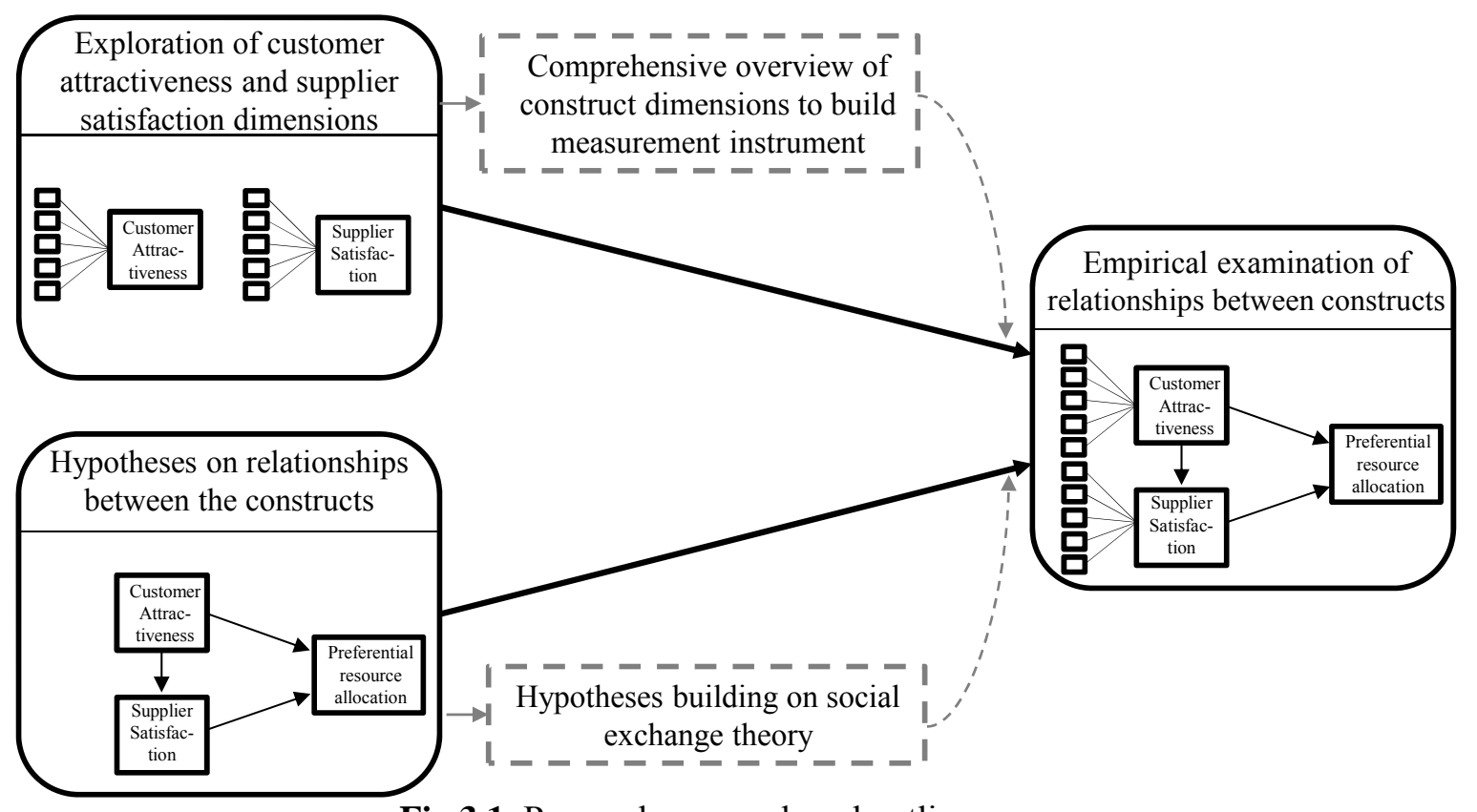

Fig.3.1. Research approach and outline paper

\subsection{Preferred customer status: obtaining preferential resource allocation from suppliers}

Recent literature has examined supplier management not only as a means to obtain the resources that are critical to attaining competitive advantages over peers (Hult, Ketchen Jr. \& Arrfelt, 2007; Hunt \& Davis, 2008). Resources are defined as the tangible or intangible financial, human, intellectual, organizational, and physical entities available to the firm that enable it to increase its competitive advantage (Hunt $\&$ Davis, 2008; Newbert, 2008). Because competitive advantage is a relative notion 
(Peteraf, 1993), the resources obtained from the supply base shared with competitors will only result in a competitive advantage when the buying firm obtains better resources than its competitors (Hult, et al., 2006; Capron \& Chatain, 2008). As a result, firms compete with their peers for the supplier's resources such as best ideas, most experienced engineers, or latest technologies (Paulraj, Lado \& Chen, 2008; Petersen, et al., 2008). Therefore, firms must find ways to obtain better resources than their competitors to gain greater advantages from shared supplier networks.

The allocation of supplier resources to relationships with buying firms is a selective process in which competing customers may be treated unequally (Mitshuhashi \& Greve, 2009). Some buyers obtain better resource allocations from their supply base than others, even though these buyers share the same supplier (Takeishi, 2002; Dyer \& Hatch, 2006). Consequently, firms must pay attention to their competitors' actions in the supply base, because if a firm has attained a superior resource allocation position from its suppliers, competitors will attempt to neutralize this advantage to accrue similar resource advantages (Hunt \& Davis, 2008; Mesquita, Anand \& Brush, 2008; Ellram, Tate \& Feitzinger, 2013). The buying firm that is able to attain a preferential resource allocation position from a shared supplier network is a preferred customer $^{2}$ (Steinle \& Schiele, 2008; Schiele, Veldman \& Hüttinger, 2011). Accordingly, a firm that receives preferential resource allocation from its supplier network has preferred customer status.

From a marketing perspective, suppliers might intentionally and openly grant buyers or consumers a preferred status for specific purposes (e.g., as a motivator for future sales; Wagner, Hennig-Thurau \& Rudolph, 2009). In industrial buyer-supplier relationships, preferential treatment is more subtle and based on less formal criteria. Examples of preferential treatment in industrial relationships might include the first offering of a new technology, the delegation of the most experienced engineering team to a collaborative NPD project, or the allocation of scarce materials in times of high demand (Ramsay, 2001b; Hüttinger, Schiele \& Veldman, 2012; Pulles, Veldman $\&$ Schiele, 2014). Only a limited amount of buyers can attain the commitment of a supplier. If one buyer obtains, superior resources, then other buyers are ipso facto allocated inferior resources (Gulati, Nohria \& Zaheer, 2000). Therefore, a preferred customer can be defined as a buyer to whom the supplier allocates better resources than to less preferred buyers. Customer attractiveness and supplier satisfaction play important roles that precede preferred customer status (Hüttinger, Schiele \& Veldman, 2012).

\subsection{Customer attractiveness and supplier satisfaction and their link to preferential resource allocation}

The concepts of attractiveness and satisfaction have their roots in social exchange theory. Based on the notion that exchanges are not limited to material goods, but also include tangible value (Homans, 1958), attractiveness and satisfaction explain the

\footnotetext{
${ }^{2}$ Critics may argue that the term 'customer' in certain streams of literature refers to the end-user. However, we speak of 'preferred customer' and 'customer attractiveness' to adopt the terminology of the preferred customer literature.
} 
motivations of actors to initiate, intensify, or discontinue a relationship to attain additional value from exchange relationships (Thibaut \& Kelley, 1959; Blau, 1964). Concepts such as 'reverse marketing' (Leenders \& Blenkhorn, 1988; Biemans \& Brand, 1995) and the importance of being a 'good customer' (Williamson, 1991; Moody, 1992), raised the awareness of attractiveness and satisfaction as explanations of the additional value buying firms might gain from their relationships with suppliers. Since then, customer attractiveness and supplier satisfaction have been used to explain how suppliers can be induced to 'go the extra mile' (Christiansen \& Maltz, 2002; Ellegaard, Johansen \& Drejer, 2003; Mortensen, Freytag \& Arlbjørn, 2008; Essig \& Amann, 2009).

\subsubsection{Customer attractiveness and supplier satisfaction}

In the early work on attractiveness and satisfaction Blau (1964) as well as Thibaut and Kelley (1959) explain the role of 'value' in attracting and satisfying partners. As Ramsay and Wagner (2009) observe, a considerable amount of (industrial) marketing research examines the role of value in buyer-supplier interactions taking the supplier's perspective (e.g., Ulaga \& Eggert, 2006). According to this perspective, customer value is the benefit that customers experience from a specific good or service, most often in monetary terms (Lindgreen \& Wynstra, 2005). Conversely, supplier value refers to the benefit a supplier receives from an interaction with a specific customer (Ramsay, 2005).

By creating attractiveness, buyers induce supplier interest by showing potential value to incentivize suppliers into (closer) collaborations (Ellegaard, Johansen \& Drejer, 2003; Mortensen, Freytag \& Arlbjørn, 2008). Therefore, customer attractiveness refers to the expected value as Hald, Cordón, and Vollmann (2009, p. 961) effectively summarize: "Blau sees perceived expected value as the primary component in what draws one actor A to another actor B and argues that actor A is attracted to actor B if actor A expects association with actor B to be rewarding for himself." Attractiveness can be seen interest two parties have to intensify, or engage in a relationship (Blau, 1964). Satisfaction refers to the perceived feeling of equity or fulfillment when the outcomes are actually achieved in the relationship (Thibaut \& Kelley, 1959; Benton \& Maloni, 2005; Essig \& Amann, 2009). Thus, supplier satisfaction refers to perceived value.

By building supplier satisfaction, buyers display value in the relationship and create a feeling of fulfillment with regard to the suppliers' relationship investments (Essig \& Amann, 2009) and a feeling of equity despite possible power imbalances (Benton \& Maloni, 2005). Thus, whereas suppliers might be attracted to certain customers both a priori and a posteriori a relationship, satisfaction can only occur $a$ posteriori. Based on this reasoning, a customer is perceived as attractive by a supplier if the supplier in question has a positive expectation towards the relationship with this customer (Schiele, Calvi \& Gibbert, 2012). These expectations are based on the expected value of a given buyer leading to the supplier's interest to intensify or engage in a relationship with this buyer. Supplier satisfaction can be seen as a condition that is achieved if the quality of outcomes from a buyer-supplier relationship meets or exceeds the supplier's expectations (Schiele, Calvi \& Gibbert, 2012). 


\subsubsection{Hypotheses}

Both customer attractiveness and supplier satisfaction might explain why certain customers are better able to obtain resources from shared supplier networks (Schiele, Calvi \& Gibbert, 2012). As stipulated in social exchange theory, interactions between partners are regulated on norms of reciprocity that are based on the expectations of giving and receiving relational benefits (Lambe, Wittmann \& Spekman, 2001). In this way, customer attractiveness can help buying firms obtain better resources because the extent to which suppliers expect value from a relationship might induce them to allocate resources to that relationship. For example, Ellegaard, Johansen and Drejer (2003) explain how potential value convinces certain suppliers to engage in closer collaborations. Because of the expected value, suppliers become interested in engaging in or intensifying a relationship and are expected to allocate their resources accordingly. Thus, customer attractiveness can help buying firms obtain supplier resources.

H3.1. Customer attractiveness is positively related to preferential resource allocation from suppliers.

Social exchange theory suggests that partners adjust their behavior and actions toward each other based on relational benefits and the expectations that these benefits are reciprocated (Nyaga, et al., 2013). If a supplier holds satisfying and unsatisfying relationships, then the supplier is expected to show more commitment to the relationship in which it experiences more relational benefits. Therefore, buying firms that invest in relationships (e.g., through supplier development or sharing knowledge) often reach higher levels of supplier commitment (Dyer \& Hatch, 2006). Conversely, suppliers that become dissatisfied with their relationship with the buying firms might eventually search for other resource allocation channels (Ellegaard \& Koch, 2012). If one firm is capable of consistently reaching higher levels of relative supplier satisfaction, then suppliers should prefer collaborating with this firm over the other (competing) firms and allocate better resources to this relationship. Therefore, supplier satisfaction can help buying firms to achieve a better resource allocation from suppliers.

H3.2. Supplier satisfaction is positively related to preferential resource allocation from suppliers.

It has been argued that buyers that are unable to attract suppliers will most likely not engage in relationships that result in supplier satisfaction (Ramsay \& Wagner, 2009). In this perspective, customer attractiveness is an important condition for suppliers to initiate or intensify a relationship (Schiele, et al., 2012). Then, if the expectations of a relationship are met, the outcome is supplier satisfaction (Hüttinger, Schiele \& Veldman, 2012). Hence, customer attractiveness is expected to positively influence supplier satisfaction. Because customer attractiveness refers to the expected value of a supplier and supplier satisfaction refers to the perceived value (see section 3.1 ), the constructs are highly related. Customer attractiveness and supplier 
satisfaction relate to supplier resource allocation in a similar way. A supplier is more likely to allocate resources to the relationship with a buying firm because this supplier either expects or perceives value. Then, customer attractiveness relates to both supplier satisfaction and to supplier resource allocation. This implies a mediating effect of supplier satisfaction: Customer attractiveness positively affects supplier resource allocation partly because customer attractiveness affects supplier satisfaction, which in turn affects supplier resource allocation ${ }^{3}$.

H3.3. The relationship between customer attractiveness and preferential resource allocation from suppliers is mediated supplier satisfaction.

\subsection{The dimensions of customer attractiveness and supplier satisfaction}

As argued in the introduction, previous empirical studies on customer attractiveness and supplier satisfaction have taken a relatively narrow approach concerning the dimensions of these constructs. This section aims to obtain a broader picture of the different dimensions of customer attractiveness and supplier satisfaction. Different workshops and seminars (e.g., Schiele, et al., 2012), together with practitioner reports (e.g., State-of-Flux, 2011), have shown that customer attractiveness, supplier satisfaction, and preferred customer status are concepts that gain interest in practice. Therefore, we build on practitioner input to explore the different dimensions that belong to customer attractiveness and supplier satisfaction. We used a relatively new methodology to do so: the World Café.

\subsubsection{The World Café methodology}

The World Café method is a conversational process that helps people from different backgrounds and from multiple hierarchies engage in a constructive dialogue. This method gathers data by stimulating café dialogues and creating a welcoming environment in which people feel free to speak up (Tan \& Brown, 2005). In these dialogues, participants discuss numerous pre-defined topics. A World Café begins with a general introduction on these topics, followed by a series of parallel small group (i.e., 4-5 participants) conversations (e.g., Pidgeon, et al., 2009). Between these parallel sessions, participants randomly rotate between tables to continually change the composition of the discussion groups. One specific topic is discussed at each table. Moderators document and facilitate the discussions (Brown \& Isaacs, 2005; Hoffmann, 2011).

The World Café can be regarded as a specialized form of the conventional focus group approach (Brennan \& Ritch, 2010). However, it has several advantages over focus group and other approaches such as (semi-)structured interviews. For example, participants in World Café discussions are not interviewees; instead, they are coresearchers that explore a certain phenomenon with scholars. This method provides an opportunity for open discussion. The moderators of the discussion are instructed to induce the participants to interact with each other and not interfere in the dialogues

\footnotetext{
${ }^{3}$ For this hypothesis we used a similar reasoning used by Cho and Pucik (2005) in their hypothesis on the relationship between innovativeness, quality and growth.
} 
(Mattila \& Antikainen, 2011). Therefore, the findings obtained from this method are less prone to interviewer bias (Hoffmann, 2011). In addition, the World Café method has several built-in iterations in which participants discuss and evaluate the outcomes of their peers from the previous discussions. These multiple rounds of discussion allow the participants to confirm, sharpen, or reject the findings of their preceding discussions, thereby increasing the robustness of the World Café outcomes.

\subsubsection{World Café exploration of the customer attractiveness and supplier satisfaction dimensions}

This study's World Café took place in the Netherlands. Three CPOs, 2 innovation managers, 1 purchasing manager (from Dutch and German multinational companies), 4 consultants, and 3 scholars participated in this World Café. The CPOs and managers were selected based on their experience and their firms' reputations as best exemplars of collaborative relationships with suppliers. A senior scholar, who discussed the recent developments in the literature and explained the concepts of customer attractiveness and supplier satisfaction, introduced the topics of discussion to the participants.

For the discussions of customer attractiveness and supplier satisfaction, the CPOs and managers divided themselves into two groups of similar sizes. Each discussion group was appointed a moderator (i.e., an experienced scholar whose primary role was to document the discussions and induce explorative discussions, rather than participate or interfere in the discussion). In addition, one of the consultants joined each group; their role was to catalyze conversations (when needed) without interfering in the discussion. Next, the groups began their discussion in two separate rooms. As a starting point for the discussion, the scholars and two of the consultants prepared bullet points on flip-overs with dimensions found to be relevant in practice (indicated with an asterisk $\left(^{*}\right)$ in Table 3.1 ). The participants commented on these dimensions and discussed (based on their own practices and experience) the dimensions that they found to most accurately describe the underlying dimensions of customer attractiveness and supplier satisfaction.

As a first step, the participants discussed the topic of customer attractiveness. A timekeeper monitored the discussion and assured that all the discussions were recorded. In addition, the moderators kept track of the conversation by writing down bullet points on a flip-over. In this way, the participants were able to see how the moderator documented the discussion and could help the moderator to formulate the bullet points, thereby reducing the risk of misinterpretation. The discussions lasted for approximately 45 minutes.

Then, the participants divided themselves in new groups to discuss the topic of supplier satisfaction. Similarly, the discussions were moderated and recorded. These discussions lasted for 40 minutes. In the plenary session that followed, the participants evaluated and discussed the bullet-points and clarified them when needed. After this procedure, they indicated the significance of each bullet-point by fixing a sticker to the dimensions that they considered important. Using this procedure, the participants were able to attach stickers to as many bullet-points as they liked. In the final iteration, the senior scholar discussed all the bullet-points. The participants of this closing session indicated that they felt that dimensions were not missing. 
Figure 3.2 shows a schematic overview of the World Café session.

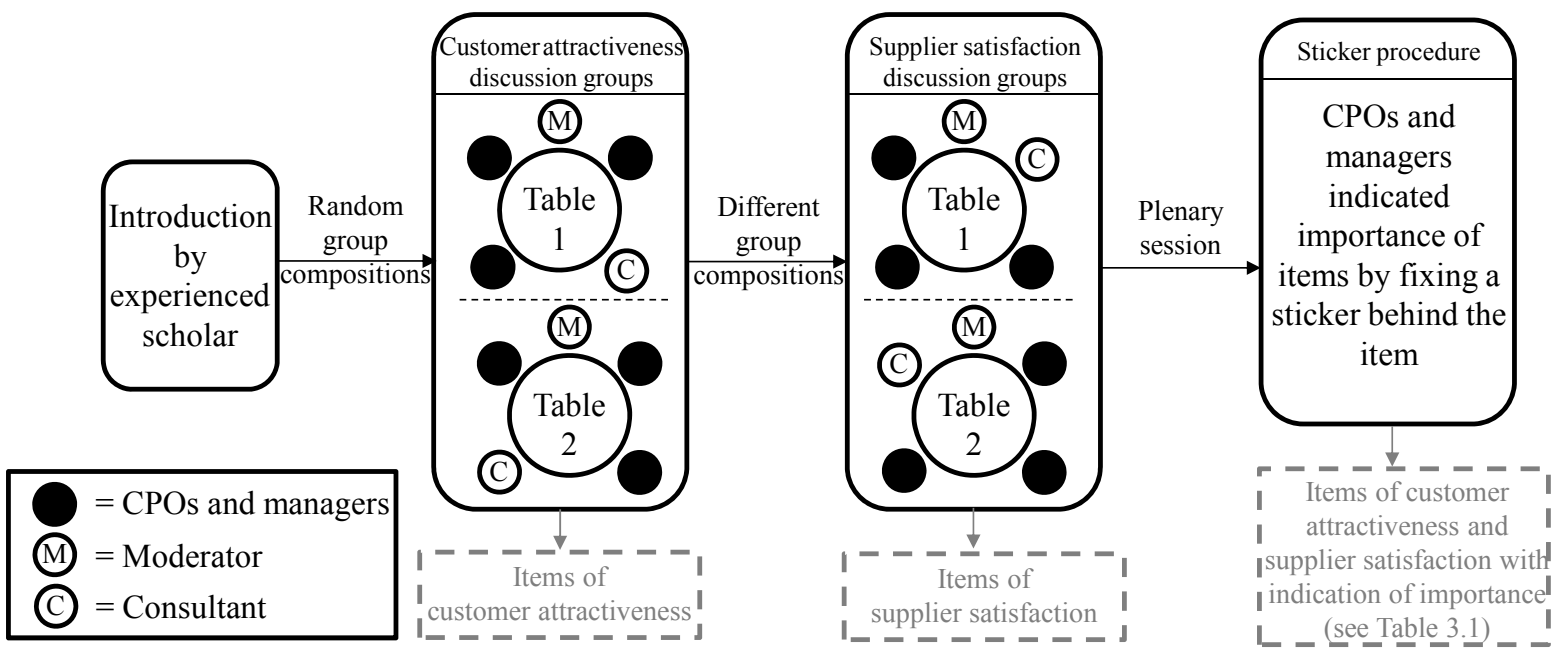

Fig. 3.2. Schematic overview of the World Café session

Table 3.1 shows the final result of the World Café. Reviews of the audio recordings revealed that the moderators did not miss bullet-points. The columns with customer attractiveness and supplier satisfaction dimensions show the bullet-points that the moderators recorded during the discussions ${ }^{4}$. The 'stickers' column shows the amount of stickers provided to each bullet-point by the participants in the plenary session.

Table 3.1.

Outcome of World Café group discussion

Group 1

Dimensions of Customer Attractiveness

Growth opportunities for suppliers

Presence of buyer in growth markets, acting as a reference

Compensating suppliers for taking risks

Reputation of high quality supplier

management* $*^{\mathrm{a}}$

Short time from first offer to actual sale

Reputation of trustworthiness*

Supplier development programs*

Continuity in demand

Values of the company (e.g., sustainability)

Simplicity in business processes/speed of

response

Providing suppliers with constructive

feedback*

Geographical spread of the buyer

Flexibility in initiating new collaborations

Providing suppliers access to advanced

knowledge

Acting as a reference to demonstrate capability

of supplier

Top-management interest for suppliers

\section{Group 2}

\section{Dimensions of Customer}

Stickers

Attractiveness

Stickers

Reputation of creating a win-win

situation

Acting as a reference helping to enter

new markets

Share technology

Supplier development programs*

Reputation of brands*a

Purchasing volume of buyer*

Providing feedback*

Advanced contracting

Firm strategy

Value proposition of the buyer

Exclusivity agreements

0 Early supplier involvement

0

0

0

0

\begin{tabular}{|l|l|}
4 \\
2 \\
2 \\
1 \\
0 \\
0 \\
0 \\
0 \\
0 \\
0 \\
0 \\
0
\end{tabular}

\footnotetext{
${ }^{4}$ In Table 3.1, some of the bullets are slightly extended with additional words to increase readability
} 
Group 1

Dimensions of Supplier Satisfaction

Relationships based on trust rather than solely on profits*b

Chemistry between acting people*

Managing realistic expectations

Cultural fit between firms

Continuous income flow

Measure satisfaction through survey

Top management accessibility

Keep close connection with supplier

Info sharing

Pay high prices for goods*

Help suppliers*

Easy ramp-up, and ease in continuation of the relationship

Key account management meeting account plans

Supplier rating, compare to competitors

Open up growth innovation opportunities
Group 2

Stickers

Dimensions of Supplier Satisfaction Stickers

Top management commitment

Trust*

Share risks with suppliers

Long-term orientation/continuity

Alignment of business between firms

Shared resource spending

Close/tight relationships

Help suppliers*

Growing purchase volumes*

Specific investments in suppliers

Joint development/test suppliers'

innovations

Good organization of relationship

Shared objectives

Feedback to suppliers

$*=$ Bullet points prepared by scholars and consultants as discussion input.

$\mathrm{a}=$ Original bullet, as starting input to the discussion was named; reputation. Bullet was rephrased during discussion

$\mathrm{b}=$ Original bullet, as starting input to the discussion was named; trust. Bullet was rephrased during discussion

Table 3.1 shows the output of the World Café sessions on customer attractiveness and supplier satisfaction. Having presented these dimensions, the following sections discuss the methodology that was used for testing hypotheses 3.1 and 3.2. In our measurement development we use the dimensions of Table 3.1 as input.

\subsection{Methodology for testing the hypotheses}

\subsubsection{Sample and data collection}

This study's data were collected in collaboration with the large German automobile manufacturer that supported this research project. An advantage of single-industry samples is that they offer greater control over sources of extraneous variation caused by industry characteristics, or environmental noise (Mohr \& Spekman, 1994). Although single-industry samples may potentially harm the generalizability of the findings, suppliers in the automobile industry typically cover a wide variety of different sectors ranging from metal, mechanics, electronics and others which would limit generalizability concerns.

In December 2012, an e-mail was sent to a random sample of 1000 suppliers in the manufacturer's database. This e-mail contained an invitation to the sales representative of the supplier to participate in an online survey hosted by the university of the authors. The respondents were informed that the survey was not related to the manufacturer and that their data would not be provided to the manufacturer. We motivated employees to answer the survey by promising to provide a summary report to all participants. Because the contact details of the suppliers were 
proprietary to the automotive manufacturers, reminder e-mails were not sent. The online survey was accessed 146 times, and 96 respondents completed the survey. Of these 96 responses, 5 surveys were removed from the sample due to missing values for key variables. Therefore, the final sample size of this study was 91, which represents a response rate of $9.1 \%$. We asked respondents to assess a single buyer with whom they were familiar on a 5-point Likert scale ranging from $1=$ "no, strongly disagree" to $5=$ "yes, strongly agree".

On average, the respondents indicated having worked for 6.4 years at their current firm. Table 3.2 shows the demographic profiles of the respondents. Eight respondents did not indicate their demographic information. Comparative $t$-tests did not reveal any significant differences among the variables of interest with regard to the demographic variables.

Table 3.2.

Profile of turnover and material group of the sample

\begin{tabular}{lrlr}
\hline & Frequency & Frequency \\
\hline Country & & & \\
Brazil & $3.3 \%$ & Italy & $2.2 \%$ \\
Canada & $1.1 \%$ & Mexico & $6.6 \%$ \\
China & $2.2 \%$ & Poland & $1.1 \%$ \\
Czech Republic & $5.5 \%$ & Portugal & $3.3 \%$ \\
France & $3.3 \%$ & Russia & $1.1 \%$ \\
Germany & $53.8 \%$ & Slovakia & $1.1 \%$ \\
India & $1.1 \%$ & United States & $5.5 \%$ \\
& & & \\
Annual turnover (€) & & Material group \\
0-10 Million & $28.6 \%$ & Chassis & \\
$11-20$ Million & $11.0 \%$ & Electric & $4.4 \%$ \\
$21-50$ Million & $14.3 \%$ & Exterior & $6.6 \%$ \\
$51-100$ Million & $9.9 \%$ & Interior & $7.7 \%$ \\
$101-500$ Million & $16.5 \%$ & Metal & $24.2 \%$ \\
$>500$ Million & $11.0 \%$ & Power Train & $31.9 \%$ \\
& & & $16.5 \%$ \\
\hline
\end{tabular}

Because non-response bias is a general concern for survey studies, we tested for nonresponse bias based on the assumption that the responses of late responders represented the responses of non-responders (Armstrong \& Overton, 1977; Paulraj, Lado \& Chen, 2008) Thus, we compared the data from early responders to late responders with regard to this study's key constructs and demographic variables. The results of these $t$-tests did not yield significance differences between early responders and late responders (at $p<0.05$ ). Thus, we did not find evidence of a non-response bias in our sample.

\subsubsection{Measure development}

Because the current literature does not provide measures of customer attractiveness and supplier satisfaction that cover all the relevant dimensions of the construct, we used the World Café output to construct the measures for these constructs. Because the preferred customer status concept is strongly based on resource-based studies, we 
built upon various research in the resource-based literature to create the indicators for our construct that measures preferential resource allocation from suppliers.

The outcomes of the World Café showed that customer attractiveness and supplier satisfaction have many dimensions that are not necessarily related to each other. To capture this variation, we constructed formative (and not reflective) measures of these constructs. Whereas reflective indicators are, in essence, interchangeable, formative indicators can be mutually exclusive (Diamantopoulos \& Winklhofer, 2001). As a group, formative indicators jointly determine the conceptual meaning of the construct (Jarvis, et al., 2003, p. 201). For example, a buying firm can be highly attractive because it is known to compensate suppliers for taking risk even though the firm is known for the long time between the first offer and the actual sale (and vice versa).

Based on the dimensions generated using the World Café method, we proceeded with the measure development and reliability assessment for the final instrument. Unlike the development of reflective scales, detailed guidelines for constructing formative measures are uncommon. However, Diamantopoulos and Winklhofer (2001) provide a generally accepted methodology to construct formative measures. We integrated their methodology with our measure development procedure and reliability assessment. Furthermore, we included a content and indicator specification, an assessment of indicator collinearity, and tests for the external validity of our measures.

\subsubsection{Content and indicator specification for customer attractiveness and supplier satisfaction}

To construct the customer attractiveness and supplier satisfaction measures, we built upon the sticker procedure used by the World Café participants and the audio recordings of the discussions. To obtain the final indicators for the constructs, we merged the dimensions from Table 3.1 into a single list. To avoid redundancy (Peng \& Lai, 2012), dimensions with a similar meaning but different phrasing were combined into a single indicator, and the number of stickers allocated to these dimensions was summed. For example, the supplier satisfaction dimensions, 'Top management accessibility' (Group 1, two stickers) and 'Top management commitment' (Group 2, five stickers) were merged into the item 'Top management commitment/accessibility' (7 stickers). Using this procedure, the original discussions were traced back to the World Café audio recordings to prevent misinterpretation and indicator rephrasing that altered the original meaning of the participants.

We made a final selection to form the measures from this merged list. The dimensions with the highest perceive importance (i.e., stickers) were used for the customer attractiveness and supplier satisfaction constructs. The final indicators were rephrased to fit the focal objects (Rossiter, 2002) of customer attractiveness and supplier satisfaction.

Unlike reflective scales, quantitative procedures cannot be used to assess the content validity of formative constructs. Still, as an ex-post check we compared the indicators in Table 3.3 with the study by Ramsay and Wagner (2009) who explored the dimensions of supplier value and the literature review of Huttinger el al. (2012). The dimensions in these studies were similar to our customer attractiveness and supplier satisfaction indicators and did not reveal dimensions that the indicators do 
not cover. Thus, we concluded that the customer attractiveness and supplier satisfaction indicators are sufficiently inclusive and capture the constructs' domains (Diamantopoulos \& Winklhofer, 2001). The measures are shown in Table 3.3.

Table 3.3.

Indicators of customer attractiveness and supplier satisfaction

\begin{tabular}{|l|l|}
\hline \multicolumn{2}{|c}{ Customer attractiveness } \\
CA 1 & $\begin{array}{l}\text { This customer is known for its open and } \\
\text { quick information sharing }\end{array}$ \\
\hline CA 2 & $\begin{array}{l}\text { This customer is known to create win-win } \\
\text { situations }\end{array}$ \\
\hline CA 3 & This customer is of substantial size \\
\hline CA 4 & $\begin{array}{l}\text { This customer compensates suppliers for } \\
\text { taking risks }\end{array}$ \\
\hline CA 5 & $\begin{array}{l}\text { This customer has a good reputation for } \\
\text { trustworthiness and fairness }\end{array}$ \\
\hline CA 6 & $\begin{array}{l}\text { This customer is known for the short time } \\
\text { between offer to actual sale }\end{array}$ \\
\hline CA 7 & $\begin{array}{l}\text { This customer is present in growth } \\
\text { markets }\end{array}$ \\
\hline
\end{tabular}

\begin{tabular}{|c|c|}
\hline \multicolumn{2}{|r|}{ Supplier satisfaction } \\
\hline SSat 1 & $\begin{array}{l}\text { This customer accounts for a large share in } \\
\text { our turnover }\end{array}$ \\
\hline SSat 2 & This customer pays high prices to us \\
\hline SSat 3 & $\begin{array}{l}\text { Trust matters more for this customer than } \\
\text { direct profits in the relationship with us }\end{array}$ \\
\hline SSat 4 & $\begin{array}{l}\text { This customer manages realistic } \\
\text { expectations }\end{array}$ \\
\hline SSat 5 & $\begin{array}{l}\text { This customer guarantees a continuous } \\
\text { income flow }\end{array}$ \\
\hline SSat 6 & This customer helps us to innovate \\
\hline SSat 7 & $\begin{array}{l}\text { This customer's top-management commits } \\
\text { itself to the relationship with us by being } \\
\text { accessible to us }\end{array}$ \\
\hline SSat 8 & $\begin{array}{l}\text { There is a chemistry between our and this } \\
\text { customer's acting people }\end{array}$ \\
\hline
\end{tabular}

\subsubsection{Content and indicator specifications for preferential resource allocation}

Earlier, we defined a preferred customer as buyer to whom the supplier allocates better resources than less preferred buyers. We provided examples of preferential resource allocation (e.g., the first offer of a new technology or the delegation of the most experienced engineering team for collaborative NPD projects). To operationalize these resources, we built on the resource-based literature. We built on Newbert (2008) who suggested measuring the availability of resources in an organization, in a way similar to the suggestion of Hunt and Davis (2008). Newbert's resource classification comprises financial resources (capital, cash), human resources (experience, intelligence of individual employees), intellectual resources (patents, ideas), organizational resources (partners, suppliers), physical resources (materials, physical technologies), and capabilities (skills, expertise). To capture the entire domain of this construct, we included these resources as indicators (Diamantopoulos \& Winklhofer, 2001; Peng \& Lai, 2012). Table 3.4 shows the preferential resource allocation measure.

\subsubsection{Indicator collinearity}

Multicollinearity is a particular concern of formative indicators (Diamantopoulos \& Winklhofer, 2001). Although a set of formative indicators need not be correlated, high collinearity among the indicators may still exist and create unstable estimates (Mathieson, Peacock \& Chin, 2001). Therefore, a multicollinearity test should be performed. We examined the variance inflation factor (VIF) to test for multicollinearity (Peng \& Lai, 2012). Using the SPSS collinearity diagnostic, our results indicated that the VIFs of all indicators showed minimal collinearity: The VIFs of customer attractiveness, supplier satisfaction, and preferential resource allocation 
ranged between 1.72 and 2.18, 1.30 and 2.32, and 1.42 and 3.58, respectively. Because these values are well below the problematic VIF range of 5 to 10 , multicollinearity does not seem to be a serious threat in this study.

Table 3.4.

Measure of preferential resource allocation

\begin{tabular}{|l|l|}
\hline PRA 1 & $\begin{array}{l}\text { Our firm allocates our best employees (e.g. most experienced, trained, intelligent, etc.) to the } \\
\text { relationship with this customer. }\end{array}$ \\
\hline PRA 2 & Our firm shares our best ideas (e.g. newest, most innovative, etc.) with this customer. \\
\hline PRA 3 & $\begin{array}{l}\text { Our firm allocates more financial resources (e.g. capital, cash, etc.) to the relationship with this } \\
\text { customer. }\end{array}$ \\
\hline PRA 4 & $\begin{array}{l}\text { In case of capacity bottlenecks, we allocate our scarce resources to this customer instead to our } \\
\text { other customers }\end{array}$ \\
\hline PRA 5 & $\begin{array}{l}\text { Our firm grants this customer better access to organizational resources (e.g. relationships with its } \\
\text { partners, distribution channels, benchmark data, etc.). }\end{array}$ \\
\hline PRA 6 & Our firm shares more of our capabilities (e.g. skills, know-how, expertise, etc.). \\
\hline
\end{tabular}

\subsubsection{External validity}

To assess the external validity of formative indicators we examined the correlation between the formative and reflective measures of a construct using a redundancy analysis (Chin, 2010; Hair, et al., 2012). To conduct this test, we included additional reflective scales in our measure that were conceptually equivalent to the formative constructs. Table 3.5 shows the reflective measures for customer attractiveness, supplier satisfaction and preferred customer status as well as the quality criteria for the reflective constructs. We included reflective measures of preferred customer status to examine if our preferential resource allocation construct fits to the preferred customer status concept. These reflective indicators loaded onto their latent construct with values greater than 0.81 , and the average variance extracted (AVE), Cronbach's alphas, and composite reliability $(\mathrm{CR})$ values were all greater than the recommended validity and reliability thresholds.

Table 3.5.

Reflective measures of customer attractiveness, supplier satisfaction, and preferred customer status Loading Indicator

Customer Attractiveness (AVE $=0.84$, Cronbach's Alpha $=0.81, \mathrm{CR}=0.91$ )

We want to intensify our relationship with this customer because of the expected value

0.91 RCA1 of this customer

0.92 RCA2 We expect this customer to be an attractive partner for future collaborations

Supplier Satisfaction (AVE $=0.83$, Cronbach's Alpha $=0.80, \mathrm{CR}=0.91$ )

0.92 RSS1 My firm experiences a feeling of equity and fulfillment in the relationship with this

0.90 RSS2 Our firm is very satisfied with the relationship with this customer

Preferred Customer Status (AVE $=0.70$, Cronbach's Alpha $=0.79, \mathrm{CR}=0.87$ )

Compared to other customers in our customer base, we like this customer more than

$0.84 \quad$ PCS1 other customers

0.85 PCS2 We consider this customer to be a preferred customer

My firm's employees prefer collaborating with this customer to collaborating with other

$0,81 \quad$ PCS3 customers 
To perform the redundancy analysis, we created sets of two latent constructs. The first construct was measured using the formative indicators presented in Table 3.3 and Table 3.4, and the second was measured with the reflective indicators suggested by Cenfetelli and Bassellier (2009) shown in Table 3.5. The set of formative indicators are adequate if their construct has a strong, significant path with the reflective construct. The path loadings (i.e., $\beta$ s) between the formative and reflective indicators for customer attractiveness and supplier satisfaction were 0.60 and 0.79 (both $p<$ 0.01 ), and the explained variances (i.e., $R^{2} \mathrm{~s}$ ) were 0.36 and 0.63 respectively. The path loading between the preferential resource allocation and preferred customer status construct was $0.58(p<0.01)$ and the explained variance 0.76 . These values indicated a sufficient degree of external validity (Wagner, 2012).

\subsection{Data analyses and results of hypotheses testing}

A partial least squares (PLS) analysis was used to test the hypotheses. PLS is a regression-based structural equation modeling technique that does not make assumptions about data distributions. This study used PLS for three major reasons. First, PLS is ideally suited to test models with latent variables, especially during the early stages of theory development and in exploratory studies (Birkinshaw, Morrison \& Hulland, 1995). Second, unlike covariance-based structural equation modeling, PLS allows for both formative and reflective indicators. Third, PLS is generally more powerful for small sample sizes compared with other techniques. As Reinartz, Haenlein, and Henseler (2009) show PLS is recommended when the number of observations is less than 250. PLS researchers often determine the minimum sample size to be ten times the largest number of structural paths that lead to any endogenous variable (e.g., Howell \& Sheab, 2001, p. 22). Our sample size of 91 exceeds this minimum requirement. This study used SmartPLS 2.0 (Ringle, Wende \& Will, 2005) to obtain the estimates.

To estimate the significance of the hypothesized paths, we employed a bootstrapping procedure with replacement using 500 resamples. To assess the stability of the estimates, likewise bootstrap samples of 250 and 1000 were employed. The results showed consistent levels of significance across the bootstrapped samples. We tested two models. In Model 1, we test the direct effect of customer attractiveness (i.e., H3.1). In Model 2 we tested the direct and mediating effect of supplier satisfaction (i.e., H3.2 and H3.3).

\subsubsection{Direct effect of customer attractiveness}

The results for Model 1 revealed a positive and significant relationship $(\beta=0.61 ; p$ $<0.01$ ) between customer attractiveness and preferential resource allocation, which supports H3.1. Customer attractiveness accounted for $37 \%$ of the explained variance of preferential resource allocation (i.e., $R^{2}=0.37$ ).

\subsubsection{Direct and mediating effect of supplier satisfaction}

Model 2 added supplier satisfaction. Supplier satisfaction had a significant and positive effect on preferential resource allocation $(\beta=0.50 ; p<0.01)$; therefore, H3.2 was also supported. The effects in Model 2 are indicative of a meditation effect of 
supplier satisfaction. That is, the direct effect of customer attractiveness on preferred customer in Model 2 was substantially reduced and became insignificant $(\beta=0.19 ; p$ $>0.1)$ while customer attractiveness had a significant effect on supplier satisfaction $(\beta$ $=0.73 ; p<0.01)$ which accounted for $54 \%$ of the variance in the supplier satisfaction construct (i.e., $R^{2}=0.54$ ).

To test the significance of the mediation effect, we followed the suggestion by Rungtusanatham et al. (2014) to apply a procedure that explicitly tests the significance of a mediation effect instead of using an implicit procedure (e.g., Sobel test). They suggest to construct a percentile bootstrap confidence interval in which the sampling distribution is based on the estimated paths bootstrap samples. We followed this procedure and used 500 resamples to determine the product terms of the constituent mediation path (i.e., customer attractiveness $\rightarrow$ supplier satisfaction, supplier satisfaction $\rightarrow$ preferential resource allocation) which served as empirical, nonparametric approximations of the sampling distributions of the indirect effects of interest (cf., Preacher \& Hayes, 2008). This procedure showed that the indirect effect of customer attractiveness on preferential resource allocation through supplier satisfaction is significant ( $95 \%$ confidence interval of 0.10 to 0.68 ). Therefore, we accepted H3.3, concluding that the mediation effect of supplier satisfaction existed in the relationship between customer attractiveness and preferential resource allocation.

A post hoc test on the moderating effect of supplier satisfaction was tested by including the product terms of customer attractiveness and supplier satisfaction. Because this study uses formative constructs, we derived the latent variable scores for customer attractiveness and supplier satisfaction and calculated their product using the latent variable scores (cf. Chin, Marcolin \& Newsted, 2003). A moderating effect was not present $(\beta=0.07 ; p>0.1)$.

The results of the two models are shown in Figure 3.3.

Model 1

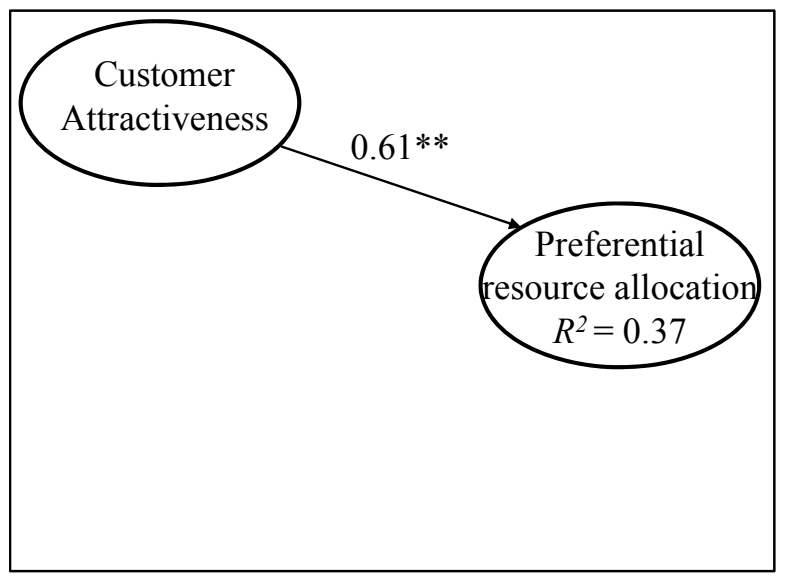

Fig. 3.3. Results

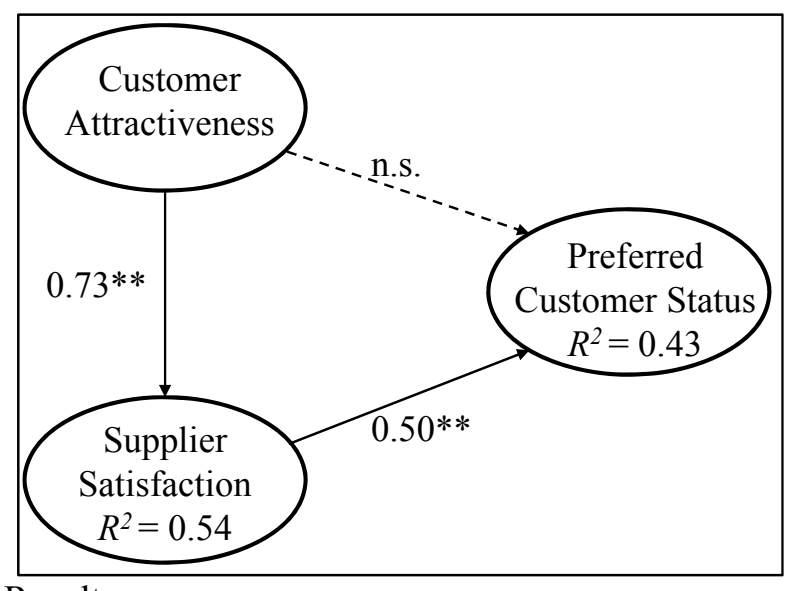

Model 2

\subsection{Discussion and implications}

Obtaining better external resources than competitors from shared supplier networks remains a key challenge for firms (Ellram, Tate \& Feitzinger, 2013). A firm's supply chain is a mechanism to obtain or co-create supplier resources that the buying firm can transform into a competitive advantage (Dyer and Singh 1998; Koufteros, 
Vickery and Dröge 2012). Firms that are a preferred customer (i.e., a buyer to whom the supplier allocates better resources than less preferred buyers because the supplier favors the buyer's behaviors, practices, business values, or some combination thereof) can therefore expect to achieve more competitive advantage through its relationships with its supplier network. This paper explained the roles that customer attractiveness and supplier satisfaction play in attaining preferred customer status.

\subsubsection{Discussion of findings and contributions to the literature}

This study's empirical analysis, which was based on the data of 91 supplying firms showed that both customer attractiveness and supplier satisfaction positively affect preferential resource allocation. Yet, the insignificant direct relationship between customer attractiveness and preferential resource allocation when supplier satisfaction was included showed that the impact of customer attractiveness on preferential resource allocation is affected by supplier satisfaction. Supplier satisfaction showed to be a significant mediator in the relationship between customer attractiveness and preferential resource allocation.

Even though both concepts build on the notion of supplier value, customer attractiveness and supplier satisfaction are conceptually different concepts. We discussed that a buying firm is perceived as attractive by a supplier if the supplier in question has a positive expectation towards the relationship with this customer (Schiele, Calvi \& Gibbert, 2012). Supplier satisfaction can be seen as a condition that is achieved if the quality of outcomes from a buyer-supplier relationship meets or exceeds the supplier's expectations (Schiele, Calvi \& Gibbert, 2012). This implies that, whereas suppliers might be attracted to certain customers both a priori and $a$ posteriori a relationship, satisfaction can only occur a posteriori. Our World Café methodology, in which we built on input of practitioners, provided a more comprehensive view on the different dimensions of customer attractiveness and supplier satisfaction.

By means of these findings, our study makes several contributions to the industrial marketing and purchasing literature. Although customer attractiveness and supplier satisfaction are clearly related, the conceptual delineation between these constructs has proved to be challenging in the current literature (La Rocca, Caruana \& Snehota, 2012). For example, although most studies refer to customer attractiveness as an expectation of certain benefits, Mortensen and Arlbjørn (2012, p. 162 and 164) discuss customer attractiveness as perceived benefits. "They are very satisfied. We provide them with knowledge about quality and provide them a large volume of supplies." And: "We have close communication with [the case company] and close knowledge sharing". In addition, scholars describe contradicting conceptual relationships between these concepts. For example, La Rocca, Caruana, and Snehota (2012, p. 1242) explain that attractiveness not only precedes trust but also is "an important part of maintaining trustworthiness and to establish satisfaction". However, Hald (2012, p. 1238) describe a reverse relationship between these concepts in his research by explaining how a change in the levels of supplier satisfaction can lead to "overall changes in the distribution of customer attractiveness." These illustration show that there are conceptual overlap and contradictory statements in the literature concerning the relationship between these concepts and their relationship to preferred 
customer status. Without sufficient formal conceptual delineation of concepts, examining specific empirical properties (e.g., operational measures or relationships) would be illogical (Wacker 2008). With this study we aimed to provide a clearer view of the properties of customer attractiveness and supplier satisfaction and to provide more consensus concerning their conceptual relationship with each other and with preferred customer status.

\subsubsection{Contributions to practice}

An important assumption in practice is that the relative attractiveness of buying firms (e.g., expressed in potential volumes) is an important indicator of the commitment of suppliers. However, our findings show that in the presence of supplier satisfaction, this initial attraction loses most of its effect on preferential resource allocation. Thus, if these buying firms fail to meets or exceed the supplier's expectations based on their initial attractiveness (i.e. supplier satisfaction), then they might fail to achieve preferred customer status. This implies that attractive customers are not necessarily preferred customers within the supplier network if they are unable to satisfy the supplier. Conversely, other buying firms might attain the best resources in the supplier network, despite their perceived lower attractiveness. This theory might explain how smaller (and in this perspective, less attractive) buying firms are able to attain preferential treatment from supplier networks that they share with powerful competitors (Ellegaard, Johansen \& Drejer, 2003; Dyer \& Hatch, 2006). Although large buying firms assume a preferred customer position due to their trade volume or growth market presence, our findings indicate that these firms should be aware that they might not be a preferred customer without living up to those expectations. Nevertheless, current practice considers leveraging power positions for bargaining gains as a best practice in many supply chain functions (Ellegaard, 2012). Becoming a preferred customer and to meet or exceed the expectations for those suppliers that might provide the buying firm with a competitive edge, might require a change in the current view of managers.

Knowing how to achieve a preferred customer status remains a challenge for buying firms. The conceptual delineation and dimensions of customer attractiveness and supplier satisfaction enable managers to better adjust their strategy to the relational outcome they want to achieve. For example, our findings indicate that promises of future value are no longer effective for firms that are already in close relationships with suppliers. Similarly, Ghijsen, Semeijn, and Ernston (2010) demonstrated how promises of future value have no effect on supplier satisfaction. Rather, firms in this situation should realize that the supplier's perceived value will lead to higher supplier satisfaction and (eventually) preferred customer status. We believe that our findings will help firms to better evaluate their position in their supplier network and recognize potential strategies concerning how to gain better resources from their suppliers.

\subsubsection{Limitations and directions for future research}

This study's findings were based on supplying firms that evaluated the customer attractiveness, supplier satisfaction and preferential resource allocation of buying firms. Some scholars argue that the conceptualization of buyer-supplier relationships 
is too simplistic to fully understand the complexity involved in the formation of preferred customer status. For example, Hald (2012) discusses the importance of micro-dyads (i.e., interpersonal relationships). Similarly, Ellegaard (2012) considers the relevance of interpersonal attraction. Therefore, future research will benefit from taking a micro-perspective. Because the concepts of attractiveness and satisfaction have their roots in social psychology, future research also calls for a behavioral approach. Behavioral operations management (Bendoly, Donohue \& Schultz, 2006) can provide a more complete explanation of the role of individuals on both sides of the dyad with regard to attaining preferred customer status.

Similar to previous research, we based our survey findings on data from the automobile industry. Although focusing on the automobile industry has its merits (as explained in the methodology section), future research should incorporate a wider range of industries to enhance the generalizability of the findings presented. For example, in more service oriented

industries firms are typically less reliant on their suppliers. The effects of customer attractiveness and supplier satisfaction (and of preferential resource allocation) might therefore differ in those industries. In addition, because the World Café participants were mainly purchasing professionals, the dimensions of the attractiveness and satisfaction measures may potentially be biased towards a buyers perspective. Although the dimensions showed a high similarity with previous works, (e.g., Ramsay \& Wagner, 2009; Hüttinger, Schiele \& Veldman, 2012) suppliers may have different perspectives on the importance of the different dimensions. Similarly, specific dimensions of attractiveness and satisfaction might have different effects on the allocation of different kind of supplier resources. For example, financial dimensions of attractiveness might relate differently to the allocation of financial resources, and could explain a different role of supplier satisfaction (Baxter, 2012). By incorporating the distinction between the different dimensions of customer attractiveness and supplier satisfaction as well as the disparate resources for which buying firms aim, future research can provide important insights regarding the contingent strategies for these firms. 



\title{
Chapter 4
}

\section{Winning competition for suppliers' resources: The role of preferential resource allocation from suppliers}

\begin{abstract}
This paper examines the concept of supplier resource competition: the competition between buying firms for the supplier's competitive resources. The purpose is to examine mechanisms by which buying firms can obtain preferential resource allocation from suppliers and how preferential resource allocation affects the competitive advantages of buying firms. Partial least squares structural equation modeling is used to analyze data of 163 buying firms that assess preferential resource allocation from suppliers. The findings show that two indirect capabilities - which refer to a firm's ability to access external resources - (a buying firm's selection capability and relational capability) positively influence the firm's competitive advantage. These relations are significantly mediated by preferential resource allocation of suppliers. The impact of preferential resource allocation appeared stronger for manufacturing firms than for service firms. These findings extend the literature examining competition in the supply market and explains how intermediate variables, such as preferential resource allocation, can significantly impact the effect of indirect capabilities on performance. In addition, this study shows the importance of separating between service and manufacturing when examining the effect of certain SCM practices. Managerially, our results imply that a firm's SCM function should, at least to a certain extent, aim at acquiring better resources than competitors in order to become truly strategic.
\end{abstract}




\subsection{Introduction}

The success of a firm increasingly depends on the resources of its suppliers (Dyer \& Hatch, 2006; Hult, Ketchen Jr. \& Arrfelt, 2007; Hunt \& Davis, 2012). However, as an increasing number of firms seek external collaboration, competition for capable suppliers grows (Takeishi, 2001). Because suppliers have limits on the resources they can devote to buyers, it has been argued that it would be "extremely difficult" for buying firms to create competitive advantages through a supply base that is shared with competitors (Dyer \& Hatch, 2006, p. 703). Therefore, competitive advantage is not a self-evident result of collaborations because competitors might obtain better resources (e.g., the best ideas, newest technologies or preferential allocation of scarce materials) from a supply base that is inherently similar. Thus, the competitiveness of firms critically depends upon the supply chain management (SCM) capabilities needed to obtain supplier resources for which competitors compete as well.

Recently, concepts such as factor market rivalry (Ellram, Tate \& Feitzinger, 2013), preferred customer status (Hüttinger, Schiele \& Veldman, 2012), supplier resource mobilization (Ellegaard \& Koch, 2012) and resource-advantage theory (Hunt \& Davis, 2008) have addressed the competition for supplier resources in greater depth. These recent perspectives have changed the emphasis of the traditional resource-based theories (e.g., Wernerfelt, 1984; Barney, 1991), which view competitive advantage as a function of internal resources, to a perspective that considers the impact of external resources on the competitiveness of firms. This perspective has been termed the extended resource-based view (ERBV; Mathews, 2003; Squire, et al., 2009; Lewis, et al., 2010). This paper builds upon the ERBV to theorize on the effect of supplier resources on the competitiveness of buying firms.

More specifically, we integrate the notion of supplier resource competition and examine the effects of preferential resource allocation from suppliers (i.e. the extent to which firms obtain better supplier resources than competitors) on the competitive advantage of buying firms. We also examine the SCM capabilities needed to obtain preferential resource allocation and draw on a recent stream in the literature that has begun to consider "indirect capabilities", which can be seen as a firms' ability to access resources of external partners (Loasby, 1998; Araujo, Dubois \& Gadde, 2003; Spring \& Araujo, 2014). In this paper, we discuss two capabilities (linking to the conceptual work of Teece, 2007) that refer to a firm's capability to observe resource opportunities in its supply base (i.e., selection capability) and the ability to form an effective relation that facilitates resource exchange (i.e., relational capability). As firms in manufacturing industries are typically more reliant on supplier resources, we also examine how the effect of supplier resource allocation might differ for manufacturing and service firms.

This paper makes several contributions to the literature. First, we integrate the notion of supplier resource competition with the ERBV and suggest that the extent to which buying firms are able to acquire preferential resource allocation is an important determinant for the competitive advantage of buying firms. Second, even though the literature has begun to explore the capabilities that can improve the outcome of interfirm collaborations (e.g., Kale \& Singh, 2007; Kasch \& Dowling, 2008; Paulraj, Lado $\&$ Chen, 2008; Schilke \& Goerzen, 2010), the literate lacks a clear examination on 
how indirect capabilities actually influence the resource allocation of suppliers and how they link to the competitiveness of buying firms. We examine the indirect capabilities that can help a buying firm in attaining competitive advantages and preferential resource allocation. Third, while little studies have examined the differences in impact of SCM practices between service and manufacturing firms, this study examines the different effects of preferential resource allocation from supplier for these industries.

\subsection{The extended resource based view and the competition for supplier resources}

Many scholars have built on resource theories in exploring the strategic role of SCM. In its original form, the resource-based view (RBV; Wernerfelt, 1984; Barney, 1991) explains the competitive advantage of a firm to be "a function of the combined value and rarity of all firm resources and resource interactions" (Lavie, 2006, p. 643). As such, the RBV has been used to explain the competitive advantage of firms in industries ranging from typical manufacturing industries such as the automobile industry (Dyer \& Hatch, 2006) to service industries such as logistics services (Lai, et al., 2008). Over the last decades, resource-based theories have developed new perspectives. Whereas the RBV mainly looked within the firm for resources (Barney, 1991; Peteraf, 1993), newer perspectives focused on the resources that are acquired external to the firm to explain competitive advantage (Dyer \& Singh, 1998; Das \& Teng, 2000; Steinle \& Schiele, 2008; Hunt \& Davis, 2012). The theory that competitive advantage is derived from both internal and external resources has been labeled the ERBV (Mathews, 2003; Squire, et al., 2009; Lewis, et al., 2010).

A central premise of the RBV is that competitive advantage is a relative notion. Only those resources which are distinctive or superior relative to those of competitors, may form the basis for competitive advantage (Peteraf, 1993). Adopting this perspective to the ERBV would imply that the resources obtained from external sources will only result in a competitive advantage if the buying firm obtains better resources than its competitors (Capron \& Chatain, 2008; Pulles, et al., 2014). Indeed, it has been argued that it would be "extremely difficult" for buying firms to create competitive advantages through their supply base if buying firms are in competition for the supplier's best resources (Dyer \& Hatch, 2006, p. 703). Nonetheless, suppliers treat competing customers differently. For example, Takeishi (2002, p. 328) showed how some buyers obtained better resource allocation than competitors "although they all outsourced to the same supplier". By allocating their best resources to some partners, other partners are consequently excluded (Gulati, Nohria \& Zaheer, 2000). If firms are able to obtain better resources from suppliers than their competitors, they are more likely to gain competitive advantages from the relationship with these suppliers. Once a buying firm achieves superior performance through superior resource allocation from its suppliers, competitors attempt to neutralize this advantage by engaging in similar relationships and by degrading the resource position of their rival (Capron \& Chatain, 2008; Hunt \& Davis, 2008).

Throughout this paper, we label these dynamics as "supplier resource competition" based on the definition of competition by Hunt and Davis (2008): 
Supplier resource competition is the constant struggle among buying firms for

supplier resources that will yield positions of competitive advantage.

\subsection{Indirect capabilities}

Organizing access to external supplier capabilities requires a firm's own set of internal capabilities (Araujo, Dubois \& Gadde, 2003). Although in its original conceptualization a dynamic capability mainly relates to the development of a firm's internal resource base, several researchers have built on Teece et al.'s (1997) dynamic capability ideas to conceptualize capabilities that enable firms to utilize interorganizational relationships to integrate external resources. These researchers have examined the effects of such capabilities on the integration of external resources (e.g., Kale \& Singh, 2007; Schilke \& Goerzen, 2010; Allred, et al., 2011). Loasby (1998, p. 149) labeled these capabilities as indirect capabilities because, he argues: "We need not only to know how to do certain things for ourselves, but also how to get other things done for us". Indirect capabilities can be regarded as a firm's ability to organize access to the complementary and dissimilar resources of other organizations (Mota \& Castro, 2004; Spring \& Araujo, 2014).

Spring and Araujo (2014) discuss several elements of indirect capabilities. They consider a firm's contracting capability to be an important component of a firm's indirect capabilities because contracting capabilities link to the performance of the exchange relationships (Poppo \& Zenger, 2002; Roehrich \& Lewis, 2014). Kasch and Dowling (2008) describes a firm's collaboration capability as a type of indirect capability. Recently, scholars have begun to consider collaboration capabilities that can improve the outcome of inter-firm collaborations. For example, Kale and Singh (2007) explain a positive link between a firm's alliance management capabilities and alliance success rate, and Paulraj et al. (2008) show how relational competences of buying firms lead to better performance outcomes in buyer-supplier relationships. Others have studied firms' network capabilities (Walter, Auer \& Ritter, 2006), collaboration capabilities (Allred, et al., 2011), or alliance management capabilities (Schilke \& Goerzen, 2010). The main focus of these studies was to examine the effects of the specific capabilities on the performance outcomes of interorganizational collaboration. However, even though indirect capabilities have been argued to affect the extent to which firms appropriate external resources, the literature provides little insights into how indirect capabilities actually link to the resource appropriation of firms. The literature that explicitly addresses the effects of indirect capabilities on a firm's external resource appropriation remains mainly conceptual (e.g., Loasby, 1998; Araujo, Dubois \& Gadde, 2003; Spring \& Araujo, 2014). Thus, the indirect capabilities that can actually provide firms with such external resources remain underexamined.

In this paper we examine two indirect capabilities. The first capability incorporates Teece's (2007) concept of "sensing", which reflects a firm's ability to identify opportunities by scanning, searching and exploring technologies and markets. Schilke and Goerzen (2010) refer to this capability as "alliance proactiveness," which they define as the extent of the routines used to identify potentially valuable partnering opportunities. We name this capability a buying firm's selection capability, which is 
defined as the firm's capability to recognize valuable opportunities for collaboration within its supply base. The second capability refers to concept of "seizing" opportunities. Once a resource opportunity is observed, a buying firm should aim to facilitate a resource exchange. We call this ability a buying firm's relational capability, which is defined as the firm's ability to build close relationships with suppliers to facilitate resource exchange.

\subsection{Conceptual model and hypotheses}

In the following we hypothesize on the effects of the defined indirect capabilities on the competitive advantages of a firm. We argue that, because indirect capabilities enable access to the resources of suppliers, buying firms that possess such capabilities will more likely attain competitive advantages from their supplier relationships. As stipulated in the resource-based theories, this relationship will be influenced by the extent to which buying firms will be allocated better resources than competitors. We build on the ERBV to theorize on the intermediate effect of preferential resource allocation from suppliers on the relationship between indirect capabilities and competitive advantage. Figure 4.1 shows the conceptual model.

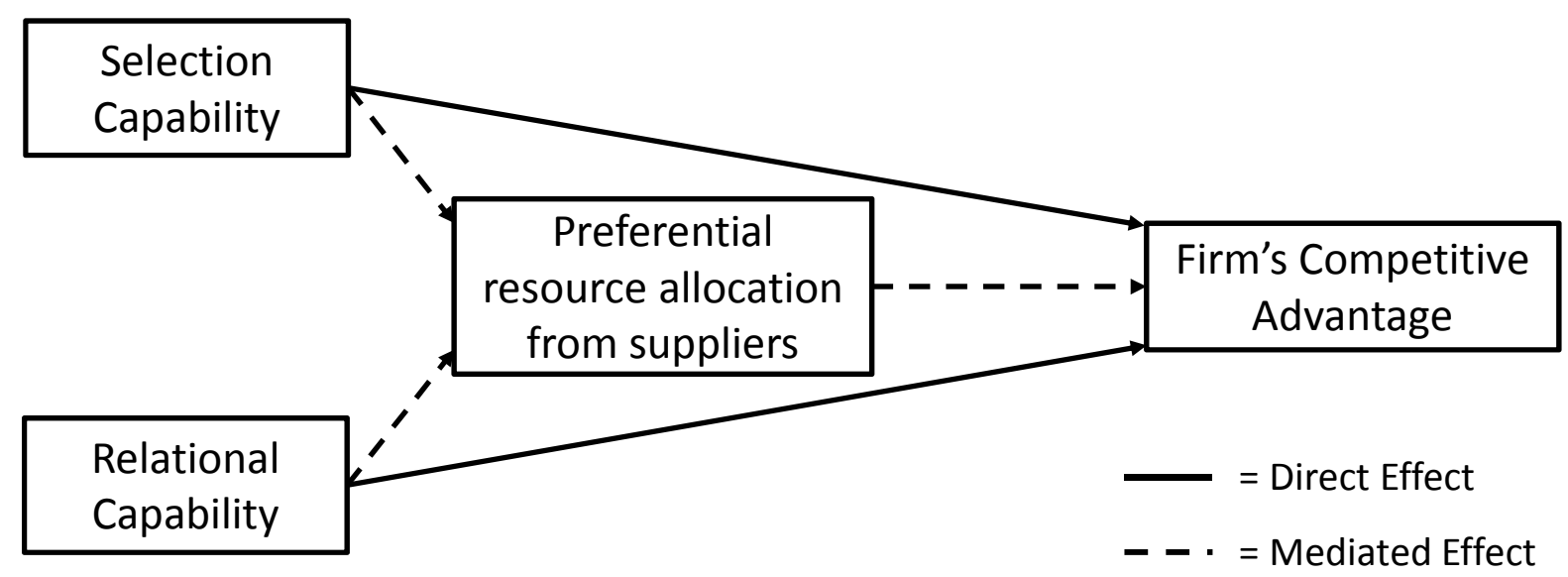

Fig. 4.1. Conceptual model

The effect of preferential resource allocation on competitive advantage could greatly depend on the kind of industry a firm operates in. In manufacturing industries firms are often highly dependent on the performance of their suppliers. In service oriented industries, however, firms are typically less reliant on their suppliers. Therefore, we include hypotheses on how the effect of preferential resource allocation from suppliers might differ for manufacturing and service firms.

\subsubsection{Selection capability, relational capability and competitive advantage}

The statement that a firm has a specific 'capability' implies that this firm (or its constituent parts) has the capacity to perform a certain activity in a reliable and at least minimally satisfactory manner (Helfat \& Winter, 2011). Such a capability has a specific and intended purpose (Winter, 2003) and firm capabilities enable repeated and reliable performance of certain firm activities, in contrast to ad hoc activities that do not reflect practiced or patterned behavior (Helfat \& Winter, 2011). There is an 
ongoing debate in the literature whether the SCM functions can have capabilities that lead to firm-level competitive advantages (e.g., Ramsay, 2001a; Mol, 2003). Indirect capabilities would enable a firm to repeatedly acquire those external resources that can increase the competitiveness of a firm. Such capabilities typically lay within the SCM realm. Thus, while firms increasingly manage their supply base as an extension of their own resource base (Kannan \& Tan, 2006), it can be expected that indirect SCM capabilities would influence firm's competitiveness.

Buying firms can have asymmetrical expectations of the value of supplier resources (Barney, 1986). Firms that have more accurate expectations about the true value of such resources can use these expectations to acquire these resources ahead of their competitors. Thus, an important element of indirect capabilities is to understand the value of supplier resources (Spring \& Araujo, 2014). Access to supplier resources is not instantaneous and indirect capabilities should offer a firm the knowledge of which supplier can provide what (Mota \& Castro, 2004). Selecting the appropriate partner is therefore a difficult but also critical issue to the success for accessing external resources (Hitt, et al., 2000). Firms that possess organizational routines associated with identifying and selecting collaboration opportunities should therefore be able to attain higher levels of performance from their relationships with their supplier base. Indeed, several empirical works in the SCM literature seem to evidence this. For example, Koufteros et al. (2012) discuss how strategic supplier selection can be seen as an important source of attaining competitive advantages through buyer-supplier relationships. In addition, Kannan and Tan (2006) show how the ability to select the right supplier influences the relationship performance of a buying firm.

Relationships with suppliers provide the opportunity to leverage the suppliers' resources and mobilize them to enhance performance. Resources are embedded within the suppliers' organization and much of the skills and knowledge needed to successfully integrate these resources are associated with complex relational interaction between the firms (Sarkar, Echambadi \& Harrison, 2001). The capacity of an organization to build close relationships with external partners may therefore facilitate resource exchange (Wasko \& Faraj, 2005; Kale \& Singh, 2007). Differences in the levels of trustworthiness and respect between partners may then relate to different levels of resource allocation from partner firms (Tsai \& Ghoshal, 1998). Simply a greater number of "horse-trading" skills will not suffice to integrate the resources into the buyer's organization (Teece, 2007). Without the relationship in place that facilitates this interaction between the buying firm and its suppliers, it would be difficult for a buying firm to replicate and integrate supplier resources. Similarly, Das and Teng (2000) argue that the extent to which firms can successfully integrate knowledge very much depends on the relationship and alignment between firms. Therefore, a firm's relational capability can be viewed as the capacity to extend a firm's resource base (Kale \& Singh, 2007).

H4.1. The selection capability of a buying firm has a positive effect on the competitive advantage of a firm.

H4.2. The relational capability of a buying firm has a positive effect on the competitive advantage of a firm. 


\subsubsection{Preferential resource allocation}

Because competition is a relative notion, the resources obtained from the supply base shared with competitors will more easily result in a competitive advantage when the buying firm obtains better resources than its competitors (Hult, et al., 2006; Capron \& Chatain, 2008; Pulles, et al., 2014). Therefore, firms must find ways to obtain better resources than their competitors to gain greater advantages from shared supplier networks. The recent literature describes a buying firm that is able to attain a preferential resource allocation position from a shared supplier network as a preferred customer (Schiele, Calvi \& Gibbert, 2012; Pulles, Veldman \& Schiele, 2014). If a buying firm is a preferred customer, the supplier will, for example, allocate its best personnel to collaborative development or offer innovations that are not available to the buying firm's competitors (Hüttinger, Schiele \& Veldman, 2012). Then, the buying firm that wins the competition for supplier resources can be expected to gain competitive advantages over its competitors that source from the same suppliers. Conversely, firms not capable of attaining a superior resource position in their supply base may lose the ability to differentiate themselves from competitors and thereby lower their competitive advantage (Gnyawali \& Madhavan, 2001; Takeishi, 2001).

A supplier's willingness to collaborate with its buyers is not always apparent (Essig \& Amann, 2009). The allocation of supplier resources to relationships with buying firms is a selective process in which competing customers may be treated unequally (Mitshuhashi \& Greve, 2009). Once a firm observes a resource opportunity in its supply base, it needs to invest in the relationships with these suppliers to seize the opportunity. Yet, buying firms should not have the aim to develop relationships with every supplier. Instead, buying firms should aim to develop collaborations with suppliers that have those resources that can increase the competitiveness of the buying firm but also are likely to provide the buying privileged access to those resources. Firms should understand the potential role of partners and the role played by rival firms (Mathews, 2003). Or, as Barney (2012) argues, the SCM function should not only understand the impact of external resources on the competitiveness in product markets, but must also understand the competition for these external resources itself. Firms that understand this competition can be expected to identify and select those opportunities that competitors may not have access to. A firm's selection capability is therefore not only expected to affect the competitive advantage directly because it enables the firm to select those supplier resources that are valuable to the firm (i.e., H4.1), but also because it can help firms in identifying and selecting those suppliers that can provide them preferential access to these competitive resources. For example, firms that are able to recognize collaboration opportunities can start this collaborating before competitors do and may, in this way, enjoy first-mover advantages that cannot be regained. Thus, a buying firm's selection capability is expected to relate both directly as indirectly to the competitive advantage of the firm.

Similarly, we expect a direct effect of a firm's relational capability on competitive advantage (i.e., H4.2) but also an indirect effect that is mediated by preferential resource allocation of suppliers. Buying firms can influence the behaviour of suppliers by investments in the relationship with suppliers (Ramsay, Wagner \& Kelly, 2013). For example, Lorenzoni and Lipparini (1999) found that the interactive process 
between actors facilitated by the relationship between the buyer and supplier created a greater exchange of information, both planned and spontaneous. Conversely, suppliers that become dissatisfied with a relationship might eventually search for other resource allocation channels (Ellegaard and Koch 2012). Thus, if a buying firm is capable of building better relationships with its suppliers, then these suppliers should prefer collaborating with this buyer over the other (competing) buyers and allocate better resources to this relationship. In turn, preferential resource allocation relates to competitive advantage because the comparative advantage (relative to competitors) in supplier resource allocation positively affects the competitive advantages in its market position (Hunt \& Davis, 2008). Therefore, because both relational capability and preferential resource relate to competitive advantage, and because relational capability positively affects supplier resource allocation, we expect a mediating effect of preferential resource allocation.

H4.3. The effect of selection capability on the competitive advantage of a firm is mediated by preferential resource allocation of suppliers.

H4.4. The effect of relational capability on the competitive advantage of a firm is mediated by preferential resource allocation of suppliers.

\subsubsection{The role of preferential resource allocation in different industries}

As explained in the previous sections, the resource-based theories have been used to explain the competitive advantage of firms in industries ranging from typical manufacturing industries to more service oriented industries. Similar to manufacturing firms, service firms are dependent on external resources which enable them to increase the quality of their services and, consequently, their competitive advantage (Helfat \& Peteraf, 2003). For instance, the healthcare industry is increasingly outsourcing strategically important services (Foxx, Bunn \& McCay, 2009). Of course, manufacturing (service) firms can, to a certain extent, rely on the services (products) of its suppliers (Araujo \& Spring, 2006). Yet, operational processes for manufacturing firms differ from those of service firms. Thus, it can be expected that the resources of suppliers have a different role in these process. The literature provides several examples of this. For instance, the SCM strategies that manufacturing firms need to adopt are different than those of service firms (Gwinner, Gremler \& Bitner, 1998) and firms need to adapt their structures as they move from selling products to selling services (Neu \& Brown, 2005). Therefore, a logical step would be to consider how the impact of supplier resource allocation on competitive advantage would differ for service firms as compared to manufacturing firms (as called for by Wagner, Coley \& Lindemann, 2011).

One of the main differences between the manufacturing and service logic of a supply chain, is that in the supply chain of a service provider the customer takes a central role (Maull, Geraldi \& Johnston, 2012). Taking such a customer perspective means that the firm works at finding opportunities and value together with the customer to create greater value for both the firm and the customer (Prahalad \& Ramaswamy, 2004). Similarly, the service-dominant logic (Vargo \& Lusch, 2004) implies that value is defined by and co-created with the consumer. Thus, whereas 
manufacturing firms rely on their supplier for, for example, the integration of new innovations (Pulles, Veldman \& Schiele, 2014) and increasing operational performance (Liu, et al., 2013), service firms tend to rely more on the inputs of their customers. From this it can be argued that the necessity to acquire better supplier resources than competitors is higher for manufacturing firms than for service firms.

H4.5. The effect of preferential resource allocation on competitive advantage will be stronger for firms in manufacturing industries than for firms in service industries.

\subsection{Methodology}

\subsubsection{Sample and data collection}

To test our hypotheses, we conducted a survey of key informants. We examine the relationships between a buying firm and key suppliers that also supply the competitors of the buying firm. Similar to other studies examining capabilities within the SCM realm (e.g., Paulraj, Lado \& Chen, 2008; Schilke \& Goerzen, 2010), we surveyed key informants from the buyer's organization. To ensure that these respondents were well informed and properly qualified to assess their firms' capabilities and preferential resource allocation from suppliers, we asked them to choose random but important (i.e., key) suppliers of which they had a good understanding regarding the relationship between their firm and these suppliers.

The data were collected during a seminar in The Netherlands on future trends for procurement (May 2012). Approximately 300 people attended this seminar. The keynote speakers of this seminar were several CPOs of multinational firms and one of the authors of this paper, who invited the participants to take part in a survey. This survey consisted of two parts; the first part questioned the participants on future SCM trends, and the second part was the measurement model of this study. The participants were motivated to complete the survey with a discussion of the results of the first part of the survey at the end of the seminar.

Collecting data via a seminar has several benefits. An important benefit is that participants of a seminar are generally willing to participate in a survey, which results in high response rates. In total, 209 participants completed the survey, which represents a response rate of approximately 70\%. Another benefit is that the respondents can be given specific instructions. In this case, to reduce the risk of socially desirable answers, we explained to the respondents that there are no "good" or "bad" answers and asked them to choose the answers that best fit their firm's situation. A limitation of collecting data at a seminar is the risk that the participants are not the key informants most suitable to filling out the survey. Therefore, to assure high-quality responses, we restricted our sample and removed respondents serving in functions other than procurement and executive functions. In total, 29 respondents were removed (e.g., consultants, HR managers, and business coaches). An additional 17 respondents were removed because they did not indicate their functions. A final limitation of collecting data at a seminar is that it is difficult to assess how a sample from seminar participants compares to a random sample from the entire population. However, as shown in the profile of the sample in Table 4.1, the respondents come from a wide range of industries. In addition, the sample contains a considerable 
proportion of service firms, which is a valid representation of Dutch industries. Considering the representative profile of the sample, we have no reason to assume that our sampling method should critically influence the quality of the conclusions that follow from data analysis and its results.

The items in the second part of the survey were pre-tested by two academics and by two of the organizers of the seminar. This resulted in a few minor changes in the final survey instrument. The total sample size of this study is 163 . In this final sample, $48.5 \%$ respondents served as procurement managers, $33.1 \%$ served as procurement employees, and $18.4 \%$ served in an executive function. On average, the respondents indicated to have worked for 5.8 years at their firms.

Table 4.1.

Profile of the sample

\begin{tabular}{lrlr}
\hline & Frequency & Frequency \\
\hline Industry sector & & & \\
$\quad$ Manufacturing & & Services & $13.5 \%$ \\
Construction & $6.1 \%$ & Trade & $12.9 \%$ \\
Food and drink & $3.1 \%$ & Public services & $10.4 \%$ \\
Mechanical engineering and machine building & $2.5 \%$ & Healthcare & $4.9 \%$ \\
Mining and basic/ raw materials & $2.5 \%$ & Transportation & $2.5 \%$ \\
Electrical and electronic engineering & $1.8 \%$ & Media and news services & $16.0 \%$ \\
Chemical. rubber and plastics & $1.2 \%$ & Other services \\
Printing & $1.2 \%$ & & \\
Textile and footwear & $1.2 \%$ & & \\
Vehicles & $0.6 \%$ & & \\
Other manufacturing & $14.1 \%$ & Unknown & \\
& & & $38.5 \%$ \\
\hline Annual turnover (€) & & Respondent function \\
0-50 Million & $24.1 \%$ & Procurement manager & $18.4 \%$ \\
$51-100$ Million & $13.0 \%$ & Procurement employee \\
101-500 Million & $36.2 \%$ & Executive function & \\
$501-1000$ Million & $7.7 \%$ & & \\
$>1000$ Million & $19.0 \%$ & & \\
& & & \\
\hline
\end{tabular}

\subsubsection{Measures}

In the operationalization of the resource allocation variable, we asked the respondents to select key suppliers of their firm that they share with their main competitors. Then, we let the respondents assess the perceived resource allocation of those suppliers to their firm compared to the suppliers' resource allocation to the firm's main competitors. Key suppliers were chosen because the respondents were expected to have more accurate information on the resource allocation from key suppliers than the resource allocation from suppliers with less relative importance. Asking respondents to assess their key suppliers (similarly to, for example, Carr \& Pearson, 1999; Eggert \& Ulaga, 2010), therefore, enables them to more reliably judge the relationships with their suppliers compared to an assessment of the entire supply base. All items were measured on a 5-point Likert scale ranging from 1, "no, fully disagree," to 5, "yes, fully agree." To reduce the risk of socially desirable answers, we explained to the respondents that there were no "good" or "bad" answers and asked them to choose the answers that best fit their firm's situation. 
The items for preferential resource allocation are based on previous RBV works. The operationalization of resources is based on the study of Newbert (2008). In his study he suggests to measure the availability of resources in an organization, in a similar way as the suggestion of Hunt and Davis (2008) and the resource mobilization measure by Villanueva et al. (2010). Newbert's classification of resources comprises financial resources (capital and cash), human resources (experience and the intelligence of individual employees), intellectual resources (patents and ideas), organizational resources (partners and suppliers), physical resources (materials and physical technologies) and capabilities (skills and expertise). The resource allocation variable is modeled as having formative indicators. Whereas reflective items are, in essence, interchangeable, formative items can be mutually exclusive. Formative indicators jointly determine the conceptual meaning of the construct (Jarvis, MacKenzie \& Podsakoff, 2003). For example, if suppliers allocate superior financial and physical resources to a buying firm, this does not necessarily mean that the buying firm will be allocated superior innovation resources as well (and vice versa). Still, the buying firm receives better resources than competitors do. Therefore, this construct is modeled as formative (Diamantopoulos \& Winklhofer, 2001).

To measure competitive advantage, we asked the respondents to assess the relationships with their suppliers based on three items adopted from Newbert's (2008) aggregate measure of competitive advantage (p. 766): the extent to which the relationship has enabled their firm to defend against competitive threats, has enabled their firm to reduce cost to a highly competitive level and has provided their firm with strategic advantages over competitors.

The measure of selection capability is based on the work of Zacharia et al. (2011), who measure a firm's capability to select opportunities for more collaborative relationships, and Lichtenthaler (2009), who found measures for recognizing opportunities in external environments. The selection capability construct is operationalized by asking the respondents to indicate their firm's capability to recognize opportunities for strategic collaborations, the capability to select suppliers with which their firm can successfully collaborate, the extent to which their firm has comprehensive information on state-of-the-art technologies within the supply base and the extent to which their firm can easily observe external sources of new technologies. Relational capability is operationalized by measuring the firm's capability to build personal relations, mutual trust and respect and to solve problems constructively (based on Kale, Singh \& Perlmutter, 2000; Walter, Lechner \& Kellermanns, 2007).

In addition, we added turnover as a control variable because it could be argued that suppliers might be more willing to allocate better resources to large buyers. The turnover of a buying firm could, for example, influence suppliers to allocate resources to this buyer out of the business sense that this buying firm could offer high potential turnovers for them. An overview of the measures is provided in Appendix 2.

\subsubsection{Data analysis}

We use a Partial Least Squares (PLS) analysis to assess the conceptual model. PLS is a regression-based structural equation modeling (SEM) technique that is ideally suited for testing models with latent variables, especially during early stages of theory 
development and with studies of an exploratory nature (Birkinshaw, Morrison \& Hulland, 1995). Compared to covariance-based SEM techniques, model complexity does not pose a severe restriction to PLS because PLS modeling only estimates a subset of parameters at any moment (Wetzels, Odekerken-Schröder \& van Oppen, 2009). Whereas sample size is an important factor in co-variance based models, PLS puts fewer restrictions on the sample size. As shown by Reinartz et al. (2009), who used Monte Carlo simulations, PLS is recommended when the number of observations is lower than 250, which fits our case. Additionally, the Shapiro-Wilk statistics indicate that our variables' selection capability, relational capability and competitive advantage are not normally distributed. Non-normal data could potentially undermine the estimates of the covariance-based SEM techniques. The advantage of PLS is that it does not require variables to be normally distributed (Peng $\&$ Lai, 2012). In addition, PLS puts no restrictions on incorporating formative items in the measurement model, making PLS the appropriate technique to analyze this study's data. SmartPLS 2.0 (Ringle, Wende \& Will, 2005) was used to obtain the PLS estimates.

\subsubsection{Construct validity and reliability}

To analyze the validity and reliability of the scales, we assessed the item reliability, convergent validity and discriminant validity (Hulland, 1999). Table 4.2 shows the cross loadings of the items in the constructs.

Table 4.2.

Cross loadings

\begin{tabular}{lccccc}
\hline & $\begin{array}{c}\text { Preferential } \\
\text { Resource } \\
\text { Item }\end{array}$ & $\begin{array}{c}\text { Competitive } \\
\text { Allocation }\end{array}$ & $\begin{array}{c}\text { Selection } \\
\text { Advantage }\end{array}$ & $\begin{array}{c}\text { Relational } \\
\text { Capability }\end{array}$ & Turnover \\
\hline PRA 1 & $\mathbf{0 . 7 7}$ & 0.38 & 0.40 & 0.31 & -0.11 \\
PRA 2 & $\mathbf{0 . 9 1}$ & 0.44 & 0.44 & 0.44 & -0.02 \\
PRA 3 & $\mathbf{0 . 6 9}$ & 0.41 & 0.30 & 0.21 & -0.18 \\
PRA 4 & $\mathbf{0 . 7 2}$ & 0.38 & 0.32 & 0.30 & -0.19 \\
PRA 5 & $\mathbf{0 . 6 5}$ & 0.27 & 0.38 & 0.30 & 0.00 \\
PRA 6 & $\mathbf{0 . 7 9}$ & 0.31 & 0.44 & 0.41 & -0.12 \\
CA 1 & 0.43 & $\mathbf{0 . 8 4}$ & 0.47 & 0.39 & -0.18 \\
CA 2 & 0.35 & $\mathbf{0 . 8 3}$ & 0.36 & 0.27 & -0.11 \\
CA 3 & 0.38 & $\mathbf{0 . 8 7}$ & 0.33 & 0.25 & -0.18 \\
SC 1 & 0.36 & 0.35 & $\mathbf{0 . 8 2}$ & 0.53 & -0.10 \\
SC 2 & 0.49 & 0.43 & $\mathbf{0 . 8 4}$ & 0.56 & -0.15 \\
SC 3 & 0.31 & 0.38 & $\mathbf{0 . 6 9}$ & 0.25 & -0.12 \\
SC 4 & 0.41 & 0.27 & $\mathbf{0 . 7 7}$ & 0.36 & -0.11 \\
RC 1 & 0.38 & 0.22 & 0.48 & $\mathbf{0 . 7 7}$ & 0.03 \\
RC 2 & 0.41 & 0.42 & 0.46 & $\mathbf{0 . 8 6}$ & 0.04 \\
RC 3 & 0.40 & 0.27 & 0.51 & $\mathbf{0 . 8 7}$ & -0.04 \\
RC 4 & 0.36 & 0.29 & 0.43 & $\mathbf{0 . 8 5}$ & -0.13 \\
TO & -0.10 & -0.19 & -0.15 & -0.03 & $\mathbf{1 . 0 0}$ \\
\hline
\end{tabular}

To test the convergent validity of the reflective constructs we first examined the average variance extracted (AVE). As shown in Table 4.3, all constructs exceeded the 
0.50 cutoff (Fornell \& Larcker, 1981). Composite reliability ranged between 0.86 and 0.90 , exceeding Nunnally's (1978) threshold of 0.7. In addition, the square roots of the AVE values are greater than their correlation coefficients with the other constructs. Therefore, the constructs fulfill the requirement for discriminant validity (Fornell \& Larcker, 1981; Rexhausen, Pibernik \& Kaiser, 2012). All of the variance inflation factors (VIF) are less than 3, implying the absence of multicollinearity (Hair, et al., 1995).

Table 4.3.

Means, standard deviations, correlations and quality criteria of constructs

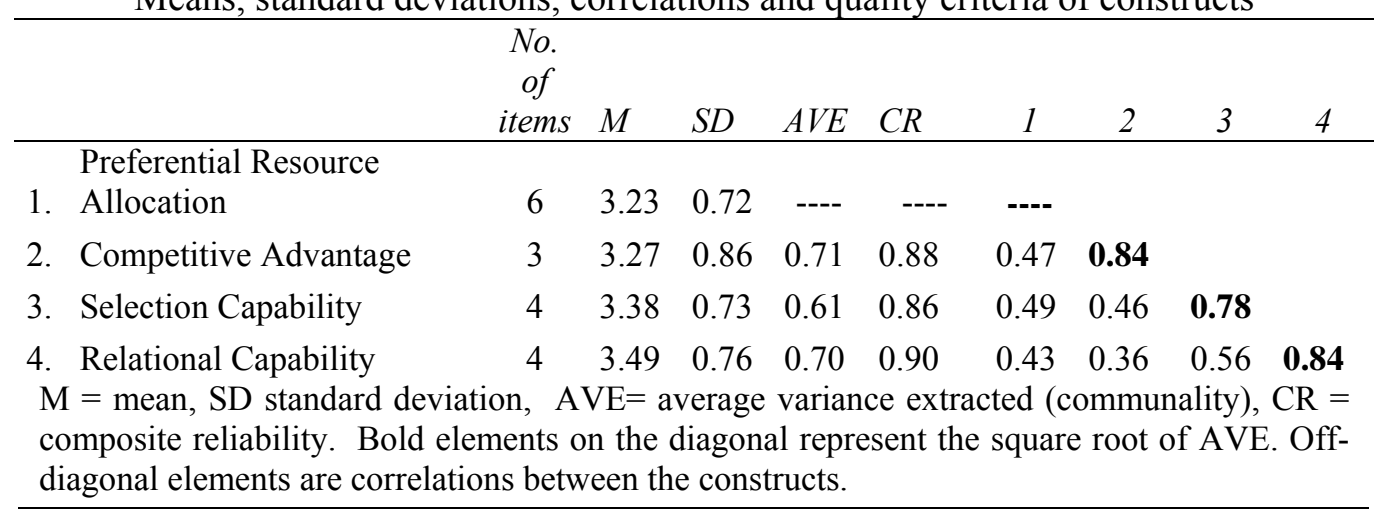

For formative constructs, the conventional procedures to assess the validity and reliability of scales are not appropriate (Diamantopoulos \& Winklhofer, 2001). Hair et al. (2012) argue that researchers should consider the absolute contribution of the formative items, by analyzing both the outer weights and outer loadings. As shown in Table 4.4, the resource allocation construct's outer loadings all are above 0.50 . This indicates that the items should be interpreted as important to the construct even when some of the outer weights are insignificant (Hair, et al., 2012). Based on the values of the outer loadings, all of the indicators are retained. Finally, each of the resource allocation items has a VIF lower than 3. Because this value is far below the cutoff threshold of 10 , multicollinearity does not seem to be a serious concern for the preferential resource allocation construct.

Table 4.4.

Outer weights and outer loadings of the preferential resource allocation construct

\begin{tabular}{ccccc}
\hline & $\begin{array}{c}\text { Outer } \\
\text { weights }\end{array}$ & $t$-values & $\begin{array}{c}\text { Outer } \\
\text { loadings }\end{array}$ & VIF \\
\hline PRA1 & 0.24 & 1.64 & 0.78 & 2.01 \\
PRA2 & 0.43 & 2.39 & 0.89 & 2.14 \\
PRA3 & 0.00 & 0.04 & 0.68 & 2.24 \\
PRA4 & 0.23 & 1.56 & 0.78 & 2.19 \\
PRA5 & 0.07 & 0.48 & 0.62 & 1.53 \\
PRA6 & 0.27 & 1.84 & 0.78 & 1.71 \\
\hline
\end{tabular}

\subsubsection{Assessment of common method bias}

Because the responses were collected from single key informants, common method bias could potentially threaten the validity of the results (Podsakoff \& Organ, 1986). Therefore, we performed an unmeasured latent methods factor test for PLS developed 
by Liang et al. (2007) to examine the extent of common method variance in the reflective constructs. Following Liang et al. (2007) we introduced a comment method factor in our PLS model whose indicators included all the principal construct's indicators. Then, we calculated each indicator's variances explained by the principle construct (i.e., substantive variance) and by the common method factor (similarly used by Rexhausen, Pibernik \& Kaiser, 2012; Perols, Zimmermann \& Kortmann, 2013). As presented in Table 4.5, the results show that the average substantive variance ( $\mathrm{CL}^{2}$ column) is 0.680 , while the average method-based variance $\left(\mathrm{MFL}^{2}\right.$ column) is 0.013 . Additionally, most of the method factor loadings are not significant. Given the results of the unmeasured latent methods factor test, common method bias is unlikely to pose a serious threat in this study.

Table 4.5.

Common method bias analysis

\begin{tabular}{cccccc}
\hline \multirow{2}{*}{ Construct } & Indicator & $\begin{array}{c}\text { Construct Loading } \\
(\text { CL })\end{array}$ & CL $^{2}$ & $\begin{array}{c}\text { Method Factor } \\
\text { Loading (MFL) }\end{array}$ & MFL $^{2}$ \\
\hline Competitive & CA 1 & 0.646 & 0.417 & 0.210 & 0.044 \\
Advantage & CA 2 & 0.917 & 0.841 & -0.086 & 0.007 \\
& CA 3 & 0.961 & 0.924 & -0.107 & 0.011 \\
\hline Selection & SC 1 & 0.868 & 0.753 & -0.051 & 0.003 \\
Capability & SC 2 & 0.685 & 0.469 & 0.173 & 0.030 \\
& SC 3 & 0.730 & 0.533 & -0.055 & 0.003 \\
& SC 4 & 0.849 & 0.721 & -0.083 & 0.007 \\
\hline Relational & RC 1 & 0.745 & 0.555 & 0.032 & 0.001 \\
Capability & RC 2 & 0.747 & 0.558 & 0.130 & 0.017 \\
& RC 3 & 0.910 & 0.828 & -0.046 & 0.002 \\
& RC 4 & 0.939 & 0.882 & -0.111 & 0.012 \\
\hline Average & & $\mathbf{0 . 8 1 8}$ & $\mathbf{0 . 6 8 0}$ & $\mathbf{0 . 0 0 1}$ & $\mathbf{0 . 0 1 3}$ \\
\hline
\end{tabular}

\subsection{Results}

To test the statistical significance of the hypothesized paths, a bootstrapping procedure using 500 resamples was used. To assess the stability of the estimates, similar bootstrap samples of 250 and 1000 were employed. The results show consistent levels of significance across the bootstrap samples. We test two models. In Model A, we test the effect of selection capability and relational capability on competitive advantage (i.e., H4.1 and H4.2). In Model B we include the preferential resource allocation construct and test its mediating effect on the relationships between the capabilities and competitive advantage (i.e., H4.3 and H4.4). The results of the two models are shown in Figure 4.2. To test whether the effect of preferential resource allocation on competitive advantage differs for firms in manufacturing industries and service industries (i.e., H4.5), we apply a PLS-based multigroup comparison approach suggested by Henseler (2012).

\subsubsection{Test of Model $A$ and Model B}

The results for Model A reveal a positive and significant relationship between selection capability and competitive advantage $(\beta=0.36 ; p<0.01)$, which supports H4.1. Also H4.2 is supported because the effect of relational capability on 
competitive advantage test significant $(\beta=0.18 ; p<0.05)$. The control variable, the buying firm's turnover, does not significantly affect competitive advantage $(\beta=-0.13)$. Model A accounts for $26 \%$ of the explained variance in competitive advantage (i.e., $\left.R^{2}=0.26\right)$.

Model B adds preferential resource allocation. Preferential resource allocation has a significant and positive effect on competitive advantage $(\beta=0.28 ; p<0.01)$. The effects in Model B are indicative of a meditation effect of preferential resource allocation. That is, both selection capability $(\beta=0.35 ; p<0.01)$ and relational capability $(\beta=0.27 ; p<0.01)$ have a significant and positive effect on preferential resource allocation. The buying firm's turnover does not significantly affect preferential resource allocation and competitive advantage $(\beta=-0.039$ and -0.12 , respectively). Model B accounts for $31 \%$ of the explained variance in preferential resource allocation (i.e., $R^{2}=0.31$ ). Compared to Model A, the direct effect of selection capability on competitive advantage was substantially reduced, but remains significant $(\beta=0.26 ; p<0.05)$. The direct effect of relational capability on competitive advantage was substantially reduced and became insignificant $(\beta=0.09)$. The increased explained variance of competitive advantage $\left(R^{2}=0.31\right.$ in Model B) indicates the relevance of the preferential resource allocation construct.

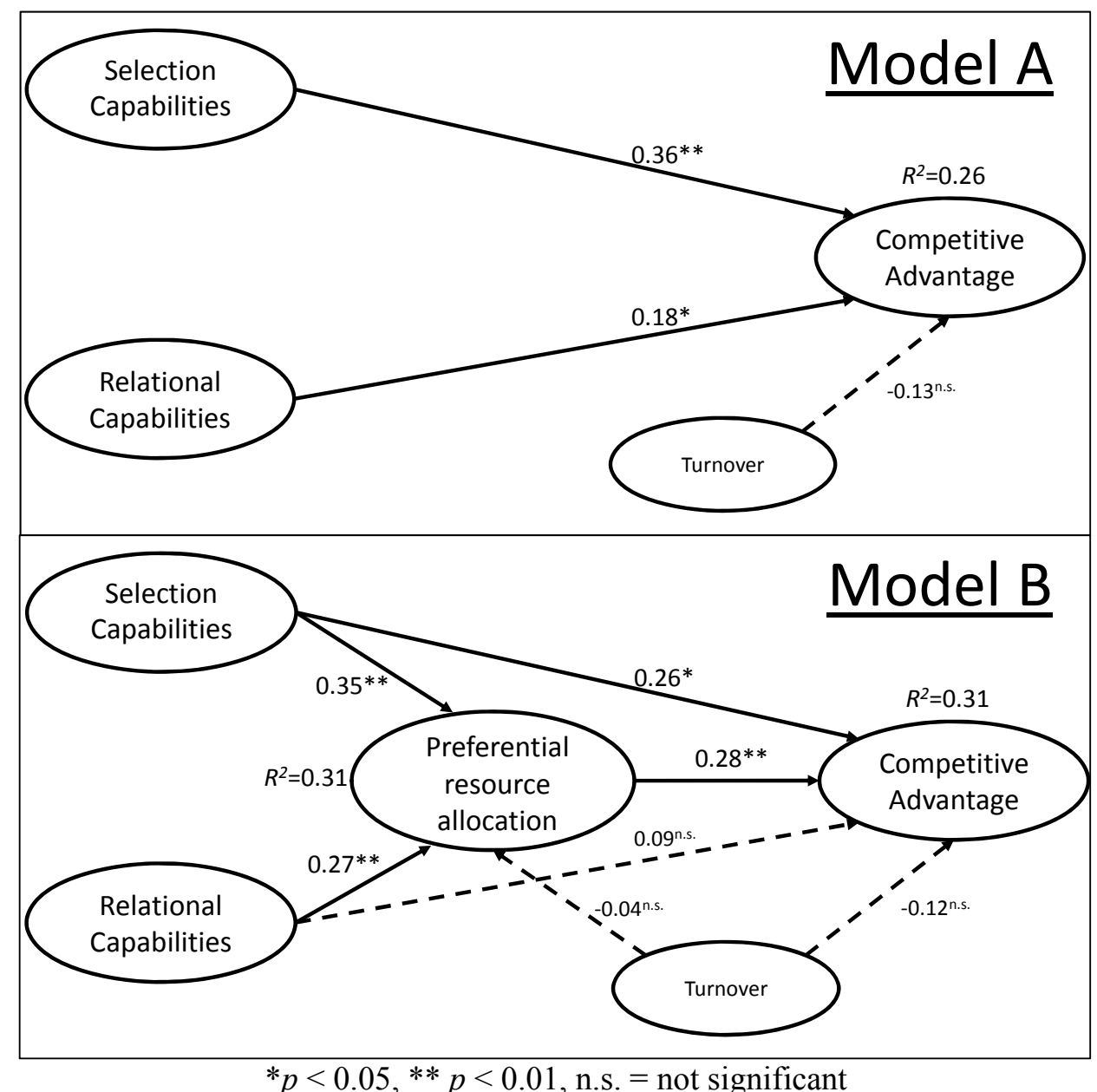

Fig. 4.2. Empirical model

To test the mediation effect of preferential resource allocation, we followed the suggestion by Rungtusanatham et al. (2014) and applied a procedure to explicitly test 
the significance of the mediation effect instead of an implicit procedure (e.g., Sobel test). They suggest constructing a percentile bootstrap confidence interval in which the sampling distribution is based on the estimated paths bootstrap samples. We followed this procedure and used 500 resamples to determine the product terms of the constituent mediation pathways which served as empirical, nonparametric approximations of the sampling distributions of the indirect effects of interest (cf., Preacher \& Hayes, 2008). This procedure showed that the indirect effect of selection capability on competitive advantage through preferential resource allocation is significant ( $95 \%$ confidence interval of 0.012 to 0.242 ), concluding that the mediation effect of preferential resource allocation exists in the relationship between selection capability and competitive advantage. Similarly the indirect effect of relational capability on competitive advantage through preferential resource allocation is significant $(95 \%$ confidence interval of 0.007 to 0.165$)$. Therefore, we accept H4.3 and H4.4. Finally, we examined the impact of preferential resource allocation on the relationships between the capabilities and competitive advantage by assessing the variance accounted for factors (cf., Hair Jr, et al., 2013). This analysis showed that $28 \%$ of the effect of selection capability on competitive advantage was mediated by preferential resource allocation and $46 \%$ of the effect of relational capability on competitive advantage was mediated by preferential resource allocation.

\subsubsection{Test of $H 4.5$}

We applied a non-parametric procedure suggested by Henseler (2012) to analyze whether path coefficients of service firms significantly differ from the path coefficients of manufacturing firms. In this procedure the structural model for service firms is compared to the same model for manufacturing firms based on bootstrap estimates (with 500 resamples) of these groups. Each centered bootstrap estimate of the manufacturing group is compared with each centered bootstrap estimate of the service group. Then, differences between these bootstrapped populations indicate the probability of the groups being different (cf., Henseler, 2012).

We divided the sample into a sample of service firms $(98$ firms $)$ and manufacturing firms (56 firms, 9 are unknown). First, we tested measurement variance. Although there are no accepted PLS-based approaches to test measurement invariance yet (Henseler, 2012), potential measurement invariance should be observed in differences between factor loadings. Therefore we used Henseler's approach to test the factor loading differences between the service and manufacturing groups. This test did not show significant differences between groups (at $p<0.05$ ). Thus, a difference in the measurement instrument does not appear to be a threat in our multigroup comparison.

Second, we used Henseler's approach to test between group differences in path loadings. Similar to the results presented in Figure 4.2, both models showed a positive link between preferential resource allocation and competitive advantage. However, the path in the service group was not significant $(\beta=0.14)$. The path coefficient of the manufacturing group was significant and substantially higher $(\beta=0.58 p<0.01)$. Indeed, Henseler's approach indicated that the relationship between preferential resource allocation and competitive advantage is significantly stronger in the manufacturing group $(p<0.01)$. Thus, $\mathrm{H} 4.5$ is supported. 


\subsection{Conclusions and discussion}

Building on the ERBV, this paper discussed the relevance of supplier resource for the competitiveness of buying firms. We integrated the notion of supplier resource competition and examined the indirect capabilities that can help firms to acquire better resources than competitors. In doing so, this study provides answers to questions raised by several scholars. For instance, Takeishi (2001, p. 403) questions: "How could a company outperform competitors who also have cooperative relations with their partners?" Similarly, Dyer and Hatch (2006, p. 703) note “(...) when manufacturers purchase the same inputs from the same suppliers (...) it would be extremely difficult for a buyer to create competitive advantages through a shared supplier network." We introduced the term supplier resource competition to frame a setting in which buying firms compete for the resources of shared suppliers. Our results show that firms that possess organizational routines associated with identifying and selecting collaboration opportunities are able to attain higher levels of competitive advantage from their relationships with their supplier base. In addition, the capability of an organization to build close relationships with its suppliers positively relates to the competitive advantage that firm attains from its relationships. A significant and substantial proportion of the relationship between the capabilities and competitive advantage was found to be mediated by preferential resource allocation.

The multigroup comparison yielded interesting results. The effect of preferential resource allocation from suppliers was found to be significantly higher in the manufacturing sample than in the sample of service firms. In fact, preferential resource allocation did not significantly affect competitive advantage in the service sample. Whereas notions in the current literature already implied that SCM practices for service firms differ from those of manufacturing firms (Tate \& Ellram, 2012), our findings indicate that the same is true for the importance of preferential resource allocation. These findings seem to confirm the belief that manufacturing firms are more likely to rely on supplier resource for increased competitiveness, while service firms rely on other sources such as customers (Maull, Geraldi \& Johnston, 2012). Therefore, the notion of supplier resource competition is particularly relevant for firms in manufacturing industries. These findings provide new insights for both academics and practitioners.

\subsubsection{Contributions to the literature}

This paper makes several contributions to the literature. First, this paper contributes to the ERBV literature that addressed the importance of supplier resources for the competitiveness of buying firms. The ERBV views competitive advantage as a function of internal resources and external resources, and therefore recognizes supplier resources as an important source for competitive advantage (Squire, et al., 2009; Lewis, et al., 2010). However, competitors often seek for similar resources. Recent works have emphasized this perspective (Hunt \& Davis, 2012; Ellram, Tate \& Feitzinger, 2013; Pulles, et al., 2014). Current ERBV studies did not yet integrate this perspective. Our study adds to the ERBV literature by integrating the notion of 
supplier resource competition in the link between supplier resource and the competitive advantage of buying firms. Our results imply that preferential resource allocation from suppliers that are shared with suppliers enables buying firms to more easily obtain competitive advantages.

Second, we contribute to the recent stream in the literature that discuss importance of indirect capabilities to appropriate supplier resources (Loasby, 1998; Araujo, Dubois \& Gadde, 2003; Spring \& Araujo, 2014). We linked to the conceptual work of Teece (2007) and discuss two capabilities that refer to a firm's ability to observe resource opportunities in its supply base (i.e., selection capability) and the ability to form an effective relation that facilitates resource exchange (i.e., relational capability). Our findings imply that these indirect capabilities within the SCM realm positively relate to the competitive advantage of buying firms. These findings contribute to the current stream in the literature debating whether the SCM functions can have capabilities that lead to firm-level competitive advantages (e.g., Mol, 2003; Barney, 2012; Hunt \& Davis, 2012). In addition, we argued that, even though the literature has begun to explore the capabilities that can improve the outcome of inter-firm collaborations (e.g., Kale \& Singh, 2007; Kasch \& Dowling, 2008; Paulraj, Lado \& Chen, 2008; Schilke \& Goerzen, 2010), a clear examination on how indirect capabilities actually link to supplier resource allocation is still missing. Our study shows that indirect capabilities are important means for obtaining preferential resource allocation from suppliers.

Third, our study shows the different effects of supplier resource allocation for manufacturing firms and service firms. The current SCM literature has been criticized for mainly seeking its empiricism in manufacturing firms and an increasing number of studies takes a service perspectives on SCM (e.g., Field \& Meile, 2008; Tate \& Ellram, 2012; Drupsteen, van der Vaart \& van Donk, 2013). Yet, little studies have actually examined the differences in impact of SCM practices between service and manufacturing firms. Our findings show how the impact of supplier resource allocation on competitive advantage differs for service firms as compared to manufacturing firms. Therefore, our findings contribute to the literature by showing the importance of separating between service and manufacturing when examining the effect of certain SCM practices.

\subsubsection{Implications for practice}

Our results imply that a firm's SCM function should, at least to a certain extent, aim at acquiring better resources than competitors in order to become truly strategic. Managers should realize that performance improvements alone might not always provide their firms with the competitive edge they seek. Suppliers collaborate with competitors as well and, even though suppliers might show improved performance to the focal firm, these suppliers could perceive even higher performance from the firm's competitors or might (co-)develop improved technologies for competitors that are not available to the focal firm. This notion is supported by the mediating effect of preferential resource allocation. It seems that, in order to gain competitive advantages from supplier relationships, buying firms should use their SCM capabilities to obtain positions of preferential resource allocation. In other words, relational capabilities that improve relationships with suppliers may not necessarily lead to competitive 
advantages. Such an advantage is more easily attained if the buying firm is able of exploiting these capabilities in ways that they enable preferential resource allocation from suppliers. Similarly, our findings imply that firms can increase the effectiveness of their selection capability by not only selecting suppliers based on their potential contributions in terms of their resources, but also by selecting those suppliers that can provide the buyer with preferential access to these resources.

\subsubsection{Limitations and future research}

Our findings are subject to several limitations that suggest the need for caution in drawing conclusions but also provide opportunities for future research. This study's dataset represents buyers' assessments of key suppliers. Therefore, the validity of our results hinge upon the reliability of the perception of our respondents. Although all respondents serve in procurement functions and, on average, indicated to have 5.8 years of experience at their firms, future research should aim for dyadic data for further validation of the results presented here. In addition, our study examined the effects of SCM capabilities on preferential resource allocation from shared key suppliers. Future research could assess single suppliers to capture potential differences between different types of suppliers and, thereby, more specifically extract strategies that enable buying firms to finely tune their resource appropriation efforts. Finally, whereas our study focused on supplier resources as source of competitive advantage, it should be noted that the compatibility with the firm's internal resources can impact the effectiveness of supplier resources. Some of the firm's internal resources are better suited to generate synergies with only specific types of supplier resources. Future research should incorporate this perspective. 



\title{
Chapter 5
}

\section{Pressure or pamper? The effects of power and trust dimensions on supplier resource allocation}

\begin{abstract}
Leveraging the supply chain for competitive resources remains a key challenge for supply chain management. Drawing on social exchange theory, this study examines SCM practices that help firms to acquire better supplier resources than rival firms that source from the same supplier. We provide a clearer picture of coercive and competence power, and goodwill and competence trust as key mechanisms to improve supplier resource allocation of physical and innovation resources. We analyze survey data of 185 supplying firms using structural equation modeling. Our analyses yield several interesting findings. First, contrary to other studies we find that coercive tactics do not necessarily affect supplier resource allocation negatively and goodwill trust does not inherently affect supplier resource allocation positively. Second, the results of a multigroup analysis indicate that the dependence of a supplier on the buying firm - in terms of share in turnover - affects the relationship between the trust dimensions and supplier resource allocation more than it does the power dimensions. Third, goodwill trust only affects supplier resource allocation when the buyer has a large share in the supplier's turnover, while competence trust is more effective if buyers account for a small share in the supplier's turnover. The contributions of our study for the supply chain management and social exchange theory literature are discussed.
\end{abstract}




\subsection{Introduction}

The relationships between a buying firm and its suppliers are crucial in acquiring resources that are essential for achieving firm-level competitive advantage (Hitt, 2011; Ellram, Tate \& Feitzinger, 2013). This is especially the case when that buying firm's rivals source from shared suppliers (i.e., suppliers that simultaneously supply rival firms). In fact, when rival firms clash it is not merely their internal resources, but rather the collective resources of their supply chains that determine the outcome (Hult, Ketchen \& Arrfelt, 2007). It would therefore be extremely difficult for firms to attain competitive advantage when competitors acquire better resources from a shared supply chain (Takeishi, 2001; Dyer \& Hatch, 2006). For example, Takeishi (2002) explains how automakers lose their competitive edge because their high-level knowledge is diffused to competitors through shared suppliers. Terpend and Ashenbaum (2012) provide an example of how, in the beginning of the 90s, GM's key suppliers became reluctant to share their latest technologies with GM and were shifting their brightest engineers to Chrysler and Ford, due to GM's aggressive supply chain practices (Kelly \& Kerwin, 1993). These examples illustrate how supply chain management (SCM) practices can influence resource allocation decisions of suppliers. However, the literature that examines resource rivalry mainly is conceptual (e.g., Capron \& Chatain, 2008; Markman, Gianiodis \& Buchholtz, 2009; Ellram, Tate \& Feitzinger, 2013). Some empirical works (e.g., Gimeno, 2004; Lavie, 2007) do seek to explain the concept of rivalry but provide little insight into the strategies firms might adopt to win the resource competition. Thus, it is unclear what SCM strategies firms might adopt to improve their resource position in the presence of competition.

This study focuses on power and trust as key mechanisms that can be used by firms to improve their resource position by acquiring better supplier resources (e.g., best ideas, key technological information, scarce materials) than competitors. Prior research identifies power and trust as main mechanisms that can be used simultaneously to influence the supplier (Bachmann, 2001; Ireland \& Webb, 2007; Terpend \& Ashenbaum, 2012). For instance, firms might use power to force their suppliers to shorten delivery times, or buyers could build trust to ensure that the supplier's best ideas are shared with them instead of with their competitors. The concepts of power and trust are multidimensional, and it is important to differentiate between these different dimensions. For example, the coercive and reward dimensions of buyer power are shown to relate differently to the supplier's performance (Terpend \& Ashenbaum, 2012), supplier commitment (Zhao, et al., 2008) and relationship cooperation (Benton \& Maloni, 2005). In addition, several conceptual works emphasize the importance of differentiating between the goodwill and competence dimensions of trust (Bachmann, 2001; Das \& Teng, 2001; Ireland \& Webb, 2007). However, the current SCM literature mainly discusses the effect of the power and trust dimensions on the absolute performance of the buyer, without taking the position of the rival into account. What is missing in the literature is a discussion of the impact of the different dimensions of power and trust on supplier resource allocation.

This study builds on social exchange theory (SET) to examine power and trust as the mechanisms that can help firms to obtain better resources from suppliers that are shared with competitors. SET is driven by the central concept that behavior of a 
company and resource exchanges in relational exchanges can be explained by relational mechanisms (Thibaut \& Kelley, 1959; Blau, 1964; Zhao, et al., 2008). We build on SET to hypothesize on the effects of coercive power, reward power, goodwill trust and competence trust on the supplier's allocation of physical resources and innovation resources. In addition, we examine the effects of the power dimensions on goodwill trust and how the effects of power and trust differ depending on the buying firm's share in the supplier's turnover. Our study makes several contributions. We contribute to the SCM literature that focuses on power and trust as antecedents of firm behavior by combining the different dimensions of both power and trust in one empirical model, by examining the link between the power dimensions and goodwill trust and by examining the effect of the buying firm's share in the supplier's turnover. Specifically, a key contribution is that we identify power and trust as key mechanisms for buying firms to acquire better supplier resources than competitors. In addition, we make an empirical contribution to the SET literature by showing the different effects of power and trust on different types of supplier resource allocation.

This paper is structured as follows. In the following sections we discuss the concept of supply base rivalry, explain how SET can explain supplier resource allocation behavior and review the relevant power and trust literature. Then, we develop our hypotheses and research model. Subsequently, we detail this study's methodology and results. We conclude with a discussion of the results, this study's limitations and directions for future research.

\subsection{Supply base rivalry}

This study's research questions originate from the stream of literature that has stressed the importance of resources that are acquired externally (Dyer \& Singh, 1998; Das \& Teng, 2000; Gulati, Nohria \& Zaheer, 2000). Resources can be defined as "the tangible and intangible entities available to the organization that enable it to produce efficiently and/or effectively a market offering that has value for some market segment" (Hunt \& Davis, 2008, p. 13). Because competitive advantage is a relative notion that is derived from superior resources (Peteraf, 1993), resources can be seen as the "axes of competition" (Markman, Gianiodis \& Buchholtz, 2009, p. 425). Consequently, a firm that attains comparative advantage (relative to competitors) in supplier resource allocation, will more easily gain competitive advantage in its market position (Hunt \& Davis, 2008). Therefore, if a firm wants to attain competitive advantage through resources obtained from its supply chain, this firm needs to obtain better supplier resources than competitors.

As a result, firms - knowingly or unknowingly - engage in a competition with their rivals to acquire superior resources (Obloj \& Capron, 2011). In the strategic management literature various perspectives emerged stressing the importance of taking into account competitors' resource positions when assessing a firm's ability to attain competitive advantage from its resources (Capron \& Chatain, 2008; Adegbesan, 2009; Markman, Gianiodis \& Buchholtz, 2009). Similarly, the recent SCM literature emphasizes the concept of rivalry in supply markets (Ellram, Tate \& Feitzinger, 2013), attaining a preferred customer status (defined by preferential resource allocation of suppliers; Hüttinger, Schiele \& Veldman, 2012; Schiele, Calvi \& 
Gibbert, 2012), supplier resource mobilization (Villanueva, Van de Ven \& Sapienza, 2010; Ellegaard \& Koch, 2012) and obtaining better supplier resources than competitors (Hunt \& Davis, 2012). Yet, as Obloj and Capron (2011) observe, most empirical studies examine the absolute resource position of firms without accounting for the role of competitors' resource positions. And, although the literature does describe certain strategic SCM practices that may influence performance (e.g., Chen, Paulraj \& Lado, 2004; Hult, Ketchen \& Arrfelt, 2007; Yeung, 2008), little is known about the actual SCM strategies that improve a firm's resource position relative to its competitors. Therefore, the question of 'What SCM strategy should a firm apply to improve its relative resource position?' remains largely unanswered.

In the following sections, we draw on SET to describe the SCM mechanisms that can help firms in acquiring better supplier resources than competitors and develop hypotheses explaining the relationship between these mechanisms and supplier resource allocation.

\subsection{Theoretical background}

SET was first established as a theory of interpersonal relations (Homans, 1958; Thibaut \& Kelley, 1959; Blau, 1964). A social exchange refers to a situation in which the actions of one individual provide the rewards or punishments for the actions of another individual (and vice versa) in repeated interactions (Muthusamy \& White, 2005). In contrast to economic exchanges, social exchanges are not limited to material goods but also include intangible value. Central to SET are norms of reciprocity that regulate interactions between partners based on the expectation of giving and receiving relational benefits (Blau, 1964; Lambe, Wittmann \& Spekman, 2001). Partners adjust their behavior and actions towards each other based on the expected relational benefits (Nyaga, et al., 2013). The benefits obtained from social exchanges often are provided voluntarily and are not explicitly contracted (Das \& Teng, 2002). Resources received as a result of interaction between partners can be seen as such benefits. Accordingly, resources can be understood as the currency of social exchange (Kankanhalli, Tan \& Wei, 2005). Foa and Foa (1980) characterized six types of resources in interpersonal exchange: love, status, information, money, goods and services.

Similar to interpersonal relationships, social exchanges are important for interorganizational relationships (Muthusamy \& White, 2005). Successful relationships with suppliers can create benefits that extend beyond the actual product or service exchange (Lindgreen \& Wynstra, 2005) and a key determinant of a successful relationship with a supplier is the relationship itself (Lambe, Wittmann \& Spekman, 2001). Similar to interpersonal relationships, relationships between firms develop through repeated interactions in which firms can use different mechanisms to influence the exchange partner. SET can therefore be used to explain the behavior of a supplying firm contingent on the relational mechanisms applied by the buying firm. For example, SET has been applied as a theoretical framework in examining the effects of time pressure in retail supply chain relationships (Thomas, Esper \& Stank, 2010) and Nyaga et al. (2013) used SET to theorize on the effects of relationship 
quality and sources of power on behavioral and operational outcomes in dyadic relationships.

As indicated above we aim to examine the effect of a buying firm's SCM strategies on supplier resource allocation. Because SET is driven by the central concept that behavior of a company and resource exchanges in relational exchanges can be explained by relational mechanisms (Thibaut \& Kelley, 1959; Blau, 1964; Zhao, et al., 2008), we base our hypotheses on the SET framework. More specifically, we build on two core variables from SET that are crucial to understand the functioning of any buyer-supplier relationship: power and trust (Hailén, Johanson \& SeyedMohamed, 1991; Donaldson \& O'Toole, 2007)

\subsection{Power, trust and supplier resource allocation}

In the SCM literature, power and trust are seen as the two main strategies used by buying firms to influence suppliers (Terpend \& Ashenbaum, 2012). Both power and trust can be seen as mechanisms to control the dynamics of social business relationships (Bachmann, 2001). Researchers of SET have provided a number of conceptualizations of power, in which the ability of one social actor to influence another actor is put central (Narasimhan, et al., 2009). Building on this conceptualization, power within the context of a buyer-supplier relationship can be defined as the ability of the buying firm to influence or control the decisions and behavior of the supplying firm (Narasimhan, et al., 2009). Therefore, power is seen as the mechanism of one firm to induce desired actions of another firm by either punishment or threatened sanctions, or by providing or withholding rewards (Maloni \& Benton, 2000; Ireland \& Webb, 2007). Trust, on the other hand, exists when a firm has confidence in a partner's reliability and integrity (Morgan \& Hunt, 1994; Kwon \& Suh, 2004). Trust is often described as one of the most important variables in SET (Lambe, Wittmann \& Spekman, 2001). Trust between firms creates an atmosphere where partners willingly exceed the minimal requirements of an exchange relationship, based on the belief that the partner will take actions that will result in positive outcomes for the firm and will not perform actions that result in negative outcomes (Anderson \& Narus, 1990; Ireland \& Webb, 2007).

\subsubsection{Power}

The literature describes different sources of power. These sources can be categorized as mediated power and nonmediated power. Nonmediated sources of power are not specifically exercised to influence the partner. In fact, a firm may not even be aware that these nonmediated sources of power exist (Maloni \& Benton, 2000; Terpend \& Ashenbaum, 2012). Using mediated sources of power, a firm deliberately controls the reinforcements guiding the partner's response (Maloni \& Benton, 2000; Terpend \& Ashenbaum, 2012). The most widely recognized sources of mediated power are coercive power and reward power. Coercive power stems from a firm's ability to punish the partner if this partner fails to conform to the firm's influence attempt (French \& Raven, 1959). Reward power depends on the firm's ability to administer positive valances if the partner conforms to the firm's influence attempt (French \& Raven, 1959). 
Buying firms use power to produce intended changes in the supplier's behavior by deliberately controlling the reinforcements guiding the supplier's response (Ramsay, 1996; Maloni \& Benton, 2000). Thus, the successful application of buyer power results in the intended changes in the behavior of the supplier (Ramsay, 1996). Consequently, failed attempts may not result in any changes in the supplier's behavior or even in undesirable behavior. For example, if a buyer decides to punish a supplier by reducing its business with this supplier, the supplier may become reluctant to make investments in processes that could have benefited the buyer. The application of power might therefore also have a negative effect on supplier resource allocation. To effectively capture better supplier resources, firms need insight into how coercive and reward power relate to supplier resource allocation ${ }^{5}$.

\subsubsection{Trust}

Trust is a multilevel concept that can exist between individuals and between organizations. Similar to power, trust has different dimensions. Based on the works of others, Das and Teng (2001) distinguish between two main dimensions: goodwill trust and competence trust. Goodwill trust refers to the degree to which a partner trusts the other to be willing to act in ways that exceed the stipulated contractual agreements without explicitly asking for such help (Roy, Sivakumar \& Wilkinson, 2004; Ireland $\&$ Webb, 2007). Competence trust refers to a firm's expectation of a partner's technical competence or expertise (Mayer, Davis \& Schoorman, 1995).

Trust is considered to be a crucial element for firms to enter in a relationship and to develop this relationship (Morgan \& Hunt, 1994; Ireland \& Webb, 2007). When a buyer and supplier trust one another, they are more willing to share resources without the fear of opportunistic behavior by the other party. Differences in levels of trustworthiness can therefore be expected to relate to different levels of resource allocation from partner firms (Tsai \& Ghoshal, 1998). The literature on trust in buyersupplier relationships mainly describes the positive effects of trust. For example, the supplier's trust in the buyer is found to be positively associated with the buyer's perception of relationship performance (Johnston, et al., 2004).

\subsection{Hypotheses}

In the following sections we build on SET reasoning and existing research to introduce our hypotheses. The first hypotheses (H5.1a-H5.4b) link power and trust to supplier resource allocation. The SET and SCM literature identify many different resources. Generally, when applied to interorganizational studies, the resources characterized in interpersonal exchange (cf., Foa \& Foa, 1980) can be divided in two fundamental categories: tangible resources and intangible resources (Cropanzano \& Mitchell, 2005; Galbreath, 2005). The strategic role of SCM can be seen as to acquire these external tangible and intangible resources in order to increase the

\footnotetext{
${ }^{5}$ Below, we operationalize coercive power and reward power as the supplier's perception of the buying firm's use of these power dimensions. For readability purposes we simply refer to "coercive power" and "reward power" in our hypotheses, even though more descriptive construct names (e.g., perceived use of coercive power) would better fit our operationalization.
} 
competitiveness of the firm. However, the extent to which power and trust affect the supplier's allocation of tangible resources, is expected to be different than the effect of power and trust on the supplier's allocation of intangible resources (Chen, 1995; Ireland \& Webb, 2007). Therefore, this study differentiates between two important supplier resources. In particular, we link power and trust to the supplier's allocation of (1) physical (tangible) and (2) innovation (intangible) resources (i.e., the extent to which the supplier allocates to the particular buyer better resources than to the buyer's competitors). These resources are crucial to a firm's competitive advantage in virtually all industries (Ellram, Tate \& Feitzinger, 2013), but are relatively underexplored in the current SCM literature and practice (Schoenherr, et al., 2012). In addition, because a firm can simultaneously use power and trust we hypothesize on the effects of power on trust (H5.5-H5.6).

The usability of power could greatly depend on whether or not the threat of sanctions and promise of rewards, or benefits, which are implied are realistic and have a good chance for being acknowledged by the supplier (Bachmann, 2001). For instance, if a buying firm accounts for a large share in the supplier's turnover, it can be expected to benefit more from using power. In addition, buyers with a small share in the supplier's turnover might have to find other ways to influence the supplier (Ramsay \& Wagner, 2009). Therefore, buyers with only a relatively small share in turnover might benefit more from building trust. To further examine this, we include hypotheses (H5.7a-H5.10b) which posit how the effects of power and trust might differ for suppliers for which the buying firm accounts for only a small fraction of the turnover compared to suppliers for which the buyer has a large share in turnover.

\subsubsection{The effect of power on supplier resource allocation}

The aim of buying firms that use coercive power is to pressure a supplier into complying with their requirements. However, many studies mainly point to the negative effects of coercive power (e.g., Brown, Lusch \& Nicholson, 1995; Maloni \& Benton, 2000). This is mainly explained from a perspective that coercive tactics will extract unfair concessions which leads to a situation where the victims seek ways to resist (Kumar, 1996). Yet, there are many examples from practice in which coercive tactics seem to have a positive effect for the buying firm. Large retailers apply coercive power to influence their suppliers into lowering delivery times or carrying extra inventory (Bloom \& Perry, 2001). Within the context of SET, selective punishment can improve the benefits attained from a relation because it may enable an actor to alter its behavior to avoid punishment (Molm, 1994). Indeed, Yeung, et al. (2009) explain how coercive power can positively relate to shared production capacity and shared inventories in Chinese manufacturing firms. Zhao et al. (2008) found that coercive power positively relates to instrumental relationship commitment (i.e. commitment based on the calculation of benefits and costs). Based on either explicit or non-explicit calculations of benefits and costs, a supplier might be more inclined to allocate its scarce materials to a partner who threatens to reduce business volumes if the supplier does not comply with its wishes. Consequently, rivals that do not apply coercive power in similar situations are not allocated these resources. Thus, we expect coercive power to positively relate to supplier allocation of physical resources. 
The resources characterized by Foa and Foa (1980) have distinct properties that relate to the effectiveness of relational mechanisms. Tangible resources are typically exchanged in impersonal settings, while intangible resources typically involve more interpersonal exchanges (Chen, 1995). Therefore, the effect of coercive power may reverse if the buying firm aims for intangible resources such as innovation resources. In that sense, coercive tactics contradict the interpersonal setting that stimulates innovation exchange. In fact, Zhao et al. (2008) found a negative relationship between coercive power and the supplier's willingness to invest relationship resources in a relationship. Similarly, Terpend and Ashenbaum (2012) found that the use of coercive power negatively impacts the buyer's quality and innovation performance. Thus, a buying firm that uses coercive power to acquire innovation resources might find the supplier allocating its best resources to competitors.

H5.1a. Coercive power is positively related to supplier allocation of physical resources.

H5.1b. Coercive power is negatively related to supplier allocation of innovation resources.

Reward power relates to the buying firm's ability to provide benefits that are attractive to the supplier. For example, the buyer can increase its business with the supplier. These benefits may reinforce the relationship by enhancing reciprocity. As stipulated in SET, a supplying firm receiving the reward will then feel obligated to perform according to the expectations of the buying firm (Nyaga, et al., 2013). Further, in choosing between decisions (e.g., resource allocation decisions), a supplier will choose the actions for which the expected benefits will be greater (Griffith, Harvey \& Lusch, 2006). Through similar reasoning, Zhao et al. (2008) found that reward power positively relates to the supplier's commitment based on a calculation of benefits and costs. Therefore, suppliers might be more inclined to allocate physical resources to buying firms that offer them benefits.

Similarly, we expect reward power to positively influence supplier resource allocation. Whereas coercive power can be viewed as a form of opportunism in which the buying firm expects to gain at the expense of the supplying firm, reward power, in contrast, is likely to encourage positive perceptions by the supplier (Nyaga, et al., 2013). If a buyer offers benefits to a supplier who shares ideas and new innovations, this supplier can be expected to be more willing to offer future innovations to this firm. Indeed, Nyaga et al. (2013) found that the use of reward power is positively related to the supply chain partner's collaborative and adaptive behavior. Similarly, the study of Zhao et al. (2008) found reward power to positively relate to the supplier's willingness to invest in relationship resources in a relationship. Thus, we expect the allocation of both physical and innovation resources to be positively influenced by reward power.

H5.2a. Reward power is positively related to supplier allocation of physical resources. 
H5.2b. Reward power is positively related to supplier allocation of innovation resources.

\subsubsection{The effects of trust on supplier resource allocation}

Goodwill trust exists when the buyer and supplier understand and do not take undue advantage of each other (Roy, Sivakumar \& Wilkinson, 2004). Goodwill trust relates to benevolence in resource allocation between partners (Ridings, Gefen \& Arinze, 2002). Trust enables actors to engage in more intense interactions which provide greater benefits to the exchange partners (Homans, 1958). Relating trust to physical resources, Li et al. (2007) identify an empirical link between trust in buyersupplier relationships and reduced product cost and higher quality of products. Similarly, Anderson, Lodish and Weitz (1987) provide an example of how trust can influence retailers and wholesalers to devote more physical resources (e.g., shelf space) to selling their partners' products.

Because goodwill trust between exchange partners cultivates a more intensive cooperation, it allows for riskier behavior such as the exchange of important information (Lambe, Wittmann \& Spekman, 2001). Goodwill trust therefore facilitates the sharing of resources that are critical to the generation of innovation (Roy, Sivakumar \& Wilkinson, 2004). Similarly, goodwill trust (expressed in the buyer's benevolence) has been linked with more cooperative supplier relationship performance (Johnston, et al., 2004) and the supplier's trust in the buying firm is linked to improved buyer performance (Lawson, Tyler \& Cousins, 2008) and higher innovation performance (Terpend \& Ashenbaum, 2012).

H5.3a. Goodwill trust is positively related to supplier allocation of physical resources.

H5.3b. Goodwill trust is positively related to supplier allocation of innovation resources.

Competence trust refers to a firm's expectation of a partner's technical competence or expertise (Mayer, Davis \& Schoorman, 1995). Suppliers can profit from a buyer's competence. For example, in supplier development programs the buyer helps the supplier to improve its performance (Krause, 1997). These programs have been shown to increase the performance of both the supplier and the buyer in terms of increased product quality and lower costs (Humphreys, Li \& Chan, 2004). In this way, competence trust can enhance reciprocity between a buying firm and its suppliers. Acts of competence of the buying firm, and the trust the supplier has that it can benefit from this competence in the future, stimulate the supplier to reciprocate with behavior that benefits the buying firm. Consequently, the supplier is expected to be more inclined to satisfy the needs of competent buyers and allocate resources accordingly.

Roy, Sivakumar and Wilkinson (2004) explain that in joint innovation programs, a supplier must not only feel confident of the buyer's technical abilities to solve current problems but also must feel confident that the buyer would be able to solve new problems as these emerge. Competence trust in this sense not only relates to intensified interaction from a rational perspective, but also from the reciprocal faith 
that actors have in one another to complete their tasks within their areas of expertise successfully (Madhavan \& Grover, 1998). From a SET perspective, trust in a partner's competences relates to an actor's extrinsic motivations (e.g., information and advice) and intrinsic motivations (e.g., social support) to intensify interactions (Whitener, et al., 1998). Therefore, in settings where several experts collaborate on innovations, Ridings, Gefen and Arinze (2002) explain that it is only natural to converse with others who have the proper knowledge and skills. For instance, participants in virtual communities are more willing to share knowledge with partners when they have trust in each other's competences (Ridings, Gefen \& Arinze, 2002). Similarly, competence trust is expected to positively influence supplier allocation of innovation resources.

H5.4a. Competence trust is positively related to supplier allocation of physical resources.

H5.4b. Competence trust is positively related to supplier allocation of innovation resources.

\subsubsection{The effects of power on goodwill trust}

As previously discussed, power and trust are both mechanisms to influence the behavior of a supplier. Traditionally, however, power and trust are conceptualized as distinct and opposing alternatives. Yet, the use of power can be intertwined with trust. Therefore, treating power and trust as distinct rather than interdependent variables can be potentially misleading (Knights, et al., 2001). Especially in long-term relationships actors may rely on both power and trust, examples of this are interpersonal relations such as parent-child or employer-employee relationships (Cook, 2005). This means that even though specific relationships are predominantly based on either power or trust, the use of one of them does not exclude the use of the other (Bachmann, 2001). Arguably, the extent to which a buying firm exerts power will have an impact on the extent the supplying firm trusts this buying firm. Specifically, we expect the use of power to influence goodwill trust, because goodwill trust refers to a supplier's trusts in a buying firm's behavior. Therefore, we hypothesize on the effect of coercive power and reward power on goodwill trust.

Goodwill trust of a supplying firm refers to the firm's faith in the good intentions of the buying firm (Das \& Teng, 2001). This trust emerges from repeated interactions in which the relationship between partners grows (Blau, 1964). Goodwill trust is built mostly through a reciprocal process, in which partners receive benefits and pay back the favor in the future (Das \& Teng, 2002). The buying firm's threats of penalties which are exhibited by the use of coercive power can oppose this reciprocal process that creates goodwill trust (Zhao, et al., 2008). It can therefore be expected that coercive power will ultimately undermine the goodwill trust in a relationship (Ireland $\&$ Webb, 2007). Indeed, Kumar (1996) provides several examples of how coercive tactics can backfire and lead to resistance at partner firms. Exerting reward power, on the other hand, can feed the reciprocal process. An example is an employer-employee relationship, in which the wages that are paid at the end of the month reward the employee and, at the same time, creates trust in the reliability and intentions of the 
established practices of the employer (Knights, et al., 2001). Thus, we expect coercive power to negatively affect goodwill trust and reward power to positively affect goodwill trust.

H5.5. Coercive power is negatively related to goodwill trust.

H5.6. Reward power is positively related to goodwill trust.

\subsubsection{The effects of power and trust of buyers with a large/small share in supplier turnover}

As explained above, buying firms use power to influence the supplier by either threatening with sanctions or by promising some sort of benefit. Brennan and Turnbull (1999) explain that the presumed causal mechanism linking supplier actions to power is based upon the dependence of the supplier on the buying firm. SET suggests that dependence inequity can be exploited by the stronger actor to control the weaker party - even though unilateral dependence does not necessarily result in the use of power (Blau, 1964; Lambe, Wittmann \& Spekman, 2001; Nyaga, et al., 2013). Brennan and Turnbull (1999, p. 489) state: "Underlying this process is the knowledge that 'you need us more than we need you,' and the threat (usually implicit, sometimes explicit) that 'if you don't do what we want, then we will take our business elsewhere." However, when the buying firm cannot enforce this, the supplier might simply not adjust its behavior to the buyer's wishes. For example, in the study of Ellegaard and Koch (2012) it was observed how an unmet promise of improved profitability by a buyer negatively affected supplier resource allocation.

When a buying firm accounts for a large share in the supplier's turnover, the supplier can be expected to be more inclined to comply to the buyer's wishes. For example, even though Walmart might sometimes squeeze its suppliers, suppliers might still be willing to make concessions in the hope that the Walmart relationship will help them expand their market share (Bloom \& Perry, 2001). Therefore, if the buyer has a large share in the supplier's turnover, we expect the buying firm will be able to more effectively apply the different dimensions of power.

H5.7a. The positive effect of coercive power on supplier allocation of physical resources will be stronger for buyers that account for a large share in the supplier's turnover.

H5.7b. The negative effect of coercive power on supplier allocation of innovation resources will be weaker for buyers that account for a large share in the supplier's turnover.

H5.8a. The effect of reward power on supplier allocation of physical resources will be stronger for buyers that account for a large share in the supplier's turnover.

H5.8b. The effect of reward power on supplier allocation of innovation resources will be stronger for buyers that account for a large share in the supplier's turnover. 
When trust is low, partner firms are more likely to base decisions on a calculation of immediate benefits versus costs (Geyskens, et al., 1996). Evidently, buying firms that only account for a small fraction of the supplier's turnover would then have a disadvantage over competitors with a relatively large share. However, firms can obtain better resources from suppliers despite a weaker position (in terms of purchasing volumes) than competitors (e.g., Dyer \& Hatch, 2006; Ellis, Henke Jr \& Kull, 2012). Building on interviews with small firm managers, Ellegaard (2006) explains that small buying firms tend to rely on close relationships built on trust to secure their supply of resources. By building such relationships based on trust, buyers might influence the supplier despite their relatively small share in turnover. In relationships where trust is a central element, partners resist short-term gains in favor of expected long-term benefits and build a relationship based on positive expectations (Morgan \& Hunt, 1994). Geyskens et al. (1996) explain that trust has a strong effect on an actor's willingness to continue a relationship because it likes the partner and enjoys collaborating with this partner. This effect might be particularly strong for buyers that only account for a small share in turnover, because the more an actor trusts its partner, the less it is inclined to make decisions based on mere calculative grounds (Gounaris, 2005).

As stipulated in SET, interactions between partners are based on the expectation of giving and receiving relational benefits (Blau, 1964; Nyaga, et al., 2013). Whitener et al. (1998) argue that such benefits often have intrinsic value (e.g. expressions of support and friendship). Direct economic benefits are less relevant in relationships with a buying firm that only accounts for a small proportion in the supplier's turnover. Therefore, the relative importance of mechanisms that relate to the supplier's intrinsic value can be expected to be more effective for buying firms that account for a small share in the supplier's turnover than for buying firms that account for a large share in the supplier's turnover. For instance, Andaleeb (1996) found that commitment in buyer-supplier dyads was significantly greater in high-trust low-dependence exchange relations, than in low-trust high-dependence relations. Therefore, if the buyer has only a small share in the supplier's turnover, we expect a stronger effect of the trust dimensions.

H5.9a. The effect of goodwill trust on supplier allocation of physical resources will be stronger for buyers that account for a small share in the supplier's turnover.

H5.9b. The effect of goodwill trust on supplier allocation of innovation resources will be stronger for buyers that account for a small share in the supplier's turnover.

H5.10a. The effect of competence trust on supplier allocation of physical resources will be stronger for buyers that account for a small share in the supplier's turnover.

H5.10b. The effect of competence trust on supplier allocation of innovation resources will be stronger for buyers that account for a small share in the supplier's turnover. 


\subsection{Methodology}

\subsubsection{Sample and data collection}

This study's data were collected in collaboration with a large Dutch multinational in the retailing industry. The retailing industry is particularly interesting because, due to fierce competition, retailers increasingly look for supplier resources that can help them to attain superior value and competitive advantages (Ganesan, et al., 2009). Because of the high similarity of our research aims and the challenges this retailer faces in forming its SCM strategy, the retailer supported the data collection by distributing a link to our questionnaire among its suppliers.

In March 2013, an e-mail was sent to a sample of 620 suppliers chosen randomly from the retailer's database. In this e-mail, the retailer invited the sales representative of the supplier to participate in an online survey hosted by the authors' university. The survey was pre-tested by two colleague researchers and by four sourcing managers of the retailer. To prevent social desirability bias, we asked the respondents to fill out the survey focusing on a customer they could choose randomly, as long as the respondent had a good understanding of the relationship between their firm and this retailer (independent of the level of satisfaction with this retailer). Thus, our sample consists of respondents that assess their firm's relationship with a random customer (not specifically the multinational retailer that distributed the invitation) of which they have a good understanding. Potential respondents were informed that the survey could not be traced back to the individual respondents, and that only aggregate results would be presented to the retailer. We explained to the respondents that there were no 'good' or 'bad' answers and asked them to choose the answers that best fitted their firm's situation. The respondents were motivated to answer the survey by promising a summary report. The online survey was accessed 378 times. After discarding the responses with missing values and the responses with an indicated share of the customer's turnover of zero, 185 useable surveys remained without missing values on this study's key variables. Therefore, the final sample size of this study was 185 , which represents a response rate of $29.8 \%$.

In this final sample, the majority of the respondents' firms are located in the Netherlands. Comparative $t$-tests did not reveal any significant differences between respondents from the Netherlands and respondents from other countries among the variables of interest. To verify the appropriateness of the respondents, questionnaire items asked about their tenure and expertise (Schilke, 2014). With an average of 10.5 years, 72.1 percent of the respondents in the final dataset had been with their current firm for five years or longer. In addition, we assessed participants' self-reported knowledge of the relationship with the chosen customer. We asked the respondent to assess the statement 'I know the relationship with this customer very well' on a fivepoint Likert scale ranging from 1 ('no, strongly disagree') to 5 ('yes, strongly agree'). The mean of 4.04 (standard deviation $=0.78$ ) suggested that the respondents were well informed. Table 5.1 shows the demographic profiles of the respondents. 
Table 5.1.

Profile of the sample ( $\mathrm{n}=185$ suppliers)

\begin{tabular}{lrlr}
\hline Retailing sector & Frequency & Frequency \\
\hline Ambient & $16.8 \%$ & Non-Food & $7.0 \%$ \\
Beauty & $1.6 \%$ & Not for resale & $8.1 \%$ \\
Bread & $1.6 \%$ & Snacks & $9.2 \%$ \\
Dairy & $8.6 \%$ & Vegetables and fruits & $3.8 \%$ \\
Frozen & $7.0 \%$ & Other (oils, petfood, software) & $29.2 \%$ \\
Health & $2.2 \%$ & & \\
Juices & $0.5 \%$ & & \\
Meat & $3.2 \%$ & Unknown & $1.1 \%$ \\
\hline Country & & & $62.2 \%$ \\
\hline Belgium & $8.6 \%$ & The Netherlands & $1.6 \%$ \\
Czech Republic & $1.6 \%$ & Spain & $2.2 \%$ \\
Denmark & $2.7 \%$ & Sweden & $1.1 \%$ \\
France & $2.2 \%$ & Switzerland & $1.6 \%$ \\
Germany & $4.9 \%$ & UK & \\
Greece & $0.5 \%$ & & $4.9 \%$ \\
Hungary & $1.1 \%$ & & \\
Italy & $4.3 \%$ & Unknown & $39.5 \%$ \\
\hline Annual turnover (€) & & Respondent function & $31.4 \%$ \\
\hline 0-50 Million & $43.8 \%$ & Executive & $13.5 \%$ \\
51-100 Million & $16.2 \%$ & Strategic & $14.6 \%$ \\
101-500 Million & $22.7 \%$ & Tactical & \\
$>500$ Million & $7.0 \%$ & Operational & $1.1 \%$ \\
Unknown & & &
\end{tabular}

Because non-response bias is a general concern for survey studies, we tested for non-response bias based on the assumption that the responses of late responders represented the responses of non-responders (Armstrong \& Overton, 1977). All of this study's 185 responses used in our analysis were received within 15 days of the survey's deployment. Similar to Hong and Hartley (2011) we compared early respondents (53 responses received within 2 days) and late respondents ( 25 responses in the last 4 days). The results of these $t$-tests did not yield significant differences between early responders and late responders (at $p<0.10$ ). In addition, we compared our final sample to 28 respondents that did not finish the questionnaire, but did assess the measures for this study's dependent variables. The $t$-tests did not yield significant differences between our final sample and the 28 non-finishers. Some non-respondents explained their reasons for non-response via e-mails and phone calls to the multinational retailer. These reasons were mainly lack of time and problems with opening the link to the survey. Based on the insignificant differences between early respondents and late respondents, our final sample and non-finishers and the e-mails we received from non-respondents, non-response bias is unlikely to pose a serious threat in our study.

\subsubsection{Measures}

Table 5.2 lists this study's measures. We measured our constructs on a five-point Likert scale ranging from 1 ('no, strongly disagree') to 5 ('yes, strongly agree'). The power and trust measures were mainly based on previously employed scales. Coercive 
power and reward power were measured based on scales of Terpend and Ashenbaum (2012) and Maloni and Benton (2000).

Table 5.2.

Measurement items

\begin{tabular}{|c|c|c|}
\hline Constructs & Measurement items & $\begin{array}{l}\text { Factor } \\
\text { loadings }\end{array}$ \\
\hline \multirow{2}{*}{$\begin{array}{c}\text { Coercive power (Terpend and } \\
\text { Ashenbaum 2012; Maloni and Benton } \\
\text { 2000) }\end{array}$} & $\begin{array}{l}\text { This customer makes it clear that failing to comply with their } \\
\text { requests will result in penalties against us }\end{array}$ & 0.64 \\
\hline & $\begin{array}{l}\text { If we do not agree with this customer's suggestions, they could } \\
\text { make things difficult for us }\end{array}$ & 0.78 \\
\hline \multirow{2}{*}{$\begin{array}{l}(\text { Cronbach's alpha }=0.83 ; \text { Composite } \\
\text { reliability }=0.83 ; \text { Average variance } \\
\text { extracted }=0.55)\end{array}$} & $\begin{array}{l}\text { If we do not do as asked, we will not receive very good treatment } \\
\text { from this customer }\end{array}$ & 0.80 \\
\hline & $\begin{array}{l}\text { If we do not go along with this customer, they might withdraw } \\
\text { certain services we need }\end{array}$ & 0.76 \\
\hline \multirow{2}{*}{$\begin{array}{c}\text { Reward power (Terpend and } \\
\text { Ashenbaum 2012; Maloni and Benton } \\
\text { 2000) }\end{array}$} & $\begin{array}{l}\text { This customer offers rewards so that we will go along with their } \\
\text { wishes }\end{array}$ & 0.67 \\
\hline & $\begin{array}{l}\text { We feel that by going along with this customer, we will be } \\
\text { favored on other occasions }\end{array}$ & 0.74 \\
\hline \multirow{2}{*}{$\begin{array}{l}(\text { Cronbach's alpha }=0.82 ; \text { Composite } \\
\text { reliability }=0.80 ; \text { Average variance } \\
\text { extracted }=0.49)\end{array}$} & $\begin{array}{l}\text { If we do not do as asked, we will not receive the rewards offered } \\
\text { by this customer }\end{array}$ & 0.70 \\
\hline & This customer offers us rewards if we agree with their requests & 0.69 \\
\hline \multirow{3}{*}{$\begin{array}{c}\text { Goodwill trust (Sako and Helper 1998; } \\
\text { Miyamoto and Rexha 2004, also based } \\
\text { on: Rody et al. 2004; Ireland and Webb } \\
\text { 2007) }\end{array}$} & $\begin{array}{l}\text { We can rely on this custome } \\
\text { our agreement with them }\end{array}$ & 0.79 \\
\hline & We can depend on this customer to always treat us fairly & 0.78 \\
\hline & $\begin{array}{l}\text { This customer takes initiatives for mutual benefits that exceed } \\
\text { the contractual agreements }\end{array}$ & 0.81 \\
\hline $\begin{array}{l}(\text { Cronbach's alpha }=0.86 ; \text { Composite } \\
\text { reliability }=0.86 ; \text { Average variance } \\
\text { extracted }=0.61)\end{array}$ & $\begin{array}{l}\text { We believe that this customer would make sacrifices for us to } \\
\text { support our firm }\end{array}$ & 0.75 \\
\hline \multirow{4}{*}{$\begin{array}{l}\text { Competence trust (Sako and Helper } \\
\text { 1998; Miyamoto and Rexha 2004, also } \\
\text { based on: Rody et al. 2004; Ireland and } \\
\text { Webb 2007) } \\
\begin{array}{c}\text { (Cronbach's alpha }=0.84 ; \text { Composite } \\
\text { reliability }=0.85 ; \text { Average variance } \\
\text { extracted }=0.65)\end{array}\end{array}$} & & 0.85 \\
\hline & of providing value to our firm & 0.80 \\
\hline & $\begin{array}{l}\text { We trust that this customer has the managerial and technical } \\
\text { capabilities to do what it says it will do }\end{array}$ & 0.75 \\
\hline & The advice this customer gives us is not always helpful & Removed \\
\hline \multirow{5}{*}{$\begin{array}{l}\text { Physical resources (based on: Hunt and } \\
\text { Davis 2008; Newbert 2008; Surroca et } \\
\text { al. 2010) } \\
\text { (Cronbach's alpha }=0.92 ; \text { Composite } \\
\text { reliability }=0.91 ; \text { Average variance } \\
\text { extracted }=0.72)\end{array}$} & & \\
\hline & $\begin{array}{l}\text {... we grant this customer better utilization of our production } \\
\text { facilities }\end{array}$ & 0.75 \\
\hline & $\begin{array}{l}\ldots \text { we choose to give this customer priority in the allocation of } \\
\text { our products in the case of extreme events (e.g., natural disasters) }\end{array}$ & 0.92 \\
\hline & $\begin{array}{l}\text {... we allocate our scarce materials to this customer in case of } \\
\text { capacity bottlenecks }\end{array}$ & 0.92 \\
\hline & $\begin{array}{l}\text {... we dedicate more specialized equipment to the relationship } \\
\text { with this customer }\end{array}$ & 0.78 \\
\hline \multirow[t]{2}{*}{$\begin{array}{l}\text { Innovation resources (based on: Hunt } \\
\text { and Davis } 2008 ; \text { Newbert 2008; } \\
\text { Surroca et al. 2010) }\end{array}$} & $\begin{array}{l}\text { Compared to our other customers... } \\
\ldots \text { we are more willing to share key technological information } \\
\text { with this customer }\end{array}$ & 0.73 \\
\hline & ... we share our best ideas with this customer first & 0.87 \\
\hline \multirow{2}{*}{$\begin{array}{l}(\text { Cronbach's alpha }=0.88 ; \text { Composite } \\
\text { reliability }=0.88 ; \text { Average variance } \\
\text { extracted }=0.65)\end{array}$} & $\begin{array}{l}\text {... we dedicate more innovation resources to the relationship } \\
\text { with this customer }\end{array}$ & 0.87 \\
\hline & $\begin{array}{l}\ldots \text { we spend more of our product development time on projects } \\
\text { of this customer }\end{array}$ & 0.75 \\
\hline
\end{tabular}


The survey items of the coercive power construct measured the extent to which the buying firm punishes the respondent's firm if their firm does not conform to the buyer's influence attempt. The construct items of reward power emphasized the extent to which the buying firm aims to influence the respondent's firm by offering benefits.

Goodwill trust and competence trust were measured with items based on the studies of Sako and Helper (1998), Miyamoto and Rexha (2004) and on the conceptual works of Ireland and Webb (2007) and Rody, Sivakumar and Wilkinson (2004). For goodwill trust, the respondents were asked to assess the extent to which they could rely on the buying firm to treat them fairly and to take initiatives that exceed the contractual agreement. Competence trust was measured with items that reflect trust of the respondent in the buying firm's capabilities and the extent to which the buyer's advice is helpful for them.

This study's dependent variables, supplier allocation of physical resources and supplier allocation of innovation resources, measured the extent to which the supplier allocates to the particular buyer better resources than to the buyer's competitors. Above we provided examples of these resources (e.g., scarce materials in times of capacity bottlenecks or the first offer of a new technology). To further operationalize these constructs, we developed items based on the resource-based studies of Newbert (2008), Hunt and Davis (2008) and Surroca, Tribó and Waddock (2010). We asked the respondents to assess their firm's resource allocation to the particular retailing firm relative to the resource allocation to this retailer's competitors. Items pertaining to physical resources capture both facility and equipment utilization as well as product and materials fulfillment because both relate to a firm's strategic physical resource bundle (Hunt \& Davis, 2008; Ellram, Tate \& Feitzinger, 2013). An example of an item for innovation resources is "compared to our other customers, we are more willing to share key technological information with this customer".

Finally, we measured the customer's share in the supplier's turnover by asking the respondents to indicate the percentage of the customer's share in their firm's turnover.

\subsubsection{Data validity and common method bias}

Several tests were conducted to assess the measurement instrument in terms of reliability and validity. We first assessed the measurement model by conducting a confirmatory factor analysis using AMOS 21.0. The overall measurement model fits the data satisfactorily $\left(\chi^{2}=344.97\right.$, d.f. $=213, \chi^{2} /$ d.f. $=1.62$, comparative fit index $[\mathrm{CFI}]=0.95$, Tucker-Lewis index $[\mathrm{TLI}]=0.94$, goodness-of-fit index $[\mathrm{GFI}]=0.87$, root mean square error of approximation $[\mathrm{RMSEA}]=0.06$ ). To test the convergent validity of the reflective constructs we examined the average variance extracted. As shown Table 5.2, all but one construct exceeded the 0.50 cut-off (Fornell \& Larcker, 1981). The Cronbach alpha values ranged between 0.82 and 0.92 . These values well exceed the recommended threshold of 0.7 (Nunnally, 1978) which indicates satisfactory levels for internal consistency reliability. The composite reliability values ranged between 0.80 and 0.91 , well exceeding the recommended threshold of 0.7 (Fornell \& Larcker, 1981). In addition, the square roots of the AVE values were greater than their correlation coefficients with the other constructs (Table 5.3). Therefore, the constructs fulfill the requirement for discriminant validity. Finally, 
because the responses were collected from single key informants, Harman's singlefactor test was employed to determine whether common method bias could potentially threaten the validity of the results (Podsakoff \& Organ, 1986). The un-rotated factor solution indicated that the explained variance of the largest factor was only $30.7 \%$, which suggests that common method bias is not a likely to be a threat to the validity of our results.

Table 5.3.

Means, standard deviations and correlations of the constructs

\begin{tabular}{|c|c|c|c|c|c|c|c|c|}
\hline & $M$ & $S D$ & 1 & 2 & 3 & 4 & 5 & 6 \\
\hline 1. Physical resources & 3.37 & 1.03 & ---- & & & & & \\
\hline 2. Innovation resources & 3.75 & 0.94 & 0.67 & 0.80 & & & & \\
\hline 3. Coercive power & 3.09 & 0.84 & 0.23 & 0.12 & 0.74 & & & \\
\hline 4. Reward power & 2.79 & 0.84 & 0.36 & 0.39 & 0.45 & 0.70 & & \\
\hline 5. Goodwill trust & 3.23 & 0.83 & 0.30 & 0.29 & -0.18 & 0.24 & 0.78 & \\
\hline 6. Competence trust & 3.83 & 0.64 & 0.24 & 0.25 & -0.12 & 0.06 & 0.45 & 0.81 \\
\hline
\end{tabular}

\subsubsection{Data analysis}

We tested the proposed hypotheses using structural equation modeling with maximum likelihood estimation. Tests of normality revealed that not all of this study's constructs are normally distributed. More specifically, in particular the items belonging to innovation resources appeared to be nonnormal. Although maximum likelihood estimation is relatively robust to non-normality, the standard error tends to be underestimated in the absence of the normality assumption (Kline, 2010). Still, maximum likelihood may be used for models with variables that are not normally distributed, given that this non-normality is not too extreme (Schermelleh-Engel, Moosbrugger \& Müller, 2003). To assure the robustness of our results, we conducted additional analyses using partial least squares structural equation modeling (PLS). PLS is a regression-based approach to structural equation modeling and this technique does not require variables to be normally distributed (Reinartz, Haenlein \& Henseler, 2009). Therefore, as suggested by Peng and Lai (2012) we use PLS as a robustness check of our maximum likelihood estimations.

We utilized the full-sample data to test H5.1a-H5.6. To test H5.7a-H5.10b, we split the sample into two groups composed of data partitioned into low shares in turnover and high shares in turnover. This approach enabled the examination of the hypothesized disparate effects of power and trust for different shares in the supplier's turnover by comparing two structural models (one for the low share group and one for the high share group). Yet, compared to structural models with moderator variables, such a multi-group approach does not incorporate the direct effect of the supplier's share in turnover on the resource allocation variables. Hence, we evaluated the validity of the results from the multigroup analyses by testing a structural model with both the moderation terms and the direct effects of share in turnover. Because the interaction among latent variables cannot be incorporated in structural equation modeling approaches that rely on maximum likelihood estimation (Jöreskog \& Yang, 
1996), we employed PLS modeling to conduct this interaction analysis. PLS is specifically suitable for estimating moderating effects (Chin, Marcolin \& Newsted, 2003), and complexity (i.e., which plays a role in models with many interaction terms as in this robustness check) does not pose a severe restriction to the estimation of path coefficients (Wetzels, Odekerken-Schröder \& van Oppen, 2009).

\subsection{Results}

This study used AMOS 21.0 to test the proposed model. SmartPLS 2.0 (Ringle, Wende \& Will, 2005) was used to obtain the PLS estimates for the robustness check and interaction effects. We first tested the effects of the power and trust dimensions on supplier resource allocation (i.e., H5.1a-H5.4b) and the effects of the power dimensions on goodwill trust (i.e., H5.5-H5.6). Then we tested how the effects of power and trust differed for groups of buyers with a small or large share in the supplier's turnover (i.e., H5.7a-H5.10b).

\subsubsection{Structural model}

As Figure 5.1 shows, coercive power is positively related to supplier allocation of physical resources $(\beta=0.17$, non-significant (NS)), but negatively related to supplier allocation of innovation resources $(\beta=-0.18$, NS). Although these effects are as hypothesized, $\mathrm{H} 5.1 \mathrm{a}$ and $\mathrm{H} 5.1 \mathrm{~b}$ are not supported because these effects are nonsignificant. Both $\mathrm{H} 5.2 \mathrm{a}$ and $\mathrm{H} 5.2 \mathrm{~b}$ are supported as reward power has a significant and positive effect on both physical resources $(\beta=0.34, p<0.05)$ and innovation resources $(\beta=0.64, p<0.01)$.

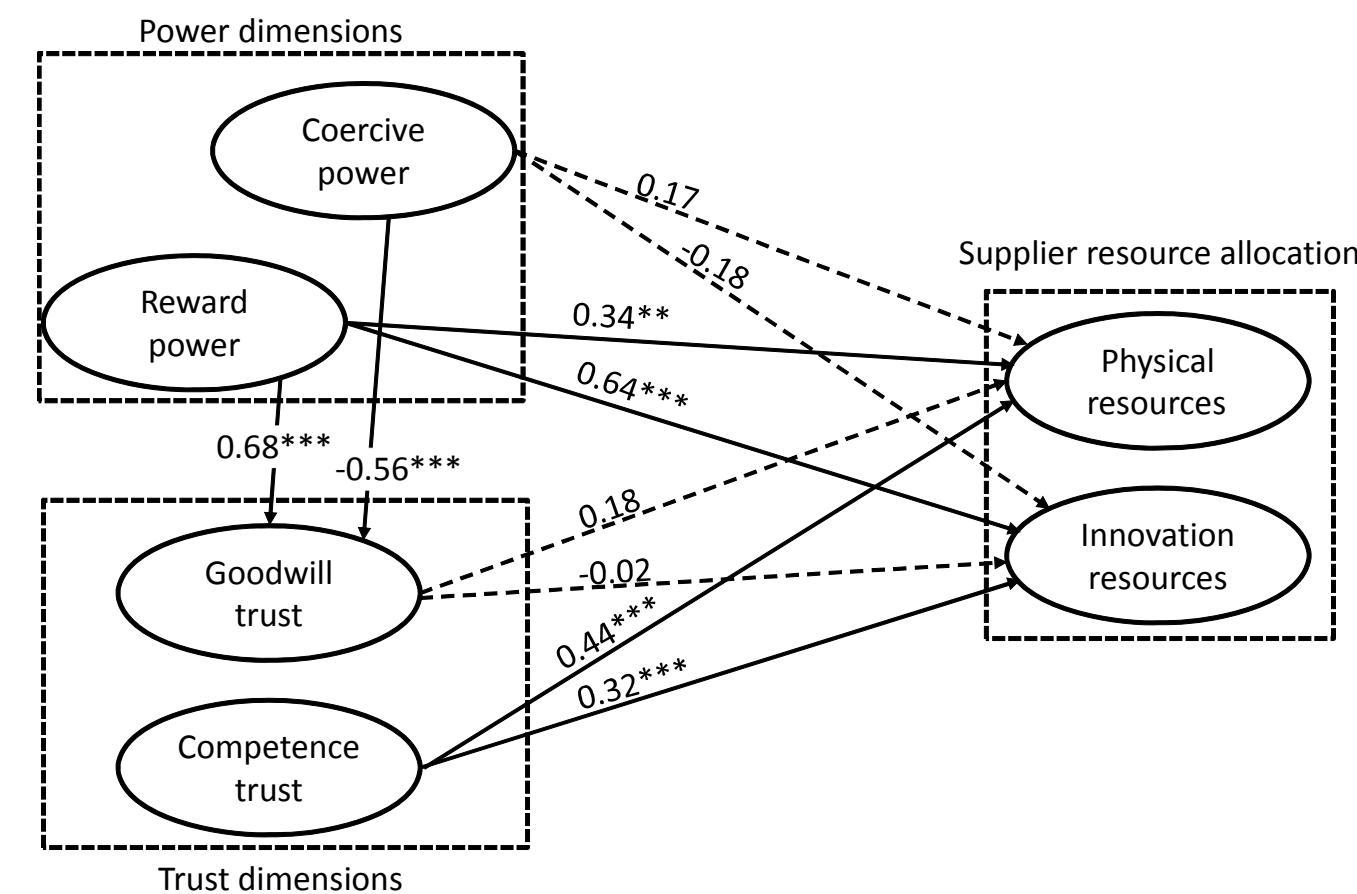

$* p<.10, * * p<.05, * * * p<.01$, dashed paths indicate non-significant results

Model Fit: $\chi 2=387.63$, d.f. $=216, \chi 2 /$ d.f. $=1.80, \mathrm{CFI}=0.93$, TLI $=0.92, \mathrm{GFI}=0.85$, RMSEA $=$ 0.07

Fig. 5.1. Results of Structural Equation Model 
The effect of goodwill trust was found to be non-significant for physical resources $(\beta=0.18, \mathrm{NS})$ and innovation resources $(\beta=-0.02, \mathrm{NS})$. Thus, both H5.3a and H5.3b are rejected. $\mathrm{H} 5.4 \mathrm{a}$ and $\mathrm{H} 5.4 \mathrm{~b}$ are supported because competence trust has a significant and positive effect on both physical resources $(\beta=0.44, p<0.01)$ and innovation resources $(\beta=0.32, p<0.01)$. The effects of both coercive power and reward power on goodwill trust were found to be significant and in the hypothesized direction $(\beta=-0.56, p<0.01$ and $\beta=0.68, p<0.01$, respectively). Thus, H5.5 and H5.6 are supported. The structural model accounted for $27 \%$ of the variance in physical resources, $30 \%$ of the variance in innovation resources and $30 \%$ of the variance in goodwill trust (i.e., $R^{2}=0.27,0.30$ and 30 , respectively). Overall, the goodness-of-fit measures showed satisfactory values $\left(\chi^{2}=387.63\right.$, d.f. $=216, \chi^{2} /$ d.f. $=1.80, \mathrm{CFI}=0.93, \mathrm{TLI}=0.92, \mathrm{GFI}=0.85, \mathrm{RMSEA}=0.07)$.

The robustness of these results was tested by conducting an additional PLS analysis. The PLS estimates did not show any substantial differences. The path coefficients, the $p$-values and the $R^{2}$-values were of comparable size and lead to similar conclusions. We can therefore conclude that the results obtained by using maximum likelihood estimation are robust.

\subsubsection{Multigroup analysis}

To test the effect of the buyer's share in the supplier's turnover, we divided the sample into two subsamples along the median of the share in turnover. This resulted in two groups; the 'small share group', the group of respondents for which the buying firm accounted for only a small share in turnover $(n=95$, average share in turnover: $3.37 \%$ ) and the 'large share group', the group of respondents for which the buying firm accounted for a large share in turnover $(\mathrm{n}=90$, average share in turnover: 23.92\%). These samples can be considered relatively small. Based on Monte Carlo simulations, Qureshi and Compeau (2009) explain that the effective sample size to accurately examine between-group differences is contingent on several conditions. Yet, potential lack of power does not affect cases in which multigroup comparisons observe significant differences. In such cases it can be concluded that between-group differences are, in fact, true (Qureshi \& Compeau, 2009). To test H5.7a-H5.10b, we followed a three step procedure. First, to assure that potential differences between the groups are not caused by differences in the measurement instrument, we assessed the measurement invariance between groups. Second, we examined whether the small share and large share group yielded different results in terms of path coefficients $(\Delta \beta)$ between the power and trust dimensions and the resource allocation variables. Third, we determined the significance of any potential differences by means of the chisquare differences $\left(\Delta \chi^{2}\right)$ between the structural models of the two groups.

The first step was to test the scale equivalence between the small share and the large share group. In the absence of scale equivalence, the comparison of structural models is ambiguous because the effects of between-group differences can be confounded by differences in the scale (Cheung \& Rensvold, 2002). We assessed partial measurement invariance (Byrne, Shavelson \& Muthén, 1989) which tests for measurement invariance by equating the factor loadings in the two subgroups, but allows for some loadings to be different across groups (Chun \& Davies, 2006; Byrne, 
2009). One item in the innovation resource construct and one item in the reward power construct differed significantly between groups. Relaxing these two factor loadings and assessing the partial measurement invariance we found that the difference in the chi-square statistic was insignificant $\left(\Delta \chi^{2}[15]=21.69\right.$, NS). Therefore partial measurement invariance had been achieved across samples. In addition, the fit index change $(\Delta C F I=0.003)$ was less than the 0.01 cutoff point proposed by Cheung and Rensvold (2002) indicating support for invariance between the small share and large share group.

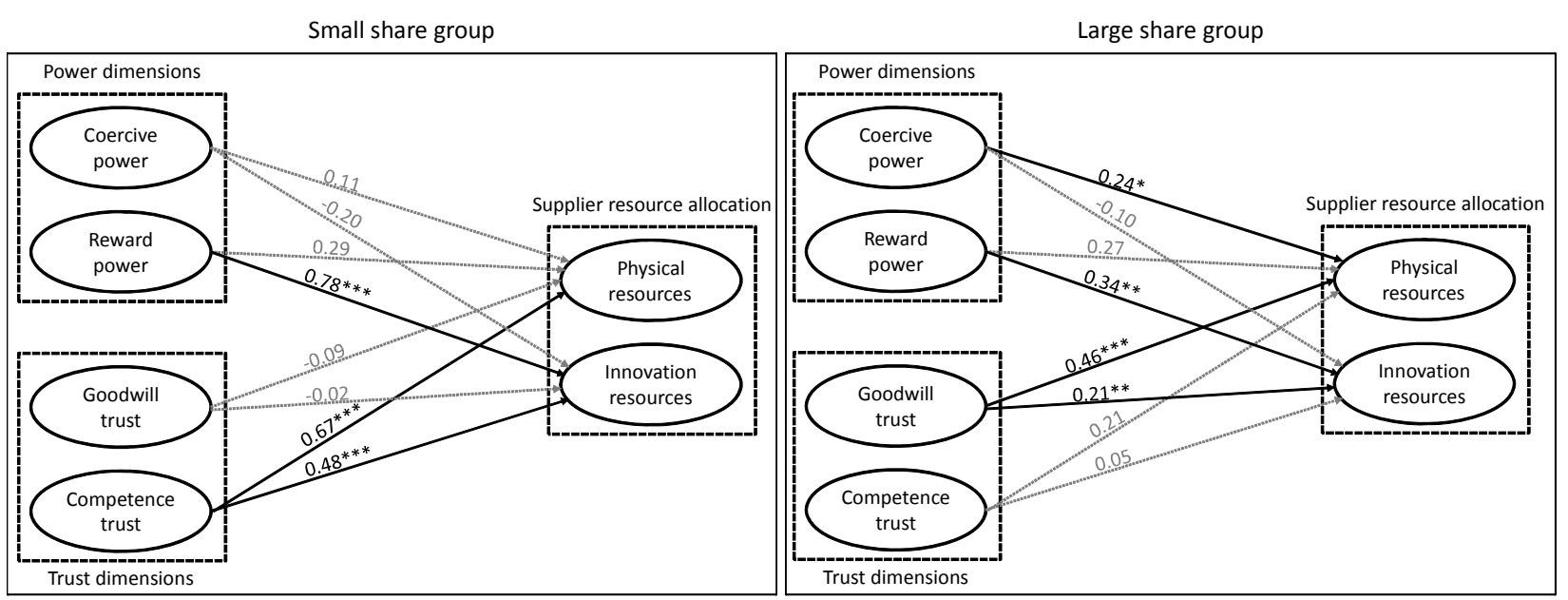

$* p<.10, * * p<.05, * * * p<.01$, dashed paths indicate non-significant results

Fig. 5.2. Multigroup Comparison

As shown in Figure 5.2, the share in the supplier's turnover affects the relationship between the power dimensions and supplier resource allocation differently than the relationship between the trust dimensions and supplier resource allocation. When assessing coercive and reward power, the differences in path coefficients between the small share and large share group show that the effect of coercive power on physical resources is significant in the large share group (i.e., we find support for H5.1a in the large share group). Yet, although the path coefficients linking coercive and reward power to physical resources are larger in the large share group, the coefficients relating the power dimensions and innovation resources are smaller in the large share group. Thus, as shown in Figure 5.2, the effects of the power dimensions are not (as we hypothesized) substantially stronger for buyers that account for a large share in the supplier's turnover.

Contrary to the power dimensions, the multigroup analysis does show substantial differences when looking at the trust dimensions. Goodwill trust did not show a significant effect on supplier resource allocation in the full sample analysis. However, the multigroup analysis shows that goodwill trust does affect supplier resource allocation when the buyer has a large share in the supplier's turnover. Thus, whereas we rejected the hypothesis that goodwill trust would positively affect supplier resource allocation $(\mathrm{H} 5.3 \mathrm{a}$ and $\mathrm{H} 5.3 \mathrm{~b})$ in the assessment of the full sample, the multigroup analysis shows that goodwill trust does have a positive and significant effect but only in the large share group. On the other hand, competence trust showed a positive and significant effect in the full sample (H5.4a and H5.4b), but the multigroup analysis shows that this effect mainly occurs in the small share group. 
Thus, as hypothesized, the path coefficients of competence trust are significant and high in the small share group but insignificant and lower in the high share group. The model of the small share group accounted for $29 \%$ of the variance in physical resources and $35 \%$ of the variance in innovation resources (i.e., $R^{2}=0.29$ and 0.35 , respectively). The model of the large share group accounted for $45 \%$ of the variance in physical resources and $25 \%$ of the variance in innovation resources (i.e., $R^{2}=0.40$ and 0.25 , respectively). Again we tested the robustness of these results by conducting additional PLS analysis. The path coefficients, the group differences between the paths, the $p$-values and the $R^{2}$-values were of comparable size. Therefore, the results obtained by using maximum likelihood estimation are also robust in the multigroup analysis.

We determined the significance of these differences in path coefficients between the small share and large share group by means of the chi-square differences of the structural models (Byrne, 2009). Given the small differences in path coefficients of the coercive power dimension, it is not surprising that these differences were insignificant $\left(\Delta \chi^{2}=0.27\right.$, NS for physical resources; $\Delta \chi^{2}=0.14$, NS for innovation resources). Thus, H5.7a and $\mathrm{H} 5.7 \mathrm{~b}$ are rejected. Similarly, the between-group differences for reward power were not large enough to yield significant values $\left(\Delta \chi^{2}=\right.$ 0.01 , NS for physical resources; $\Delta \chi^{2}=2.37$, NS for innovation resources). Consequently, H5.8a and H5.8b are rejected. Contrary to our predictions in H5.9a and $\mathrm{H} 5.9 \mathrm{~b}$, goodwill trust showed higher path coefficients for the large share group. The effect of goodwill trust on supplier resource in the large share group showed to be significantly higher for physical resources $\left(\Delta \chi^{2}=5.42, p<0.05\right)$ and substantially higher (although not significantly) for innovation resources $\left(\Delta \chi^{2}=1.12\right.$, NS). Thus, $\mathrm{H} 5.9 \mathrm{a}$ and $\mathrm{H} 5.9 \mathrm{~b}$ are rejected because the multigroup analysis showed results that opposed these hypotheses. Finally, the path coefficients between competence trust and physical resources and innovation resources were found to be significantly higher for the small share group $\left(\Delta \chi^{2}=2.96, p<0.10\right.$ for physical resources; $\Delta \chi^{2}=3.61, p<$ 0.10 for innovation resources). Therefore, both H5.10a and H5.10b are supported.

As a final step in our analysis, we also conducted PLS structural equation modeling in which we included the interaction terms of share in turnover and the power and trust dimensions. Because the share in turnover variable was extremely right skewed, we conducted a logarithmic transformation on this variable. Then, we included share in turnover in the PLS model to build the interaction terms. The results of this PLS model lent further support for our hypotheses as they show highly comparable results that did not change our conclusions. With the exception of the moderating effect of share in turnover on coercive power on innovation resources (which showed a negative interaction effect of negligible size), all interaction terms showed path coefficients in similar directions as suggested by the multigroup comparison.

\subsection{Conclusions and discussion}

A key challenge is to identify those practices that leverage the supply chain for resources that help firms to achieve competitive advantage (Schoenherr, et al., 2012). This study aimed to identify such practices by examining the impact of the different dimensions of power and trust on supplier resource allocation relative to competitors. 
We found that coercive power does not significantly affect supplier resource allocation. However, coercive power did have a significant effect on physical resources for buyers accounting for a large share in the supplier's turnover. Reward power was found to positively relate to supplier allocation of physical and innovation resources. The effect of reward power on supplier resource allocation did not significantly differ between the small share and large share group. Goodwill trust was found to have no significant effect on supplier resource allocation in the full sample. However, the multigroup analysis revealed that goodwill trust does have a significant effect on physical resources and innovation resources when the buyer accounts for a large share in the supplier's turnover. Competence trust was found to positively relate to supplier allocation of physical and innovation resources. The multigroup analysis showed that the effects of competence trust on supplier resource allocation are significantly higher for firms that account for only a small share in the supplier's turnover. These findings contribute to the literature that includes both power and trust as antecedents of firm behavior. By combining the different dimensions of both power and trust in one empirical model, by examining the link between the power dimensions and goodwill trust and by examining the effect of the buying firm's share in the supplier's turnover our analyses yield several interesting findings. More specifically, there are three key findings that we highlight.

First, this study combines the different dimensions of both power and trust in one empirical model. This yielded interesting results. For instance, even though trust is typically portrayed as a crucial element for buyer-supplier relationships (Morgan \& Hunt, 1994; Ireland \& Webb, 2007), our full sample analysis showed no significant effects of goodwill trust on supplier resource allocation. In addition, many studies mainly point to the negative effects of coercive power (e.g., Brown, Lusch \& Nicholson, 1995; Maloni \& Benton, 2000). However, our results indicate that coercive tactics can be effective practices when firms aim for better physical supplier resources and account for a large share in the supplier's turnover.

Second, based on the general notion that in the case of buyer dominance buying firms should exploit this dominance by using power strategies (e.g., Caniëls \& Gelderman, 2005), we expected power dimensions to be more effective for buyers accounting for a large share in the supplier's turnover. Surprisingly, the multigroup analysis yielded different results. The trust dimensions showed the most substantial differences between the small share and large share groups. Apparently, even though buyer dominance is assumed to form the basis for the buyer to leverage the supplier's performance (Cox, 2001), our results imply that the dependence of a supplier on the buying firm in terms of share in turnover does not affect the effectiveness of the power dimensions as much as it affects the trust dimensions.

Third, although we hypothesized that the effects of goodwill trust on supplier allocation of physical resources and innovation resources would be stronger for buyers that account for a small share in the supplier's turnover goodwill trust actually appeared to have stronger effect for buying firms that accounted for a large share in the supplier's turnover. Thus, we could not find evidence for the popular belief that when buyers do not have the purchasing volumes to influence suppliers, they should 'befriend' the supplier to obtain better resources (e.g., Ellegaard, 2006, p. 280). This might also explain why the full sample analysis revealed no significant effect of 
goodwill trust. The observation that goodwill trust only affects supplier resource allocation positively when the buyer has a large share in the supplier's turnover may be explained by the work of Das and Teng (2001). They link the need for goodwill trust to the perceived risk in a relationship. A high reliance on the buyer's turnover increases the relational risk for suppliers; the need for suppliers to rely on goodwill trust becomes critical then (Das \& Teng, 2001).

By means of these findings, we show that power and trust dimensions can be used by buying firms to influence the resource allocation behavior of supplying firms. As such, we contribute additional insights into the SCM strategies that can improve resource allocation from shared suppliers to the stream of literature examining competition for supplier resources (e.g., Ellegaard \& Koch, 2012; Hunt \& Davis, 2012; Ellram, Tate \& Feitzinger, 2013; Pulles, Veldman \& Schiele, 2014). In addition, we believe that our findings provide additional insights of SET's application within SCM. Even though SET is driven by the central concept that behavior of a company and resource exchanges in relational exchanges can be explained by relational mechanisms (Thibaut \& Kelley, 1959; Blau, 1964; Zhao, et al., 2008), its application within SCM is still limited (Narasimhan, et al., 2009) despite several recent contributions (cf., Schiele, Calvi \& Gibbert, 2012). This study contributes a new application of SET in the SCM literature by examining the effect of two of its core mechanisms - power and trust - on supplier resource allocation. In addition, the current SET literature provides only limited insights into how different types resources are exchanged in two types of relationships (Cropanzano \& Mitchell, 2005). Thus, we make an empirical contribution to the SET literature by showing the different effects of power and trust on different types of supplier resource allocation.

Managerially, our study provides new insights into the strategic implications of SCM practices. For the multinational retailer that helped in collecting this study's data, the key managerial take-away was the realization that suppliers are shared with competitors and that, to truly gain strategic advantages, SCM practices should aim at increasing the performance of this supplier relative to the performance of this supplier to competitors. The retailer adopted this perspective in its supplier management workbooks and sourcing strategies. For the retailer, for instance, the realization that the reward power (e.g., increased collaboration in product development, offering long-term contracts) can be used as an alternative to coercive tactics (e.g., threats of taking business elsewhere, relocating products to less prominent shelf spaces, less attractive payment conditions, not involving the supplier in future business developments) can make the subtle difference in the resource allocation behavior of the supplier. In addition, the process of building trust with suppliers is often painstaking and lengthy (Ring \& Van de Ven, 1994; Mol, 2004). Our results showed that buying firms with a relatively small share in turnover would benefit more from building competence trust and buying firms with a relatively large share in turnover would benefit more from building goodwill trust. This understanding may enable firms to better align their efforts to build trust in a relationship with the intended outcomes. Finally, the awareness that coercive tactics could deteriorate - but that reward power could stimulate - the goodwill trust of suppliers can especially help large buying firms in balancing the use of power and trust in their supply chain relationships. 


\subsection{Limitations and future research}

The findings of this study should be viewed in light of some limitations that suggest the need for caution in drawing conclusions, but also provide opportunities for future research. We based our findings on data from the retailing industry because of the strategic relevance of SCM for this industry. Although focusing on a single industry has its merits, this approach may not be sufficient to fully assess the scope of the results presented here. Also, we did not collect data on the customers that were assessed by the respondents. Consequently, we cannot evaluate how our findings would differ for different relationships (e.g., expressed in relationship strength). Therefore, future research should incorporate a wider range of industries and collect data on the relationship settings to expand the scope of the findings. In addition, the results of this study are based on subjective data that rely on the respondents' perceptions and survey studies could be subject to misinterpretation. Even though our pre-tests that not reveal any such misinterpretations, future research should address these shortcomings by making use of objective data. Furthermore, our study used suppliers to assess buying firms. Future research may consider examining the buyer's perspective. Such a perspective would enable scholars to investigate the competitive actions that these firms undertake to attain better resource positions in more detail (cf., Capron \& Chatain, 2008). Finally, although our sample size is comparable to other multigroup analyses applied in a supply chain setting (Paiva, Roth \& Fensterseifer, 2008) and even though the multigroup analysis enabled us to support or reject our hypotheses, our sample size is rather small for performing multigroup analyses. Thus, the results of our study should be interpreted with a certain degree of caution considering the limitation of sample size.

Factor market rivalry theory describes different types of rivalry between firms that use similar resources (Markman, Gianiodis \& Buchholtz, 2009). For example, resource rivalry occurs between direct competitors (e.g., Ford vs. General Motors), as well as between firms that are not direct competitors (e.g., Walmart hiring Amazon's key logistic personnel; cf., Ellram, Tate \& Feitzinger, 2013). This rivalry for resources with firms that are not direct competitors is an interesting dimension for future research, specifically for firms that outsource globally. In addition, the concepts of resource rivalry in supply markets (Ellram, Tate \& Feitzinger, 2013) and preferential supplier resource allocation (Hüttinger, Schiele \& Veldman, 2012) both explain the importance of acquiring better supplier resources than competitors to achieve firm-level competitive advantage. Assuming that resource-oriented SCM strategies should be contingent on the behavior of competitors (Ramsay \& Croom, 2008) suggests that firms would need some knowledge of the resource position of their competitors. This opens up to other streams examining the actions and reactions of competing firms. The literature about the competitive dynamics theorizes on competitive behavior of firms and specific competitive actions and reactions (see Chen \& Miller, 2012). The themes in this stream can provide a fruitful basis for theorizing about strategic SCM actions. For example, it would be interesting to investigate the use and effect of competitor analysis practices (Chen, 1996) in competitors' resource-oriented SCM strategies or the awareness and capability of firms to react to a competitive action in their supply base (Chen, SU \& Tsai, 2007). In 
addition, behavioral theories of the strategic actions of firms (e.g., Cyert \& March, 1963) can explain how firms relate their own actions to the position and (anticipated) actions of competing firms based on such concepts as bounded rationality and organizational aspirations (Greve, 2013). Such theories could provide an interesting framework for shaping a fuller picture of a firm's strategic SCM actions which are contingent on its relative resource position. 



\section{Chapter 6}

\section{Summary and discussion}

This dissertation examined how buying firms can obtain preferential resource allocation from suppliers. Chapter 6 reflects on the key findings of the preceding chapters by linking to the ROs formulated in Chapter 1. Also, the implications for the literature and practice as well as the limitations and directions for future research are discussed. 


\subsection{Main findings}

A central question in this dissertation was how can buying firms obtain preferential resource allocation from suppliers? The four ROs formulated in Chapter 1 each examined different aspects of the antecedents and effects of preferential resource allocation from suppliers. Although the chapters that link to these ROs can be read as separate contributions, they share one common theme in the sense that they all describe the practices that firms can adopt to gain better access to their supplier's resources. Gradually the ROs showed a more detailed focus on these practices, from examining the effect of preferred customer status only as a part of several characteristics by which buying firms can recognize innovative suppliers (RO1) to a detailed examination into how buying firms can influence supplier's allocation of different types of resources (RO4). The findings of the individual chapters contribute to the knowledge on how firms can adopt their behavior in their relationships with suppliers to attain preferential resource allocation from suppliers.

RO1 examined the effect of preferred customer status as a part of several characteristics by which buying firms can recognize innovative suppliers. RO2 and $\mathrm{RO} 3$ took a more theoretical approach and introduced the preferential resource allocation from suppliers construct. Finally, RO4 addressed how buying firms can influence preferential allocation of suppliers' physical and innovation resources. The research linking to these ROs was presented in this dissertation's four core chapters, Chapter 2 to 5, respectively. The main findings of these chapters are presented in this section.

RO1 stated: To examine those characteristics of suppliers and the characteristics of the buyer-supplier relationship, including preferred customer status, that significantly contribute to supplier contributions in buyer-supplier innovations. Chapter 2 addressed this objective. Building on the current literature a conceptual model was constructed in which three groups of constructs were identified: (1) supplier characteristics, (2) the supplier's collaborative attitude, and (3) the relational characteristics of the buyer-supplier relationship. The findings of this study show that supplier professionalism and specialization have a positive effect on suppliers' innovation contributions to the buyer-supplier relationship. Interestingly, although previous findings in the literature suggest differently, the $R \& D$ expenditures of suppliers were not found to significantly affect supplier contributions. In addition to these technical characteristics, a supplier's collaborative attitude represents a substantial fraction of the explained variance of the suppliers' innovative contribution. Also, a buying firm's preferred customer status and supplier development programs have a positive effect on a supplier's contribution to the buying firm's innovations.

The findings in Chapter 2 justified a more detailed investigation into the preferred customer concept. Chapter 3 introduces the preferential resource allocation from supplier construct and examined customer attractiveness and supplier satisfaction as its antecedents. $\mathrm{RO} 2$ was to generate a comprehensive view on the dimensions of customer attractiveness and supplier satisfaction and to examine the relationship between these constructs as well as their effects on preferential resource allocation from suppliers. Chapter 3 built on discussions with CPOs and managers to generate customer attractiveness and supplier satisfaction dimensions that provide a 
comprehensive view on the different dimensions of these constructs. Table 3.1 shows the output of these discussions and presents the dimensions that practitioners, who have a reputation for successful innovation collaboration with suppliers, indicated with their relative importance. Measures were constructed from these dimensions (see Table 3.3), to test hypotheses on the relationships between customer attractiveness and supplier satisfaction and their effect on preferential resource allocation from suppliers. This yielded interesting findings. Whereas both customer attractiveness and supplier satisfaction relate positively to preferential resource allocation from suppliers, the effect of customer attractiveness on preferential resource allocation showed to be mediated by supplier satisfaction.

RO3 aimed to identify SCM capabilities that have a positive effect on a buying firm's competitive advantage and to test how preferential resource allocation from suppliers affects this relationship. Chapter 4 addressed this objective. The results imply that that firms that possess selection and relational capabilities are able to attain higher levels of competitive advantage from their relationships with their suppliers. A significant and substantial proportion of the relationship between the capabilities and competitive advantage was found to be mediated by preferential resource allocation from suppliers. The results showed another interesting finding. The effect of preferential resource allocation from suppliers was found to be significantly higher for manufacturing firms than for service firms. In fact, preferential resource allocation did not significantly affect competitive advantages of service firms.

Whereas $\mathrm{RO} 2$ and $\mathrm{RO} 3$ addressed preferential resource allocation as a single multidimensional construct, the fourth and last research objective examined preferential resource allocation of different types of resources. RO4 aimed to examine how the different dimensions of power and trust relate to supplier resource allocation of different types of resources. The study in Chapter 5 yielded interesting results. For instance, even though goodwill trust is typically portrayed as a crucial element for buyer-supplier relationships, our analysis showed no significant effects of goodwill trust on supplier resource allocation. In addition, many studies mainly point to the negative effects of coercive power. However, our results indicate that coercive tactics can be effective practices when firms aim for better physical supplier resources and account for a large share in supplier's turnover. In general, a buying firm's share in the supplier's turnover had a surprising effect. Although it was hypothesized that the effects of goodwill trust on supplier allocation of physical resources and innovation resources would be stronger for buyers that account for a small share in supplier's turnover, goodwill trust actually appeared to have stronger effect for buying firms that accounted for large share in supplier's turnover.

\subsection{Implications and contributions}

The contributions of the studies in this dissertation are discussed in the respective discussion sections of the individual chapters. This section highlights the main contributions for theory and practice.

\subsubsection{Identifying innovative suppliers}

Chapter 2 focused on identifying those suppliers that can make significant contributions to a buyer-supplier innovations. Whereas previous conceptual research 
already examined decision models for selecting the right supplier (Rese, 2006) and proposed a framework that introduced supplier characteristics as well as relational characteristics as antecedents of supplier innovativeness (Schiele, 2006), the literature provides few empirical insights into the antecedents of buyer-supplier innovation. The study in Chapter 2 makes an empirical contribution to the literature by testing characteristics that help a firm to distinguish suppliers with a high propensity to contribute to a buying firm's innovation. In addition, Chapter 2 contributes to the preferred customer stream in the literature by explaining and empirically testing the relevance of the construct for buyer-supplier innovation.

Managerially, Chapter 2 provides new suggestions for choosing the right supplier. Supply managers might want to move away from considering only "hard facts" on suppliers (e.g., R\&D expenditures and certifications) in selecting innovative suppliers and give more consideration to the relational aspects in the buyer-supplier dyad and to suppliers' collaborative attitudes. The findings in Chapter 2 suggest that firms might want to strengthen their relationships through supplier development programs and pursue a preferred customer status to attain a higher contribution from a supplier to their innovation programs. The relevance of preferred customer status suggests a strategic implication. Because suppliers cannot dedicate their best resources to every buyer, they are forced to make choices between buyers. Therefore, a buying firm's own position as perceived by the supplier is important. The supplier will award some of its customers with preferential treatment by allocating its best resources to these firms. This study implied that including these relational aspects enables managers to select suppliers that have a high likelihood of high performance in buyer-supplier innovations.

\subsubsection{Customer attractiveness, supplier satisfaction and preferential resource allocation}

Chapter 3 presented a study which makes contributions to the upcoming preferred customer literature. Whereas the previous literature defined a preferred customer as a buying firm that receives preferential resource allocation from suppliers (Steinle \& Schiele, 2008), the studies on preferred customer status did not actually measure or examine supplier resource allocation. For example, the measure used in Chapter 2 (which built on current literature) assesses whether the supplier "cares" or "has made sacrifices" for the buying firm but does not directly measure whether a buying firms receives preferential resource allocation. Chapter 3 links to the literature on resourcebased theories to address the "resource allocation" notion in the preferred customer concept more directly. The study operationalized preferred customer status as preferential resource allocation from suppliers which allows a more accurate examination of preferred customer status and its antecedents and benefits. In addition, the findings in Chapter 3 give a clearer view on the conceptual differences between customer attractiveness and supplier satisfaction and provide a more comprehensive view of the construct dimensions than currently available in literature. The examination of these concepts extends the current theory on the relationships between customer attractiveness, supplier satisfaction and preferential resource allocation from suppliers. 
In practice, the conceptual delineation and dimensions of customer attractiveness and supplier satisfaction can enable supply managers to better adjust their strategy to the relational outcome they want to achieve. The findings show that initial attractiveness of buying firms (e.g., expressed in purchasing volumes) might not be enough to achieve preferred customer status. Instead, if buying firms fail to meet or exceed the supplier's expectations based on their initial attractiveness (i.e. supplier satisfaction), they might fail to achieve preferred customer status. This implies that managers should monitor the satisfaction of those supplier that possess resources that are relevant for the competitiveness of the buying firm. To meet or exceed the expectations for those suppliers can give the buying firm the competitive edge searched for in their supply management practices.

\subsubsection{The role of preferential resource allocation from suppliers}

The findings in Chapter 4 yield several contributions to the literature. First, Chapter 4 contributes to the literature by integrating the notion of supplier resource competition with the extended resource-based view. The findings suggest that the extent to which buying firms are able to acquire preferential resource allocation is an important determinant for the competitive advantage of buying firms. Second, even though the literature has begun to explore the capabilities that can improve the outcome of inter-firm collaborations (e.g., Kale \& Singh, 2007; Schilke \& Goerzen, 2010; Allred, et al., 2011), the literate lacks a clear examination on how indirect capabilities actually influence the resource allocation of suppliers. Chapter 4 examined the indirect capabilities that can help a buying firm in attaining preferential resource allocation. Third, whereas only a limited number of studies have examined the differences between service and manufacturing firms in a SCM setting, Chapter 4 shows how the effect of preferential resource allocation on the competitive advantage of buying firms can differ for these two industries.

Managerially, Chapter 4 exemplifies how firms can increase the effectiveness of their selection capability by not only selecting suppliers based on their potential contributions in terms of their resources, but also by selecting those suppliers that can provide the buyer with preferential access to these resources. Similarly, firms can increase the effectiveness of their relational capabilities by developing relationships with suppliers that possess resources that can contribute to the buying firm's competitiveness. In sum, managers could benefit from realizing that the extent to which their firm obtains the better benefits from the collaborations in their supply base that is shared with competitors can be influenced by the capabilities of their firm's supply management function.

\subsubsection{The effects of power and trust dimensions on supplier resource allocation}

The study presented in Chapter 5 contributes to the literature in several ways. First, contrary to other studies it shows that coercive tactics do not necessarily affect supplier resource allocation negatively and goodwill trust does not inherently affect supplier resource allocation positively. Second, the results of a multigroup analysis indicate that the dependence of a supplier on the buying firm -in terms of share in turnover- affects the relationship between the trust dimensions and supplier resource allocation more than it does the power dimensions. Third, goodwill trust only affects 
supplier resource allocation when the buyer has a large share in supplier's turnover, while competence trust is more effective if buyers account for a small share in supplier's turnover. In addition, whereas Chapter 3 and 4 examined preferential resource allocation from suppliers as a single multidimensional construct, Chapter 5 distinguishes between innovation and physical resources. In doing so, it shows how the mechanisms to acquire preferential resource allocation from supplier can be further focused towards specific supply management practices to acquire specific supplier resources.

The managerial relevance of these findings was demonstrated in the organization of the multinational retailer that helped in collecting the data of Chapter 5. The realization that suppliers are shared with competitors and that, to truly gain strategic advantages, SCM practices should aim at increasing the performance of this supplier relative to the performance of this supplier to competitors, inspired the retailer to adopt the preferred customer perspective in its supplier management workbooks and sourcing strategies. Other implications follow from the impact of a buying firm's share in the supplier's turnover. These findings imply that managers may want to adopt practices of building competence trust if they have a relatively small share in turnover and buying firms with a relatively large share in turnover would benefit more from building goodwill trust. This understanding may enable managers to better align their supply management practices with the intended outcomes.

\subsubsection{Reflection on this dissertation's contributions}

As explained in Chapter 1, this dissertation aimed to contribute to the upcoming field in the literature that investigates the impact of supplier resources on the buying firm's competitive advantage. Despite several recent contributions (e.g., Ellegaard \& Koch, 2012; Hunt \& Davis, 2012; Ellram, Tate \& Feitzinger, 2013; Hüttinger, 2014), the current literature provides little insight into the mechanisms firms can apply to improve their resource allocation from suppliers. This dissertation examined the dimensions, antecedents and effects of preferential resource allocation from suppliers. Chapters 3, 4 and 5 discussed different types of antecedents and practices to acquire supplier resources. The findings in these chapters showed that customer attractiveness and supplier satisfaction, a firm's selection and relational capabilities and the different dimensions of power and trust are all important factors for firms seeking preferential resource allocation from their suppliers. Trying to fit all these constructs into one conceptual model would be complex and, considering the different dimensions of these constructs, perhaps even impossible. Whereas customer attractiveness and supplier satisfaction (Chapter 3 ) reflect a certain process towards a preferred customer status, the power and trust dimensions of Chapter 5 illustrate a snapshot in time of a buyer's behavior. The indirect capabilities described in Chapter 4 also refer to the process of attaining preferential resource allocation. In this process, a buying firm should be able to select a supplier that holds resources that can benefit the buying firm. At this stage, it is important that the supplier considers the buying firms to be an attractive partner, since a positive expectation of the relationship with this buyer would arouse the supplier's interest to engage in a collaboration with the buyer. In the stage that follows, a firm's relational capability would apply. Once a buying firm has started a collaboration with a supplying firm, a buying firm's relational capability 
would allow the firm to access the supplier's resources. At this stage, it is important that the buying firm is satisfied with the relationship, but the buying firms should also adopt its power practices and trust building efforts to the type of resource it aims to acquire. The different studies in this dissertation have examined supplier resource competition from different perspectives and contribute to a better understanding of how firms can gain preferential resource allocation from suppliers.

The different perspectives provide many opportunities for future research. For example, longitudinal research can examine the importance of the different antecedents in different stages of a relationship and comparative case studies could yield interesting insights on how the effectiveness of antecedents can differ for different types of suppliers and supplier resources. The findings in this dissertation provide a foundation for such research.

\subsection{Limitations and future research}

In addition to the specific limitations and suggestions for future research for the individual studies discussed in Chapters 2-5, this dissertation has two general limitations. The first limitation refers to the mainly quantitative methodology. Although the chosen approach has its merits in terms of testing the hypotheses of interest, generalizability of the findings as well as the required time span of data collection and analysis, a quantitative approach is too abstract to assess specific contexts and can therefore miss out on certain phenomena. For example, so-called outliers may reveal influencing factors that are missed in the current theory. For instance, it is possible that some buying firms are allocated better supplier resources than competitors despite that these buying firms are less attractive than their competitors. What conditions can lead to such a situation? Answers to these type of questions cannot be distinctively answered with the theory presented in this dissertation. Eisenhardt (1989) explains how a qualitative examination of cases that disconfirm the certain relationships can provide an opportunity to refine a theory. Future research should aim to examine outliers that may reveal influencing factors that are missed in this dissertation. Including additional influencing factors in the tested relations from this dissertation can increase the predictive power of the preferential resource allocation frameworks.

A second limitation refers to the dissertation's main focus on the direct link between supplier resources and competitive advantage. As observed by reviewers and attendees of conferences, the extent to which a buying firm can create competitive advantages with supplier resources also depends on the internal resources of the buying firm. For instance, if a buying firm obtains better resources from a supplier than a competitor, but if this competitor is able to create more synergies with these resources, or if the supplier resource are more compatible with the competitor's overall strategy, the competitor can still be expected to create the greater performance benefits. Or, as put by Freytag and Young (2014, p. 363) "competitive advantage through cooperation in networks is not only a matter of having the competencies to take advantage of the opportunities available, but is also a matter of the way competencies are combined." This dissertation did not directly address this perspective. Although the observed significant link between preferential resource 
allocation and competitive advantage in Chapter 4 does support a direct link between these constructs, integrating the compatibility of supplier resources with the buying firm's internal resources and firm strategy will provide a fuller picture of the role of preferential resource allocation from suppliers on a firm's competitive advantages. The relevance of taking this perspective is demonstrated by Weigelt (2013) who examined the interaction between supplier IT capabilities and a buying firm's operational capabilities. She observed that stronger buyer capabilities enhance the application of supplier capabilities when the supplier capabilities are deployed in the buyer's organization. Yet, if the buying firm has lower operational capabilities it appeared more beneficial to completely outsource IT capabilities to the supplier (Weigelt, 2013). Thus, future research on preferential resource allocation from suppliers should incorporate the interaction between supplier resources and the buying firm's resources as well as the compatibility of the supplier's resources with the buying firm's strategy.

Finally, in addition to the opportunities for future research discussed in the individual chapter, there are two directions for future research worth highlighting in conclusion of this dissertation. The first direction ${ }^{6}$ relates to the concept of supplier resource competition. This notion adds to the growing stream in the literature that takes a strategic perspective on supply management (van Weele \& van Raaij, 2014). According to Mintzberg and Quinn (1998) a crucial part of a well-formulated strategy is the integration of anticipated moves by intelligent opponents. This would suggest that the literature on strategic supply management would somehow integrate the interplay between competing firms in its perspectives. However, the relative position of a firm versus its rivals and the competitive interactions between them seems to have received only limited attention the strategic supply management literature. The question then is how can a firm's supply management strategies be linked to "competitive positions" or "competitive advantage" if the concept of competition is not integrated into the supply management strategies? Future supply management research should aim to theorize on competitive behavior of firms in terms of their supply management strategies. Two streams in the strategic management literature seem to be particularly relevant to do so: (1) the literature on competitive dynamics that theorizes on competitive behaviors of firms and specific competitive actions and reactions (see Chen \& Miller, 2012) and (2) the behavioral theory of the firm (Cyert \& March, 1963) can explain how firms relate their own actions to the position and (anticipated) actions of competing firms based on concepts as bounded rationality and organizational aspirations (Greve, 2013).

The second direction for future research relates to the concept of coopetition. Coopetition refers to a situation in which competing firms also cooperate. Bengtsson and Kock (2014, p. 182) define this concept as "a paradoxical relationship between two or more actors simultaneously involved in cooperative and competitive interactions". Whereas this dissertation argues that competition between firms extends to suppliers, similarly practices of coopetition can be observed in the way firms manage their suppliers. For example, it may be in the interest of two competing

\footnotetext{
${ }^{6}$ This paragraph mainly builds on the paper of Pulles, Vos and Veldman (2014) presented at the $23^{\text {rd }}$ IPSERA conference in Pretoria, South Africa.
} 
buying firms to jointly support a financially distressed supplier. Or two competing firms may decide to join forces against a third competitor by means of a joint supplier development program that excludes the competitor from the benefits achieved. In these situations it is in the best interest of both firms to develop their supplier, yet, the firms must also defend their own interest and aim to capture more value from this supplier than their competitor. Although the concept of coopetition has been examined for situations in which multiple suppliers share one customer (e.g., $\mathrm{Wu}$, Choi \& Rungtusanatham, 2010), coopetition between multiple buying firms that share one supplier remains an underexplored topic. Therefore, an interesting opportunity for future research is to examine the cooperative and competitive interactions (i.e., coopetition) of buying firms in a shared supply base. 


\section{References}

Adegbesan, J.A. (2009). On the origins of competitive advantage: Strategic factor markets and heterogeneous resource complementarity. Academy of Management Review, 34 (3), 463-475.

Ahuja, G. (2000). Collaboration networks, structural holes, and innovation: A longitudinal study. Administrative Science Quarterly, 45 (3), 425-455.

Allred, C.R., Fawcett, S.E., Wallin, C. \& Magnan, G.M. (2011). A dynamic collaboration capability as a source of competitive advantage. Decision Sciences, 42 (1), 129-161.

Andaleeb, S.S. (1996). An experimental investigation of satisfaction and commitment in marketing channels: The role of trust and dependence. Journal of Retailing, 72 (1), 77-93.

Andersen, P.H. \& Christensen, P.R. (2000). Inter-partner learning in global supply chains: Lessons from Novo Nordisk. European Journal of Purchasing \& Supply Management, 6 (2), 105-116.

Anderson, E., Lodish, L.M. \& Weitz, B.A. (1987). Resource allocation behavior in conventional channels. Journal of Marketing Research, 24 (1), 85-97.

Anderson, J.C. \& Narus, J.A. (1990). A model of distributor firm and manufacturer firm working partnerships. Journal of Marketing, 54 (1), 42-58.

Araujo, L., Dubois, A. \& Gadde, L.-E. (2003). The multiple boundaries of the firm. Journal of Management Studies, 40 (5), 1255-1277.

Araujo, L. \& Spring, M. (2006). Services, products, and the institutional structure of production. Industrial Marketing Management, 35 (7), 797-805.

Armstrong, J.S. \& Overton, T.S. (1977). Estimating nonresponse bias in mail surveys. Journal of Marketing Research, 14 (3), 396-402.

Azadegan, A., Dooley, K.J., Carter, P.L. \& Carter, J.R. (2008). Supplier innovativeness and the role of interorganizational learning in enhancing manufacturer capabilities. Journal of Supply Chain Management, 44 (4), 14-35.

Bachmann, R. (2001). Trust, power and control in trans-organizational relations. Organization Studies, 22 (2), 337-365.

Barney, J.B. (1986). Strategic factor markets: Expectations, luck, and business strategy. Management Science, 32 (10), 1231-1241.

Barney, J.B. (1991). Firm resources and sustained competitive advantage. Journal of Management, 17 (1), 99-120.

Barney, J.B. (2012). Purchasing, supply chain management and sustained competitive advantage: The relevance of resource-based theory. Journal of Supply Chain Management, 48 (2), 3-6.

Baum, J.A.C., Calabrese, T. \& Silverman, B.S. (2000). Don't go it alone: Alliance network composition and startups' performance in Canadian biotechnology. Strategic Management Journal, 21 (3), 267-294.

Baxter, R. (2012). How can business buyers attract sellers' resources?: Empirical evidence for preferred customer treatment from suppliers. Industrial Marketing Management, 41 (8), 1249-1258.

Beaumont, N. \& Sohal, A. (2004). Outsourcing in Australia. International Journal of Operations \& Production Management, 24 (7), 688-700.

Bendoly, E., Donohue, K. \& Schultz, K.L. (2006). Behavior in operations management: Assessing recent findings and revisiting old assumptions. Journal of Operations Management, 24 (6), 737-752.

Bengtsson, M. \& Kock, S. (2014). Coopetition — quo vadis? Past accomplishments and future challenges. Industrial Marketing Management, 43 (2), 180-188. 
Benner, M.J. \& Tushman, M.L. (2003). Exploitation, exploration, and process management: The productivity dilemma revisited. Academy of Management Review, 28 (2), 238-256.

Benton, W.C. \& Maloni, M. (2005). The influence of power driven buyer/seller relationships on supply chain satisfaction. Journal of Operations Management, 23 (1), 1-22.

Bernardes, E.S. \& Zsidisin, G.A. (2008). An examination of strategic supply management benefits and performance implications. Journal of Purchasing and Supply Management, 14 (4), 209-219.

Bidault, F., Despres, C. \& Butler, C. (1998). The drivers of cooperation between buyers and suppliers for product innovation. Research Policy, 26 (7-8), 719-732.

Biemans, W.G. \& Brand, M.J. (1995). Reverse marketing: A synergy of purchasing and relationship marketing. Journal of Supply Chain Management, 31 (3), 28-37.

Birkinshaw, J., Morrison, A. \& Hulland, J. (1995). Structural and competitive determinants of a global integration strategy. Strategic Management Journal, 16 (8), 637-655.

Blau, P.M. (1964). Exchange and power in social life. New York, John Wiley \& Sons, Inc.

Bloom, P.N. \& Perry, V.G. (2001). Retailer power and supplier welfare: The case of WalMart. Journal of Retailing, 77 (3), 379-396.

Bosch-Sijtsema, P.M. \& Postma, T.J.B.M. (2009). Cooperative innovation projects: Capabilities and governance mechanisms. Journal of Product Innovation Management, 26 (1), 58-70.

Brennan, C. \& Ritch, E. (2010). Capturing the voice of older consumers in relation to financial products and services. International Journal of Consumer Studies, 34 (2), $212-$ 218.

Brennan, R. \& Turnbull, P.W. (1999). Adaptive behavior in buyer-supplier relationships. Industrial Marketing Management, 28 (5), 481-495.

Briggs, E., Landry, T.D. \& Daugherty, P.J. (2010). Investigating the influence of velocity performance on satisfaction with third party logistics service. Industrial Marketing Management, 39 (4), 640-649.

Brown, J. \& Isaacs, D. (2005). The World Café: Shaping our futures through conversations that matter. San Fransisco, Berrett-Koehler Publishers.

Brown, J.R., Lusch, R.F. \& Nicholson, C.Y. (1995). Power and relationship commitment: Their impact on marketing channel member performance. Journal of Retailing, 71 (4), 363-392.

Byrne, B.M. (2009). Structural equation modeling with amos: Basic concepts, applications, and programming. New York, Routledge/Taylor \& Francis.

Byrne, B.M., Shavelson, R.J. \& Muthén, B. (1989). Testing for the equivalence of factor covariance and mean structures: The issue of partial measurement invariance. Psychological Bulletin, 105 (3), 456-466.

Cabral, J. \& Traill, W.B. (2001). Determinants of a firm's likelihood to innovate and intensity of innovation in the Brazilian food industry. Journal on Chain and Network Science, 1 (1), $33-48$.

Cagliano, R., Caniato, F., Corso, M. \& Spina, G. (2005). Collaborative improvement in the extended manufacturing enterprise: Lessons from an action research process. Production Planning \& Control, 16 (4), 345-355.

Caniëls, M.C.J. \& Gelderman, C.J. (2005). Purchasing strategies in the Kraljic matrix-a power and dependence perspective. Journal of Purchasing and Supply Management, 11 (2-3), 141-155.

Capron, L. \& Chatain, O. (2008). Competitors' resource-oriented strategies: Acting on competitors' resources through interventions in factor markets and political markets. Academy of Management Review, 33 (1), 97-121. 
Carr, A.S. \& Pearson, J.N. (1999). Strategically managed buyer-supplier relationships and performance outcomes. Journal of Operations Management, 17 (5), 497-519.

Cassiman, B. \& Veugelers, R. (2006). In search of complementarity in innovation strategy: Internal R\&D and external knowledge acquisition. Management Science, 52 (1), 68-82.

Cenfetelli, R.T. \& Bassellier, G. (2009). Interpretation of formative measurement in information systems research. MIS Quarterly, 33 (4), 689-707.

Chen, C.C. (1995). New trends in rewards allocation preferences: A Sino-U.S. comparison. Academy of Management Journal, 38 (2), 408-428.

Chen, I.J., Paulraj, A. \& Lado, A.A. (2004). Strategic purchasing, supply management, and firm performance. Journal of Operations Management, 22 (5), 505-523.

Chen, M.-J. (1996). Competitor analysis and interfirm rivalry: Toward a theoretical integration. Academy of Management Review, 21 (1), 100-134.

Chen, M.-J. \& Miller, D. (2012). Competitive dynamics: Themes, trends, and a prospective research platform. Academy of Management Annals, 6 (1), 135-210.

Chen, M.-J., Su, K.-H. \& Tsai, W. (2007). Competitive tension: The awareness-motivationcapability perspective. Academy of Management Journal, 50 (1), 101-118.

Chesbrough, H.W. (2003). Open innovation: The new imperative for creating and profiting from technology. Boston, Harvard Business School Press.

Cheung, G.W. \& Rensvold, R.B. (2002). Evaluating goodness-of-fit indexes for testing measurement invariance. Structural Equation Modeling: A Multidisciplinary Journal, 9 (2), 233-255.

Chin, W. (2010). How to write up and report PLS analyses. In Esposito Vinzi, V., Chin, W. W., Henseler, J. \& Wang, H. (Eds.), Handbook of partial least squares Springer Berlin Heidelberg.

Chin, W.W., Marcolin, B.L. \& Newsted, P.R. (2003). A partial least squares latent variable modeling approach for measuring interaction effects: Results from a monte carlo simulation study and an electronic-mail emotion/adoption study. Info. Sys. Research, 14 (2), 189-217.

Cho, H.-J. \& Pucik, V. (2005). Relationship between innovativeness, quality, growth, profitability, and market value. Strategic Management Journal, 26 (6), 555-575.

Christiansen, P.E. \& Maltz, A. (2002). Becoming an "interesting" customer: Procurement strategies for buyers without leverage. International Journal of Logistics Research and Applications, 5 (2), 177-195.

Chun, R. \& Davies, G. (2006). The influence of corporate character on customers and employees: Exploring similarities and differences. Academy of Marketing Science, 34 (2), 138-146.

Cohen, J. (2001). A power primer. Psychological Bulletin, 112 (1), 155-159.

Cook, K.S. (2005). Networks, norms, and trust: The social psychology of social capital. Social Psychology Quarterly, 68 (1), 4-14.

Cormican, K. \& O'Sullivan, D. (2004). Auditing best practice for effective product innovation management. Technovation, 24 (10), 819-829.

Corsaro, D., Ramos, C., Henneberg, S.C. \& Naudé, P. (2012). The impact of network configurations on value constellations in business markets - the case of an innovation network. Industrial Marketing Management, 41 (1), 54-67.

Corsten, D. \& Felde, J. (2005). Exploring the performance effects of key-supplier collaboration: An empirical investigation into Swiss buyer-supplier relationships. International Journal of Physical Distribution \& Logistics Management, 35 (6), 445-461.

Cox, A. (2001). Understanding buyer and supplier power: A framework for procurement and supply competence. Journal of Supply Chain Management, 37 (2), 8-15. 
Croom, S.R. (2001). The dyadic capabilities concept: Examining the processes of key supplier involvement in collaborative product development. European Journal of Purchasing \& Supply Management, 7 (1), 29-37.

Cropanzano, R. \& Mitchell, M.S. (2005). Social exchange theory: An interdisciplinary review. Journal of Management, 31 (6), 874-900.

Cyert, R.M. \& March, J.G. (1963). A behavioral theory of the firm. Englewood Cliffs, NJ, Prentice Hall.

Damanpour, F. (1991). Organizational innovation: A meta-analysis of effects of determinants and moderators. Academy of Management Journal, 34 (3), 555-590.

Das, T.K. \& Teng, B.-S. (2000). A resource-based theory of strategic alliances. Journal of Management, 26 (1), 31-61.

Das, T.K. \& Teng, B.-S. (2001). Trust, control, and risk in strategic alliances: An integrated framework. Organization Studies, 22 (2), 251-283.

Das, T.K. \& Teng, B.-S. (2002). Alliance constellations: A social exchange perspective. Academy of Management Review, 27 (3), 445-456.

Deshpandé, R., Farley, J.U. \& Webster, F.E. (1993). Corporate culture, customer orientation, and innovativeness in Japanese firms: A quadrad analysis. Journal of Marketing, 57 (January), 23-27.

Diamantopoulos, A. \& Winklhofer, H.M. (2001). Index construction with formative indicators: An alternative to scale development. Journal of Marketing Research, 38 (2), 269-277.

Donaldson, B. \& O'Toole, T. (2007). Strategic market relationships: From strategy to implementation. Chichester, John Wiley \& Sons.

Drupsteen, J., van der Vaart, T. \& van Donk, D.P. (2013). Integrative practices in hospitals and their impact on patient flow. International Journal of Operations \& Production Management, 33 (7), 912-933.

Dyer, J.H. (1996). Specialized supplier networks as a source of competitive advantage: Evidence from the auto industry. Strategic Management Journal, 17 (4), 271-291.

Dyer, J.H. \& Hatch, N.W. (2006). Relation-specific capabilities and barriers to knowledge transfers: Creating advantage through network relationships. Strategic Management Journal, 27 (8), 701-719.

Dyer, J.H. \& Singh, H. (1998). The relational view: Cooperative strategy and sources of interorganizational competitive advantage. Academy of Management Review, 23 (4), 660679.

Eggert, A. \& Ulaga, W. (2010). Managing customer share in key supplier relationships. Industrial Marketing Management, 39 (8), 1346-1355.

Eisenhardt, K.M. (1989). Building theories from case study research. Academy of Management Review, 14 (4), 532-550.

Ellegaard, C. (2006). Small company purchasing: A research agenda. Journal of Purchasing and Supply Management, 12 (5), 272-283.

Ellegaard, C. (2012). Interpersonal attraction in buyer-supplier relationships: A cyclical model rooted in social psychology. Industrial Marketing Management, 41 (8), 1219-1227.

Ellegaard, C., Johansen, J. \& Drejer, A. (2003). Managing industrial buyer-supplier relations-the case for attractiveness Integrated Manufacturing Systems, 14 (4), 346-356.

Ellegaard, C. \& Koch, C. (2012). The effects of low internal integration between purchasing and operations on suppliers' resource mobilization. Journal of Purchasing and Supply Management, 18 (3), 148-158.

Ellis, S.C., Henke Jr, J.W. \& Kull, T.J. (2012). The effect of buyer behaviors on preferred customer status and access to supplier technological innovation: An empirical study of supplier perceptions. Industrial Marketing Management, 41 (8), 1259-1269. 
Ellram, L.M., Tate, W.L. \& Feitzinger, E.G. (2013). Factor-market rivalry and competition for supply chain resources. Journal of Supply Chain Management, 49 (1), 29-46.

Essig, M. \& Amann, M. (2009). Supplier satisfaction: Conceptual basics and explorative findings. Journal of Purchasing and Supply Management, 15 (2), 103-113.

Ethiraj, S.K., Kale, P., Krishnan, M.S. \& Singh, J.V. (2005). Where do capabilities come from and how do they matter? A study in the software services industry. Strategic Management Journal, 26 (1), 25-45.

Field, J.M. \& Meile, L.C. (2008). Supplier relations and supply chain performance in financial services processes. International Journal of Operations \& Production Management, 28 (2), 185-206.

Foa, E.B. \& Foa, U.G. (1980) "Resource theory." In Gergen, K. J., Greenberg, M. S. \& Willis, R. H. (Eds.), Social exchange: Advances in theory and research, Plenum, New York.

Fornell, C. \& Larcker, D.F. (1981). Evaluating structural equation models with unobservable variables and measurement error. Journal of Marketing Research, 18 (February), 39-50.

Foxx, W.K., Bunn, M.D. \& McCay, V. (2009). Outsourcing services in the healthcare sector. Journal of Medical Marketing: Device, Diagnostic and Pharmaceutical Marketing, 9 (1), 41-55.

French, J.R.P. \& Raven, B. (1959). The bases of social power. In Cartwright, D. (Ed.), Studies in social power, Institute for Social Research, Ann Arbor, MI.

Freytag, P. \& Young, L. (2014). Introduction to special issue on innovations and networks: Innovation of, within, through and by networks. Industrial Marketing Management, 43 (3), 361-364.

Freytag, P.V., Clarke, A.H. \& Evald, M.R. (2012). Reconsidering outsourcing solutions. European Management Journal, 30 (2), 99-110.

Galbreath, J. (2005). Which resources matter the most to firm success? An exploratory study of resource-based theory. Technovation, 25 (9), 979-987.

Ganesan, S. (1994). Determinants of long-term orientation in buyer-seller relationships. Journal of Marketing, 58 (2), 1-19.

Ganesan, S., George, M., Jap, S., Palmatier, R.W. \& Weitz, B. (2009). Supply chain management and retailer performance: Emerging trends, issues, and implications for research and practice. Journal of Retailing, 85 (1), 84-94.

Geyskens, I., Steenkamp, J.-B.E.M., Scheer, L.K. \& Kumar, N. (1996). The effects of trust and interdependence on relationship commitment: A trans-Atlantic study. International Journal of Research in Marketing, 13 (4), 303-317.

Ghijsen, P.W.T., Semeijn, J. \& Ernstson, S. (2010). Supplier satisfaction and commitment: The role of influence strategies and supplier development. Journal of Purchasing and Supply Management, 16 (1), 17-26.

Gimeno, J. (2004). Competition within and between networks: The contingent effect of competitive embeddedness on alliance formation. Academy of Management Journal, 47 (6), 820-842.

Gnyawali, D.R. \& Madhavan, R. (2001). Cooperative networks and competitive dynamics: A structural embeddedness perspective. Academy of Management Review, 26 (3), 431-445.

Gounaris, S.P. (2005). Trust and commitment influences on customer retention: Insights from business-to-business services. Journal of Business Research, 58 (2), 126-140.

Greve, H.R. (2013). Microfoundations of management: Behavioral strategies and levels of rationality in organizational action. Academy of Management Perspectives, 27 (2), 103-119.

Griffith, D.A., Harvey, M.G. \& Lusch, R.F. (2006). Social exchange in supply chain relationships: The resulting benefits of procedural and distributive justice. Journal of Operations Management, 24 (2), 85-98. 
Griffith, R., Huergo, E., Mairesse, J. \& Peters, B. (2006). Innovation and productivity across four european countries. Oxford Review of Economic Policy, 22 (4), 483-498.

Gulati, R., Nohria, N. \& Zaheer, A. (2000). Strategic networks. Strategic Management Journal, 21 (3), 203-215.

Gwinner, K., Gremler, D. \& Bitner, M. (1998). Relational benefits in services industries: The customer's perspective. Academy of Marketing Science, 26 (2), 101-114.

Hailén, L., Johanson, J. \& Seyed-Mohamed, N. (1991). Interfirm adaptation in business relationships. Journal of Marketing, 55 (2), 29-37.

Hair, J.F., Sarstedt, M., Pieper, T.M. \& Ringle, C.M. (2012). The use of partial least squares structural equation modeling in strategic management research: A review of past practices and recommendations for future applications. Long Range Planning, 45 (5-6), 320-340.

Hair, J.F.J., Anderson, R.E., Tatham, R.L. \& Black, W.C. (1995). Multivariate data analysis. New York, Macmillan.

Hair Jr, J.F., Hult, G.T.M., Ringle, C. \& Sarstedt, M. (2013). A primer on partial least squares structural equation modeling (PLS-SEM). Thousand Oaks, SAGE Publications, Incorporated.

Håkansson, H. (1987). Industrial technological development: A network approach. London, Croom Helm.

Håkansson, H. \& Snehota, I. (1995). Developing relationships in business networks. London, Routledge.

Hald, K.S. (2012). The role of boundary spanners in the formation of customer attractiveness. Industrial Marketing Management, 41 (8), 1228-1240.

Hald, K.S., Cordón, C. \& Vollmann, T.E. (2009). Towards an understanding of attraction in buyer-supplier relationships. Industrial Marketing Management, 38 (8), 960-970.

Hansen, M.T. (2002). Knowledge networks: Explaining effective knowledge sharing in multiunit companies. Organization Science, 13 (3), 232-248.

Helfat, C.E. \& Peteraf, M.A. (2003). The dynamic resource-based view: Capability lifecycles. Strategic Management Journal, 24 (10), 997-1010.

Helfat, C.E. \& Winter, S.G. (2011). Untangling dynamic and operational capabilities: Strategy for the (n)ever-changing world. Strategic Management Journal, 32 (11), 12431250.

Henseler, J. (2012). PLS-MGA: A non-parametric approach to partial least squares-based multi-group analysis. In Gaul, W. A., Geyer-Schulz, A., Schmidt-Thieme, L. \& Kunze, J. (Eds.), Challenges at the interface of data analysis, computer science, and optimization Springer Berlin Heidelberg.

Hitt, M.A. (2011). Relevance of strategic management theory and research for supply chain management. Journal of Supply Chain Management, 47 (1), 9-13.

Hitt, M.A., Dacin, M.T., Levitas, E., Arregle, J.-L. \& Borza, A. (2000). Partner selection in emerging and developed market contexts: Resource-based and organizational learning perspectives. Academy of Management Journal, 43 (3), 449-467.

Ho, W., Xu, X. \& Dey, P.K. (2010). Multi-criteria decision making approaches for supplier evaluation and selection: A literature review. European Journal of Operational Research, 202 (1), 16-24.

Hoffmann, P. (2011). Innovative supply risk management. University of Twente, Enschede.

Hoholm, T. \& Olsen, P.I. (2012). The contrary forces of innovation: A conceptual model for studying networked innovation processes. Industrial Marketing Management, 41 (2), 344356.

Homans, G.C. (1958). Social behavior as exchange. The American Journal of Sociology, 63 (6), 597-606. 
Hong, Y. \& Hartley, J.L. (2011). Managing the supplier-supplier interface in product development: The moderating role of technological newness. Journal of Supply Chain Management, 47 (3), 43-62.

Howell, J.M. \& Sheab, C.M. (2001). Individual differences, environmental scanning, innovation framing, and champion behavior: Key predictors of project performance. Journal of Product Innovation Management, 18 (1), 15-27.

Hulland, J. (1999). Use of partial least squares (PLS) in strategic management research: A review of four recent studies. Strategic Management Journal, 20 (2), 195-204.

Hult, G.T.M. (1998). Managing the international strategic sourcing process as a marketdriven organizational learning system. Decision Sciences, 29 (1), 193-216.

Hult, G.T.M., Ketchen Jr., D.J. \& Arrfelt, M. (2007). Strategic supply chain management: Improving performance through a culture of competitiveness and knowledge development. Strategic Management Journal, 28 (10), 1035-1052.

Hult, G.T.M., Ketchen Jr., D.J., Cavusgil, S.T. \& Calantone, R.J. (2006). Knowledge as a strategic resource in supply chains. Journal of Operations Management, 24 (5), 458-475.

Humphreys, P.K., Li, W.L. \& Chan, L.Y. (2004). The impact of supplier development on buyer-supplier performance. Omega, 32 (2), 131-143.

Hunt, S.D. \& Davis, D.F. (2008). Grounding supply chain management in resourceadvantage theory. Journal of Supply Chain Management, 44 (1), 10-21.

Hunt, S.D. \& Davis, D.F. (2012). Grounding supply chain management in resourceadvantage theory: In defense of a resource-based view of the firm. Journal of Supply Chain Management, 48 (2), 14-20.

Hurley, R.F. \& Hult, G.T.M. (1998). Innovation, market orientation, and organizational learning: An integration and empirical examination. Journal of Marketing, 62 (3), 52-54.

Hüttinger, L. (2014). Preferential customer treatment by suppliers: Identifying benefits and antecedents. University of Twente, Enschede.

Hüttinger, L., Schiele, H. \& Veldman, J. (2012). The drivers of customer attractiveness, supplier satisfaction and preferred customer status: A literature review. Industrial Marketing Management, 41 (8), 1194-1205.

Ireland, R.D. \& Webb, J.W. (2007). A multi-theoretic perspective on trust and power in strategic supply chains. Journal of Operations Management, 25 (2), 482-497.

Jarvis, Cheryl B., MacKenzie, Scott B. \& Podsakoff, Philip M. (2003). A critical review of construct indicators and measurement model misspecification in marketing and consumer research. Journal of Consumer Research, 30 (2), 199-218.

Jarvis, C.B., Mackenzie, S.B., Podsakoff, P.M., Mick, D.G. \& Bearden, W.O. (2003). A critical review of construct indicators and measurement model misspecification in marketing and consumer research. Journal of Consumer Research, 30 (2), 199-218.

Johnston, D.A., McCutcheon, D.M., Stuart, F.I. \& Kerwood, H. (2004). Effects of supplier trust on performance of cooperative supplier relationships. Journal of Operations Management, 22 (1), 23-38.

Jöreskog, K.G. \& Yang, F. (1996). Nonlinear structural equation models: The Kenny-Judd model with interaction effects. In Marcoulides, G. A. \& Schumacker, R. E. (Eds.), Advanced structural equation modeling: Issues and techniques, New Jersey, Lawrence Erlbaum Associates.

Kale, P. \& Singh, H. (2007). Building firm capabilities through learning: The role of the alliance learning process in alliance capability and firm-level alliance success. Strategic Management Journal, 28 (10), 981-1000.

Kale, P., Singh, H. \& Perlmutter, H. (2000). Learning and protection of proprietary assets in strategic alliances: Building relational capital. Strategic Management Journal, 21 (3), 217 237. 
Kankanhalli, A., Tan, B.C.Y. \& Wei, K.-K. (2005). Contributing knowledge to electronic knowledge repositories: An empirical investigation. MIS Quarterly, 29 (1), 113-143.

Kannan, V.R. \& Tan, K.C. (2002). Supplier selection and assessment: Their impact on business performance. Journal of Supply Chain Management, 38 (4), 11-21.

Kannan, V.R. \& Tan, K.C. (2006). Buyer-supplier relationships: The impact of supplier selection and buyer-supplier engagement on relationship and firm performance. International Journal of Physical Distribution \& Logistics Management, 36 (10), 755775.

Kasch, S. \& Dowling, M. (2008). Commercialization strategies of young biotechnology firms: An empirical analysis of the U.S. industry. Research Policy, 37 (10), 1765-1777.

Kaufman, A., Wood, C.H. \& Theyel, G. (2000). Collaboration and technology linkages: A strategic supplier typology. Strategic Management Journal, 21 (6), 649-663.

Kelly, K. \& Kerwin, K., There's another side to the lopez saga, http://www.businessweek.com/stories/1993-08-22/theres-another-side-to-the-lopez-saga, Accessed July 28, 2013.

Kline, R.B. (2010). Principles and practice of structural equation modeling. New York, Guilford Press.

Knights, D., Noble, F., Vurdubakis, T. \& Willmott, H. (2001). Chasing shadows: Control, virtuality and the production of trust. Organization Studies, 22 (2), 311.

Kocabasoglu, C. \& Suresh, N.C. (2006). Strategic sourcing: An empirical investigation of the concept and its practices in U.S. manufacturing firms. Journal of Supply Chain Management, 42 (2), 4-16.

Koufteros, X., Vickery, S.K. \& Dröge, C. (2012). The effects of strategic supplier selection on buyer competitive performance in matched domains: Does supplier integration mediate the relationships? Journal of Supply Chain Management, 48 (2), 93-115.

Krause, D.R. (1997). Supplier development: Current practices and outcomes. Journal of Supply Chain Management, 33 (2), 12-19.

Krause, D.R. (1999). The antecedents of buying firms' efforts to improve suppliers. Journal of Operations Management, 17 (2), 205-224.

Krause, D.R., Handfield, R.B. \& Tyler, B.B. (2007). The relationships between supplier development, commitment, social capital accumulation and performance improvement. Journal of Operations Management, 25 (2), 528-545.

Krause, D.R., Pagell, M. \& Curkovic, S. (2001). Toward a measure of competitive priorities for purchasing. Journal of Operations Management, 19 (4), 497-512.

Kumar, N. (1996). The power of trust in manufacturer-retailer relationships. Harvard Business Review, 74 (6), 92-106.

Kwon, I.-W.G. \& Suh, T. (2004). Factors affecting the level of trust and commitment in supply chain relationships. Journal of Supply Chain Management, 40 (2), 4-14.

La Rocca, A., Caruana, A. \& Snehota, I. (2012). Measuring customer attractiveness. Industrial Marketing Management, 41 (8), 1241-1248.

Lai, F., Li, D., Wang, Q. \& Zhao, X. (2008). The information technology capability of thirdparty logistics providers: A resource-based view and empirical evidence from China. Journal of Supply Chain Management, 44 (3), 22-38.

Lambe, C.J., Wittmann, C.M. \& Spekman, R.E. (2001). Social exchange theory and research on business-to-business relational exchange. Journal of Business-to-Business Marketing, 8 (3), 1-36.

Laursen, K. \& Salter, A. (2006). Open for innovation: The role of openness in explaining innovation performance among U.K. manufacturing firms. Strategic Management Journal, 27 (2), 131-150. 
Lavie, D. (2006). The competitive advantage of interconnected firms: An extension of the resource-based view. Academy of Management Review, 31 (3), 638-658.

Lavie, D. (2007). Alliance portfolios and firm performance: A study of value creation and appropriation in the U.S. software industry. Strategic Management Journal, 28 (12), 1187-1212.

Lawson, B., Tyler, B.B. \& Cousins, P.D. (2008). Antecedents and consequences of social capital on buyer performance improvement. Journal of Operations Management, 26 (3), 446-460.

Leenders, M.R. \& Blenkhorn, D.L. (1988). Reverse marketing: The new buyer-supplier relationship. New York, Free Press.

Legler, H. \& Frietsch, R. (2007) Neuabgrenzung der wissenswirtschaft-forschungsintensive industrien und wissensintensive dienstleistungen (niw/isi listen 2006).

Lewis, M., Brandon-Jones, A., Slack, N. \& Howard, M. (2010). Competing through operations and supply: The role of classic and extended resource-based advantage. International Journal of Operations \& Production Management, 30 (10), 1032-1058.

Li, W., Humphreys, P.K., Yeung, A.C.L. \& Edwin Cheng, T.C. (2007). The impact of specific supplier development efforts on buyer competitive advantage: An empirical model. International Journal of Production Economics, 106 (1), 230-247.

Liang, H., Saraf, N., Hu, Q. \& Xue, Y. (2007). Assimilation of enterprise systems: The effect of institutional pressures and the mediating role of top management. MIS Quarterly, 31 (1), 59-87.

Lichtenthaler, U. (2009). Absorptive capacity, environmental turbulence, and the complementarity of organizational learning processes. Academy of Management Journal, 52 (4), 822-846.

Liker, J.K., Collins, P.D. \& Hull, F.M. (1999). Flexibility and standardization: Test of a contingency model of product design-manufacturing integration. Journal of Product Innovation Management, 16 (3), 248-267.

Liker, J.K., Kamath, R.R., Nazli Wasti, S. \& Nagamachi, M. (1996). Supplier involvement in automotive component design: Are there really large US Japan differences? Research Policy, 25 (1), 59-89.

Lindgreen, A. \& Wynstra, F. (2005). Value in business markets: What do we know? Where are we going? Industrial Marketing Management, 34 (7), 732-748.

Liu, H., Ke, W., Wei, K.K. \& Hua, Z. (2013). Effects of supply chain integration and market orientation on firm performance: Evidence from China. International Journal of Operations \& Production Management, 33 (3), 322-346.

Loasby, B.J. (1998). The organisation of capabilities. Journal of Economic Behavior \& Organization, 35 (2), 139-160.

Lockström, M., Schadel, J., Harrison, N., Moser, R. \& Malhotra, M.K. (2010). Antecedents to supplier integration in the automotive industry: A multiple-case study of foreign subsidiaries in China. Journal of Operations Management, 28 (3), 240-256.

Lorenzoni, G. \& Lipparini, A. (1999). The leveraging of interfirm relationships as a distinctive organizational capability: A longitudinal study. Strategic Management Journal, 20 (4), 317-338.

MacCallum, R.C. \& Browne, M.W. (1993). The use of causal indicators in covariance structure models: Some practical issues. Psychological Bulletin, 114 (3), 119-136.

Madhavan, R. \& Grover, R. (1998). From embedded knowledge to embodied knowledge: New product development as knowledge management. Journal of Marketing, 62 (4), 1-12.

Maloni, M. \& Benton, W.C. (2000). Power influences in the supply chain. Journal of Business Logistics, 21 (1), 49-73. 
Markman, G.D., Gianiodis, P.T. \& Buchholtz, A.K. (2009). Factor-market rivalry. Academy of Management Review, 34 (3), 423-441.

Mathews, J.A. (2003). Competitive dynamics and economic learning: An extended resource-based view. Industrial and Corporate Change, 12 (1), 115-145.

Mathieson, K., Peacock, E. \& Chin, W.W. (2001). Extending the technology acceptance model: The influence of perceived user resources. SIGMIS Database, 32 (3), 86-112.

Mattila, T. \& Antikainen, R. (2011). Backcasting sustainable freight transport systems for Europe in 2050. Energy Policy, 39 (3), 1241-1248.

Maull, R., Geraldi, J. \& Johnston, R. (2012). Service supply chains: A customer perspective. Journal of Supply Chain Management, 48 (4), 72-86.

Mayer, R.C., Davis, J.H. \& Schoorman, F.D. (1995). An integrative model of organizational trust. Academy of Management Review, 20 (3), 709-734.

Mesquita, L.F., Anand, J. \& Brush, T.H. (2008). Comparing the resource-based and relational views: Knowledge transfer and spillover in vertical alliances. Strategic Management Journal, 29 (9), 913-941.

Miles, J. \& Shevlin, M. (2001). Applying regression and correlation. London, Sage Publications.

Mintzberg, H. \& Quinn, J.B. (1998). Readings in the strategy process. Upper Saddle River, NJ, Prentice Hall.

Mishra, A.A. \& Shah, R. (2009). In union lies strength: Collaborative competence in new product development and its performance effects. Journal of Operations Management, 27 (4), 324-338.

Mitshuhashi, H. \& Greve, H.R. (2009). A matching theory of alliance formation and organizational success: Complementarity and compatibility. Academy of Management Journal, 52 (5), 975-995.

Miyamoto, T. \& Rexha, N. (2004). Determinants of three facets of customer trust: A marketing model of Japanese buyer-supplier relationship. Journal of Business Research, 57 (3), 312-319.

Mohr, J. \& Spekman, R. (1994). Characteristics of partnership success: Partnership attributes, communication behavior, and conflict resolution techniques. Strategic Management Journal, 15 (2), 135-152.

Mol, M.J. (2003). Purchasing's strategic relevance. Journal of Purchasing and Supply Management, 9 (1), 43-50.

Mol, M.J. (2004). Outsourcing, supplier relations, and the external span of control. Proceedings, 13th IPSERA Conference.

Molm, L.D. (1994). Is punishment effective? Coercive strategies in social exchange. Social Psychology Quarterly, 57 (2), 75-94.

Moody, P.E. (1992). Customer supplier integration: Why being an excellent customer counts. Business Horizons, 35 (4), 52.

Mooi, E.A. \& Frambach, R.T. (2012). Encouraging innovation in business relationships-a research note. Journal of Business Research, 65 (7), 1025-1030.

Moran, P. (2005). Structural vs. relational embeddedness: Social capital and managerial performance. Strategic Management Journal, 26 (12), 1129-1151.

Morgan, R.M. \& Hunt, S.D. (1994). The commitment-trust theory of relationship marketing. Journal of Marketing, 58 (3), 20.

Mortensen, M. \& Arlbjørn, J. (2012). Inter-organisational supplier development: The case of customer attractiveness and strategic fit. Supply Chain Management, 17 (2), 152-171.

Mortensen, M.H., Freytag, P.V. \& Arlbjørn, J.S. (2008). Attractiveness in supply chains: A process and matureness perspective. International Journal of Physical Distribution \& Logistics Managemen, 38 (10), 799 - 815. 
Mota, J. \& Castro, L.M.D. (2004). A capabilities perspective on the evolution of firm boundaries: A comparative case example from the Portuguese moulds industry. Journal of Management Studies, 41 (2), 295-316.

Moultrie, J., Clarkson, P.J. \& Probert, D. (2007). Development of a design audit tool for SMEs. Journal of Product Innovation Management, 24 (4), 335-368.

Mouzas, S. \& Ford, D. (2009). The constitution of networks. Industrial Marketing Management, 38 (5), 495-503.

Muthusamy, S.K. \& White, M.A. (2005). Learning and knowledge transfer in strategic alliances: A social exchange view. Organization Studies, 26 (3), 415-441.

Narasimhan, R., Nair, A., Griffith, D.A., Arlbjørn, J.S. \& Bendoly, E. (2009). Lock-in situations in supply chains: A social exchange theoretic study of sourcing arrangements in buyer-supplier relationships. Journal of Operations Management, 27 (5), 374-389.

Naveh, E. (2007). Formality and discretion in successful r\&d projects. Journal of Operations Management, 25 (1), 110-125.

Neu, W.A. \& Brown, S.W. (2005). Forming successful business-to-business services in goods-dominant firms. Journal of Service Research, 8 (1), 3-17.

Newbert, S.L. (2008). Value, rareness, competitive advantage, and performance: A conceptual-level empirical investigation of the resource-based view of the firm. Strategic Management Journal, 29 (7), 745-768.

Nunnally, J. (1978). Psychometric methods. New York, McGraw-Hill.

Nyaga, G.N., Lynch, D.F., Marshall, D. \& Ambrose, E. (2013). Power asymmetry, adaptation and collaboration in dyadic relationships involving a powerful partner. Journal of Supply Chain Management, 49 (3), 42-65.

Nyaga, G.N., Whipple, J.M. \& Lynch, D.F. (2010). Examining supply chain relationships: Do buyer and supplier perspectives on collaborative relationships differ? Journal of Operations Management, 28 (2), 101-114.

O'brien, R. (2007). A caution regarding rules of thumb for variance inflation factors. Quality \& Quantity, 41 (5), 673-690.

Obloj, T. \& Capron, L. (2011). Role of resource gap and value appropriation: Effect of reputation gap on price premium in online auctions. Strategic Management Journal, 32 (4), 447-456.

Paiva, E.L., Roth, A.V. \& Fensterseifer, J.E. (2008). Organizational knowledge and the manufacturing strategy process: A resource-based view analysis. Journal of Operations Management, 26 (1), 115-132.

Park, D. \& Krishnan, H.A. (2001). Supplier selection practices among small firms in the United States: Testing three models. Journal of Small Business Management, 39 (3), 259271.

Paulraj, A., Lado, A.A. \& Chen, I.J. (2008). Inter-organizational communication as a relational competency: Antecedents and performance outcomes in collaborative buyersupplier relationships. Journal of Operations Management, 26 (1), 45-64.

Peng, D.X. \& Lai, F. (2012). Using partial least squares in operations management research: A practical guideline and summary of past research. Journal of Operations Management, 30 (6), 467-480.

Peng, D.X., Schroeder, R.G. \& Shah, R. (2008). Linking routines to operations capabilities: A new perspective. Journal of Operations Management, 26 (6), 730-748.

Perols, J., Zimmermann, C. \& Kortmann, S. (2013). On the relationship between supplier integration and time-to-market. Journal of Operations Management, 31 (3), 153-167.

Peteraf, M.A. (1993). The cornerstones of competitive advantage: A resource-based view. Strategic Management Journal, 14 (3), 179-191. 
Petersen, K.J., Handfield, R.B., Lawson, B. \& Cousins, P.D. (2008). Buyer dependency and relational capital formation: The mediating effects of socialization processes and supplier integration. Journal of Supply Chain Management, 44 (4), 53-65.

Petroni, A. \& Panciroli, B. (2002). Innovation as a determinant of suppliers' roles and performances: An empirical study in the food machinery industry. European Journal of Purchasing \& Supply Management, 8 (3), 135-149.

Pidgeon, N., Harthorn, B.H., Bryant, K. \& Rogers-Hayden, T. (2009). Deliberating the risks of nanotechnologies for energy and health applications in the United States and United Kingdom. Nature Nanotechnology, 4 (2), 95-98.

Podsakoff, P.M. \& Organ, D.W. (1986). Self-reports in organizational research: Problems and prospects. Journal of Management, 12 (4), 531-544.

Poppo, L. \& Zenger, T. (2002). Do formal contracts and relational governance function as substitutes or complements? Strategic Management Journal, 23 (8), 707-725.

Powell, W.W., Koput, K.W. \& Smith-Doerr, L. (1996). Interorganizational collaboration and the locus of innovation: Networks of learning in biotechnology. Administrative Science Quarterly, 41 (1), 116-145.

Prahalad, C.K. \& Ramaswamy, V. (2004). Co-creation experiences: The next practice in value creation. Journal of Interactive Marketing, 18 (3), 5-14.

Preacher, K. \& Hayes, A. (2008). Asymptotic and resampling strategies for assessing and comparing indirect effects in multiple mediator models. Behavior Research Methods, 40 (3), 879-891.

Pulles, N.J., Veldman, J., Schiele, H. \& Sierksma, H. (2014). Pressure or pamper? The effects of power and trust dimensions on supplier resource allocation. Journal of Supply Chain Management 50(3), 16-36

Pulles, N.J., Veldman, J. \& Schiele, H. (2014). Identifying innovative suppliers in business networks: An empirical study. Industrial Marketing Management, 43 (3), 409-418.

Pulles, N.J., Vos, F.G.S. \& Veldman, J. (2014). Competitor oriented supply management strategies, presented at the $23^{\text {rd }}$ Annual IPSERA Conference Proceedings, Pretoria, South Africa.

Pulles, N.J. \& Schiele, H. (2013). Social capital determinants of preferential resource allocation in regional clusters. Management Revue, 24(2), 96-113.

Qureshi, I. \& Compeau, D. (2009). Assessing between-group differences in information systems research: A comparison of covariance- and component-based SEM. MIS Quarterly, 33 (1), 197-214.

Ragatz, G.L., Handfield, R.B. \& Petersen, K.J. (2002). Benefits associated with supplier integration into new product development under conditions of technology uncertainty. Journal of Business Research, 55 (5), 389-400.

Ramsay, J. (1996). Power measurement. European Journal of Purchasing \& Supply Management, 2 (2-3), 129-143.

Ramsay, J. (2001a). Purchasing's strategic irrelevance. European Journal of Purchasing \& Supply Management, 7 (4), 257-263.

Ramsay, J. (2001b). The resource based perspective, rents, and purchasing's contribution to sustainable competitive advantage. Journal of Supply Chain Management, 37 (3), 38-47.

Ramsay, J. (2005). The real meaning of value in trading relationships. International Journal of Operations \& Production Management, 25 (6), 549-565.

Ramsay, J. \& Croom, S. (2008). The impact of evolutionary and developmental metaphors on purchasing and supply management: A critique. Journal of Purchasing and Supply Management, 14 (3), 192-204.

Ramsay, J., Wagner, B. \& Kelly, S. (2013). Purchase offering quality. International Journal of Operations \& Production Management, 33 (10), 1260-1282. 
Ramsay, J. \& Wagner, B.A. (2009). Organisational supplying behaviour: Understanding supplier needs, wants and preferences. Journal of Purchasing and Supply Management, 15 (2), 127-138.

Reinartz, W., Haenlein, M. \& Henseler, J. (2009). An empirical comparison of the efficacy of covariance-based and variance-based SEM. International Journal of Research in Marketing, 26 (4), 332-344.

Rese, M. (2006). Successful and sustainable business partnerships: How to select the right partners. Industrial Marketing Management, 35 (1), 72-82.

Rexhausen, D., Pibernik, R. \& Kaiser, G. (2012). Customer-facing supply chain practicesthe impact of demand and distribution management on supply chain success. Journal of Operations Management, 30 (4), 269-281.

Ridings, C.M., Gefen, D. \& Arinze, B. (2002). Some antecedents and effects of trust in virtual communities. The Journal of Strategic Information Systems, 11 (3-4), 271-295.

Ridley, M. (2010). The rational optimist: How prosperity evolves. New York, HarperCollins.

Ring, P.S. \& Van de Ven, A.H. (1994). Developmental processes of cooperative interorganizational relationships. Academy of Management Review, 19 (1), 90-118.

Ringle, C.M., Wende, S. \& Will, A. SmartPLS 2.0 (beta), University of Hamburg, Hamburg, 2005.

Roehrich, J. \& Lewis, M. (2014). Procuring complex performance: Implications for exchange governance complexity. International Journal of Operations \& Production Management, 34 (2), 221-241.

Romer, P.M. (1990). Endogenous technological change. The Journal of Political Economy, $98(5), 71-102$.

Rong, B. \& Wilkinson, I.F. (2011). What do managers' survey responses mean and what affects them? The case of market orientation and firm performance. Australasian Marketing Journal, 19 (3), 137-147.

Rossiter, J.R. (2002). The C-OAR-SE procedure for scale development in marketing. International Journal of Research in Marketing, 19 (4), 305-335.

Roy, S., Sivakumar, K. \& Wilkinson, I.F. (2004). Innovation generation in supply chain relationships: A conceptual model and research propositions. Academy of Marketing Science, 32 (1), 61-79.

Rungtusanatham, M., Miller, J.W. \& Boyer, K.K. (2014). Theorizing, testing, and concluding for mediation in SCM research: Tutorial and procedural recommendations. Journal of Operations Management, 32 (3), 99-113.

Sako, M. \& Helper, S. (1998). Determinants of trust in supplier relations: Evidence from the automotive industry in Japan and the United States. Journal of Economic Behavior \& Organization, 34 (3), 387-417.

Salomo, S., Weise, J. \& Gemünden, H.G. (2007). NPD planning activities and innovation performance: The mediating role of process management and the moderating effect of product innovativeness. Journal of Product Innovation Management, 24 (4), 285-302.

Sarkar, M.B., Echambadi, R.A.J. \& Harrison, J.S. (2001). Alliance entrepreneurship and firm market performance. Strategic Management Journal, 22 (6-7), 701-711.

Schermelleh-Engel, K., Moosbrugger, H. \& Müller, H. (2003). Evaluating the fit of structural equation models: Tests of significance and descriptive goodness-of-fit measures. Methods of Psychological Research, 8 (2), 23-74.

Schiele, H. (2006). How to distinguish innovative suppliers? Identifying innovative suppliers as new task for purchasing. Industrial Marketing Management, 35 (8), 925-935.

Schiele, H., Calvi, R. \& Gibbert, M. (2012). Customer attractiveness, supplier satisfaction and preferred customer status: Introduction, definitions and an overarching framework. Industrial Marketing Management, 41 (8), 1178-1185. 
Schiele, H. \& Krummaker, S. (2011). Consortium benchmarking: Collaborative academicpractitioner case study research. Journal of Business Research, 64 (10), 1137-1145.

Schiele, H., Veldman, J. \& Hüttinger, L. (2011). Supplier innovativeness and supplier pricing: The role of preferred customer status. International Journal of Innovation Management, 15 (1), 1-27.

Schiele, H., Veldman, J., Hüttinger, L. \& Pulles, N. (2012). Towards a social exchange theory perspective on preferred customership - concept and practice. In Bogaschewsky, R., Essig, M., Lasch, R. \& Stölzle, W. (Eds.), Supply management research Gabler Verlag.

Schilke, O. (2014). On the contingent value of dynamic capabilities for competitive advantage: The nonlinear moderating effect of environmental dynamism. Strategic Management Journal, 35 (2), 179-203.

Schilke, O. \& Goerzen, A. (2010). Alliance management capability: An investigation of the construct and its measurement. Journal of Management, 36 (5), 1192-1219.

Schoenherr, T., Modi, S.B., Benton, W.C., Carter, C.R., Choi, T.Y., Larson, P.D., Leenders, M.R., Mabert, V.A., Narasimhan, R. \& Wagner, S.M. (2012). Research opportunities in purchasing and supply management. International Journal of Production Research, 50 (16), 4556-4579.

Scott-Young, C. \& Samson, D. (2008). Project success and project team management: Evidence from capital projects in the process industries. Journal of Operations Management, 26 (6), 749-766.

Song, M. \& Di Benedetto, C.A. (2008). Supplier's involvement and success of radical new product development in new ventures. Journal of Operations Management, 26 (1), 1-22.

Soosay, C.A., Hyland, P.W. \& Ferrer, M. (2008). Supply chain collaboration: Capabilities for continuous innovation. Supply Chain Management: An International Journal, 13 (2), 160169.

Spekman, R.E. \& Carraway, R. (2006). Making the transition to collaborative buyer-seller relationships: An emerging framework. Industrial Marketing Management, 35 (1), 10-19.

Spring, M. \& Araujo, L. (2014). Indirect capabilities and complex performance: Implications for procurement and operations strategy. International Journal of Operations \& Production Management, 34 (2), 150-173.

Squire, B., Cousins, P.D., Lawson, B. \& Brown, S. (2009). The effect of supplier manufacturing capabilities on buyer responsiveness: The role of collaboration. International Journal of Operations \& Production Management, 29 (8), 766-788.

State-of-Flux. (2011). The SRM dividend: Developing collaborative relationships for competitive advantage.

Steinle, C. \& Schiele, H. (2008). Limits to global sourcing?: Strategic consequences of dependency on international suppliers: Cluster theory, resource-based view and case studies. Journal of Purchasing and Supply Management, 14 (1), 3-14.

Surroca, J., Tribó, J.A. \& Waddock, S. (2010). Corporate responsibility and financial performance: The role of intangible resources. Strategic Management Journal, 31 (5), 463-490.

Takeishi, A. (2001). Bridging inter- and intra-firm boundaries: Management of supplier involvement in automobile product development. Strategic Management Journal, 22 (5), 403-433.

Takeishi, A. (2002). Knowledge partitioning in the interfirm division of labor: The case of automotive product development. Organization Science, 13 (3), 321-338.

Tan, S. \& Brown, J. (2005). The World Café in Singapore. The Journal of Applied Behavioral Science, 41 (1), 83-90.

Tate, W.L. \& Ellram, L.M. (2012). Service supply management structure in offshore outsourcing. Journal of Supply Chain Management, 48 (4), 8-29. 
Teece, D.J. (2007). Explicating dynamic capabilities: The nature and microfoundations of (sustainable) enterprise performance. Strategic Management Journal, 28 (13), 1319-1350.

Teece, D.J., Pisano, G. \& Shuen, A. (1997). Dynamic capabilities and strategic management. Strategic Management Journal, 18 (7), 509-533.

Terpend, R. \& Ashenbaum, B. (2012). The intersection of power, trust and supplier network size: Implications for supplier performance. Journal of Supply Chain Management, 48 (3), 52-77.

Thibaut, J.W. \& Kelley, H.H. (1959). The social psychology of groups. New York, John Wiley \& Sons, Inc.

Thomas, R.W., Esper, T.L. \& Stank, T.P. (2010). Testing the negative effects of time pressure in retail supply chain relationships. Journal of Retailing, 86 (4), 386-400.

Thomke, S.H. \& Von Hippel, E. (2002). Customers as innovators: A new way to create value. Harvard Business Review, 80 (4), 74-81.

Trent, R.J. \& Monczka, R.M. (1999). Achieving world-class supplier quality. Total Quality Management, 10 (6), 927-938.

Tsai, W. \& Ghoshal, S. (1998). Social capital and value creation: The role of intrafirm networks. Academy of Management Journal, 41 (4), 464-476.

Ulaga, W. \& Eggert, A. (2006). Value-based differentiation in business relationships: Gaining and sustaining key supplier status. Journal of Marketing, 70 (1), 119-136.

van Weele, A.J. \& van Raaij, E.M. (2014). The future of purchasing and supply management research: About relevance and rigor. Journal of Supply Chain Management, 50 (1), 56-72.

Vargo, S.L. \& Lusch, R.F. (2004). Evolving to a new dominant logic for marketing. Journal of Marketing, 68 (1), 1-17.

Villanueva, J., Van de Ven, A.H. \& Sapienza, H.J. (2010). Resource mobilization in entrepreneurial firms. Journal of Business Venturing, 27 (1), 19-30.

von Corswant, F. \& Tunälv, C. (2002). Coordinating customers and proactive suppliers: A case study of supplier collaboration in product development. Journal of Engineering and Technology Management, 19 (3-4), 249-261.

von Hippel, E. (1988). The sources of innovation. New York, Oxford University Press.

Wagner, S.M. (2012). Tapping supplier innovation. Journal of Supply Chain Management, $48(2), 37-52$.

Wagner, S.M., Coley, L.S. \& Lindemann, E. (2011). Effects of suppliers' reputation on the future of buyer-supplier relationships: The mediating roles of outcome fairness and trust. Journal of Supply Chain Management, 47 (2), 29-48.

Wagner, T., Hennig-Thurau, T. \& Rudolph, T. (2009). Does customer demotion jeopardize loyalty? Journal of Marketing, 73 (3), 69-85.

Wakelin, K. (2001). Productivity growth and R\&D expenditure in UK manufacturing firms. Research Policy, 30 (7), 1079-1090.

Walter, A. (1999). Relationship promoters: Driving forces for successful customer relationships. Industrial Marketing Management, 28 (5), 537-551.

Walter, A., Auer, M. \& Ritter, T. (2006). The impact of network capabilities and entrepreneurial orientation on university spin-off performance. Journal of Business Venturing, 21 (4), 541-567.

Walter, A., Ritter, T. \& Gemünden, H.G. (2001). Value creation in buyer-seller relationships: Theoretical considerations and empirical results from a supplier's perspective. Industrial Marketing Management, 30 (4), 365-377.

Walter, J., Lechner, C. \& Kellermanns, F.W. (2007). Knowledge transfer between and within alliance partners: Private versus collective benefits of social capital. Journal of Business Research, 60 (7), 698-710. 
Wasko, M.M. \& Faraj, S. (2005). Why should I share? Examining social capital and knowledge contribution in electronic networks of practice. MIS Quarterly, 29 (1), 35-57.

Wasti, S.N. \& Liker, J.K. (1999). Collaborating with suppliers in product development: A US and Japan comparative study. Engineering Management, IEEE Transactions on, 46 (4), 444-460.

Weigelt, C. (2013). Leveraging supplier capabilities: The role of locus of capability deployment. Strategic Management Journal, 34 (1), 1-21.

Wernerfelt, B. (1984). A resource-based view of the firm. Strategic Management Journal, 5 (2), 171-180.

Wetzels, M., Odekerken-Schröder, G. \& van Oppen, C. (2009). Using PLS path modeling for assessing hierarchical construct models: Guidelines and empirical illustration. MIS Quarterly, 33 (1), 177-195.

Whitener, E.M., Brodt, S.E., Korsgaard, M.A. \& Jon, M.W. (1998). Managers as initiators of trust: An exchange relationship framework for understanding managerial trustworthy behavior. Academy of Management Review, 23 (3), 513-530.

Wilkinson, I. \& Young, L. (2002). On cooperating: Firms, relations and networks. Journal of Business Research, 55 (2), 123-132.

Williamson, P.J. (1991). Supplier strategy and customer responsiveness: Managing the links. Business Strategy Review, 2 (2), 75.

Winter, S.G. (2003). Understanding dynamic capabilities. Strategic Management Journal, 24 (10), 991-995.

Wognum, P.M., Fisscher, O.A.M. \& Weenink, S.A.J. (2002). Balanced relationships: Management of client-supplier relationships in product development. Technovation, 22 (6), 341-351.

Wu, Z., Choi, T.Y. \& Rungtusanatham, M.J. (2010). Supplier-supplier relationships in buyer-supplier-supplier triads: Implications for supplier performance. Journal of Operations Management, 28 (2), 115-123.

Wynstra, F., Von Corswant, F. \& Wetzels, M. (2010). In chains? An empirical study of antecedents of supplier product development activity in the automotive industry. Journal of Product Innovation Management, 27 (5), 625-639.

Yeung, A.C.L. (2008). Strategic supply management, quality initiatives, and organizational performance. Journal of Operations Management, 26 (4), 490-502.

Yeung, J.H.Y., Selen, W., Zhang, M. \& Huo, B. (2009). The effects of trust and coercive power on supplier integration. International Journal of Production Economics, 120 (1), 66-78.

Young, L., Wiley, J. \& Wilkinson, I. (2008). A comparison of European and Chinese supplier and customer functions and the impact of connected relations. Journal of Business \& Industrial Marketing, 24 (1), 35-45.

Zacharia, Z.G., Nix, N.W. \& Lusch, R.F. (2011). Capabilities that enhance outcomes of an episodic supply chain collaboration. Journal of Operations Management, 29 (6), 591-603.

Zhao, X., Huo, B., Flynn, B.B. \& Yeung, J.H.Y. (2008). The impact of power and relationship commitment on the integration between manufacturers and customers in a supply chain. Journal of Operations Management, 26 (3), 368-388.

Zsidisin, G.A. \& Smith, M.E. (2005). Managing supply risk with early supplier involvement: A case study and research propositions. Journal of Supply Chain Management, 41 (4), 4457. 


\section{Appendix 1. Measures Chapter 2}

Supplier contributions in buyer-supplier innovations (SIC, $\alpha=0.90)$

SIC1 (0.90) The level of technological capability the supplier possesses and is willing to use for our products is high ${ }^{\mathrm{a}}$

SIC2 (0.83) The supplier is willing to share key technological information ${ }^{a}$

SIC3 (0.90) This supplier is capable of supporting collaborative processes in product development and process improvement ${ }^{\mathrm{a}}$

SIC4 (0.89) This supplier is frequently proactive in approaching us with innovations ${ }^{\mathrm{a}}$

Supplier Professionalism (SP, $\alpha=0.72)$

SP1 (0.83) The supplier obtained relevant quality certificates (e.g., ISO TS 16949 in the SP2 (0.93) This supplier has well-developed project management capabilities ${ }^{\text {a }}$

Supplier's R\&D Expenditure (SRD)

SRD1 Please indicate the magnitude of this supplier's R\&D expenditure in relation to annual sales: ${ }^{\mathrm{b}}$

\section{Supplier Specialization (SSP)}

SSP1 This supplier develops products exactly in line with our requirements. We are not just offered "standard solutions" a

SSP2 This unit of the supplier sells its products to many industries ${ }^{\mathrm{a}^{*}}$

SSP3 How many direct competitors does this supplier have? ${ }^{\mathrm{c}}$

Supplier Collaborative Attitude (SCA, $\alpha=0.66$ )

SCA1 (0.71) This supplier is involved in several collaborative ventures, not only with our company ${ }^{\mathrm{a}}$

SCA2 (0.86) This supplier's management attaches importance to collaborative customer relationships ${ }^{\mathrm{a}}$

SCA3 (0.74) This supplier involves its sub-suppliers in its development process ${ }^{\mathrm{a}}$

Preferred Customer Status (PCS, $\alpha=0.90$ )

PCS1 (0.74) This supplier has made sacrifices for us in the past ${ }^{\mathrm{a}}$

PCS2 (0.90) This supplier cares for us ${ }^{\text {a }}$

PCS3 (0.88) In case of shortages, this supplier has gone out on a limb for us ${ }^{\text {a }}$

PCS4 (0.91) We feel this supplier is on our side ${ }^{\text {a }}$

PCS5 (0.86) The best resources of this supplier work for us ${ }^{\text {a }}$

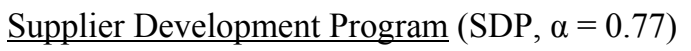

SDP1 (0.58) We do a lot of things to continually improve this supplier ${ }^{\mathrm{a}}$

We have been collaborating with this supplier in the following areas:

SDP2 (0.84) - product quality ${ }^{\mathrm{a}}$

SDP3 (0.86) - technical assistance ${ }^{\text {a }}$

SDP4 (0.78) - innovation and improvement workshops ${ }^{\text {a }}$

${ }^{\mathrm{a}}$ Item measured on five-point scale: $1=$ fully disagree, $5=$ fully agree

${ }^{\mathrm{b}}$ Item measured in percentage

${ }^{c}$ Item was measured in integer

* Item was reverse-scaled 


\section{Appendix 2. Measures Chapter 4}

All items were measured on a 5-point Likert scale, ranging from 1 "no, fully disagree" to 5 "yes, fully agree".

\section{Introduction to survey}

The following questions refer to important suppliers for your firm that you share with main competitors. For these 'shared' suppliers we would like to know how you perceive the 'commitment' of these suppliers. There are no 'good' or 'bad' answers, please fill in the questionnaire as it best describes your firm's situation

\section{Preferential resource allocation from suppliers}

Our key suppliers - which we share with our main competitors -...

PRA1 ... allocate their best employees to the relationship with my firm

PRA2 ...share their best ideas with my firm

PRA3 ...allocate more financial resources to the relationship with my firm

PRA4 ...grant my firm better utilization of their physical resources

PRA5 ...grant my firm better access to their social network

PRA6 ...shares more of its knowledge and expertise

\section{Selection capability}

My organization...

SC 1 ...has good ability to recognize opportunities for strategic collaborations

SC 2 ...has good ability to select suppliers we can successfully collaborate with

SC 3 ...has comprehensive information on state-of-the-art technologies in the supply base

SC $4 \quad$...easily observes external sources of new technologies

\section{Relational capability}

My organization has the ability to...

RC 1 ...build good personal relationships with suppliers

RC 2 ...almost always solve problems constructively with our suppliers

RC 3 ...build mutual trust between us and our suppliers

RC 4 ...build mutual respect between us and our suppliers

\section{Competitive advantage}

The relationship with our suppliers...

CA 1 ...has provided my firm with strategic advantages over competitors

CA 2 ...enabled my firm to reduce cost to a highly competitive level

CA 3 ...enabled my firm to defend against competitive threats

\section{Turnover}

TO

Please indicate your firm's (in case of groups of firms: your business unit's); annual turnover (in Mio. $€$ ) 


\section{Samenvatting (Summary in Dutch)}

Veel bedrijven zijn sterk afhankelijk van hun leveranciers. De producten en services die industriële bedrijven bij hun leveranciers inkopen bepalen vaak in hoge mate de kwaliteit, prijs, innovativiteit en beschikbaarheid van de eindproducten die deze bedrijven zelf op de markt brengen. Leveranciers hebben daarom een belangrijke invloed op de concurrentiepositie van bedrijven. De wetenschappelijke literatuur geeft vele voorbeelden van hoe bedrijven beter kunnen samenwerken met hun leveranciers om zodoende een betere concurrentiepositie te bemachtigen. Echter, concurrerende bedrijven werken vaak samen met dezelfde leveranciers. De vraag is dan, hoe kan een bedrijf concurrentievoordeel behalen uit een relatie met een leverancier die ook aan de concurrenten van dit bedrijf levert?

Dit proefschrift richt zich op het bovenstaande vraagstuk. De theorie die wordt gebruikt, komt voort uit de literatuur die zich baseert op het resource perspectief. Resources zijn financiële, menselijke, intellectuele, organisatorische en fysieke goederen of middelen die een bedrijf kan inzetten om een competitief voordeel te behalen. Voorbeelden van resources zijn goede ideeën, productiecapaciteit, patenten, kennis, financiële middelen en zakelijke netwerken. Bedrijven met betere resources dan concurrenten kunnen eenvoudiger een competitief voordeel behalen. Niet elk bedrijf beschikt echter over voldoende resources om zijn doelstellingen te behalen. Wanneer een bedrijf zelf niet een resource bezit, zal het dus op zoek moeten gaan naar een partner die deze resource wel bezit. De literatuur laat zien dat leveranciers belangrijke partners kunnen zijn om externe resources te bemachtigen. Ook hier geldt dat een bedrijf eenvoudiger zijn concurrentiepositie verbetert naarmate het betere resources van leveranciers bemachtigt. Zoals hierboven gesteld, werken concurrenten echter ook samen met de leveranciers en proberen deze ook de beste resources te bemachtigen. Er is dus sprake van competitie voor de resources van leveranciers. Een belangrijke stelling in dit proefschrift is dat als een bedrijf daadwerkelijk competitief voordeel wil behalen uit relaties met leveranciers, dit bedrijf betere resources van leveranciers (hierna: leveranciersresources) moet bemachtigen dan dat concurrenten doen.

Hoewel de academische literatuur zich in toenemende mate richt op het strategisch belang van leveranciersresources, is de competitie voor leveranciersresources nog relatief onderbelicht. Er is nog onvoldoende bekend over wat bedrijven kunnen doen om de resourceallocatie (het toewijzen van resources) van leveranciers te kunnen beïnvloeden. Dit is belangrijk om te weten want, zoals hierboven is beschreven, het bedrijf dat de beste resources krijgt zal beter in staat zijn om zijn concurrentiepositie te verbeteren. Wanneer een bedrijf betere leveranciersresources gealloceerd krijgt, noemen we dit preferentiële resourceallocatie. Dit proefschrift heeft als doel om een bijdrage te leveren aan de literatuur door middel van onderzoek naar preferentiële resourceallocatie van leveranciers. Dit proefschrift gaat in op vier onderzoeksthema's die de methodes beschrijven waarmee bedrijven de resourceallocatie van leveranciers kunnen beïnvloeden en op die manier preferentiële resourceallocatie kunnen creëren.

Het eerste onderzoeksthema betreft het preferred customer (een klant met voorkeursbehandeling) concept. Omdat beoogde innovaties een belangrijke reden zijn 
voor samenwerking met leveranciers, gaat het eerste onderzoeksthema in hoofdstuk 2 in op de invloed van een preferred customer status op de innovatiecontributies van een leverancier. De bevindingen in hoofdstuk 2 laten een significant en positief verband zien tussen de innovatiecontributies van een leverancier en de mate waarin een industriële klant een preferred customer status heeft. Ook blijkt de bereidheid tot samenwerking van een leverancier een belangrijke invloed te hebben op de innovatiecontributies van een leverancier. Deze bevindingen tonen de relevantie aan van het preferred customer concept en rechtvaardigen meer systematisch onderzoek naar preferentiële resourceallocatie van leveranciers.

Waar het eerste onderzoeksthema de positieve effecten van een preferred customer status liet zien, gaat het tweede onderzoeksthema in hoofdstuk 3 in op de vraag hoe bedrijven een preferred customer kunnen worden. De literatuur laat zien dat twee concepten een centrale rol spelen in het bemachtigen van een preferred customer status: de percepties van een leverancier wat betreft de attractiviteit van een klant (klantattractiviteit) en de tevredenheid van een leverancier over de relatie met een klant (leverancierstevredenheid). Hoewel er veel aandacht wordt besteed aan deze concepten, maakt de literatuur nog onvoldoende onderscheid in de onderliggende dimensies van de klantattractiviteit en leverancierstevredenheid. Daardoor is het moeilijk om te bepalen hoe een bedrijf deze concepten kan inzetten om preferentiële resourceallocatie van leveranciers te bemachtigen. Op basis van de huidige literatuur wordt in hoofdstuk 3 beschreven dat klantattractiviteit verwijst naar de waarde die een leverancier verwacht in een relatie met een klant en dat leverancierstevredenheid betrekking heeft op de relationele waarde die een leverancier ervaart. De bevindingen in hoofdstuk 3 laten zien dat zowel klantattractiviteit als leverancierstevredenheid een positief effect heeft op preferentiële resourceallocatie van leveranciers. Echter, de relatie tussen preferentiële resourceallocatie en klantattractiviteit wordt gemedieerd door leverancierstevredenheid. Dit duidt erop dat, hoewel het belangrijk is dat een leverancier een positieve verwachting heeft van een relatie met een klant, het tevreden stellen van een leverancier op basis van de relationele waarde die deze leverancier ervaart, effectiever is in het bemachtigen van een preferentiële resourceallocatie bij deze leverancier.

Het derde onderzoeksthema richt zich op de effecten van preferentiële resourceallocatie van leveranciers op de concurrentiepositie van bedrijven. In hoofdstuk 4 is het verband besproken tussen preferentiële resource allocatie en de interorganisationele vaardigheden van een inkoopfunctie. Hoewel zulke vaardigheden in de literatuur vaak worden geassocieerd met een betere samenwerking tussen een bedrijf en zijn leveranciers, is het nog onduidelijk hoe deze vaardigheden van een inkoopfunctie gerelateerd zijn aan de concurrentiepositie van een bedrijf. De bevindingen in hoofdstuk 4 laten zien dat bedrijven met de vaardigheid om kansen voor samenwerking te herkennen meer competitief voordeel halen uit hun relatie met leveranciers. Ook blijkt dat de vaardigheid om een goede relatie op te bouwen met leveranciers een positief effect heeft op het competitieve voordeel van deze relaties. Een significant deel van deze relatie wordt gemedieerd door preferentiële resourceallocatie. Dat wil zeggen dat het positieve effect van de vaardigheden op het competitieve voordeel dat bedrijven uit hun relaties met leveranciers halen, voor een substantieel deel wordt verklaard door de vaardigheden die een bedrijf in staat stellen 
om preferentiële resourceallocatie van leveranciers te bemachtigen. Naast een direct effect, hebben de vaardigheden van een inkoopfunctie dus ook een indirect effect op de concurrentiepositie van een bedrijf, via preferentiële resourceallocatie van leveranciers. Verder blijkt uit de resultaten dat het effect van preferentiële resourceallocatie van leveranciers vooral belangrijk is voor bedrijven in de maakindustrie en minder relevant is voor bedrijven in service-industrieën.

Het vierde en laatste onderzoeksthema in hoofdstuk 5 richt zich op verschillende types resources. Waar de voorgaande onderzoeksthema's geen onderscheid maken tussen verschillende resources, maakt het vierde onderzoeksthema onderscheid tussen fysieke (bijvoorbeeld speciale machines en schaarse producten) en innovatieresources (bijvoorbeeld technische kennis en ideeën). Hoewel deze resources fundamenteel van elkaar verschillen, geeft de literatuur nog onvoldoende duidelijkheid over de verschillende tactieken die een bedrijf kan toepassen om deze leveranciersresources te bemachtigen. Hoofdstuk 4 beschrijft hoe verschillende dimensies van vertrouwen en van het uitoefenen van macht de allocatie van fysieke en innovatie leveranciersresources beïnvloedt. In de literatuur wordt vertrouwen in een klant vaak als positief beschreven en het uitoefenen van macht vaak als negatief. De bevindingen in hoofdstuk 5 laten echter een ander beeld zien. Vertrouwen heeft niet per se een positief effect en het uitoefenen van macht heeft niet per se een negatief effect op de resourceallocatie van een leverancier. Het vertrouwen van een leverancier in het gedrag van een klant heeft alleen effect als de klant een groot aandeel heeft in de omzet van deze leverancier. Als de klant slechts een klein aandeel in de omzet heeft, is het vertrouwen in de vaardigheden van deze klant juist belangrijk. Het uitoefenen van macht door te dreigen met boetes heeft een positief effect op de allocatie van fysieke resources als de klant een groot aandeel heeft in de omzet van een leverancier. Het uitoefenen van macht door gewenst gedrag te belonen heeft een positief effect op de allocatie van zowel fysieke als innovatieresources en lijkt niet sterk te worden beïnvloed door het aandeel dat de klant heeft in de omzet van de leverancier.

De bevindingen die voortvloeien uit de vier onderzoeksthema's geven nieuwe inzichten in hoe bedrijven preferentiële allocatie van leveranciersresources kunnen bemachtigen om een concurrentievoordeel te behalen uit relaties met leveranciers die ook concurrenten leveren. Deze inzichten bieden mogelijkheden voor toekomstig onderzoek naar de concurrentie voor leveranciersresources. Bijvoorbeeld, welke acties kan een bedrijf ondernemen om leveranciers van concurrenten "af te pakken", in welke situatie is dat verstandig om te doen en hoe reageren de concurrenten daarop? En wanneer is het verstandig om met concurrenten samen te werken om de resources van gemeenschappelijke leveranciers te bemachtigen? Dergelijke vragen bieden mogelijkheden voor toekomstig onderzoek. 


\section{Acknowledgements}

September 2010 I started the research project that lead to this dissertation. Now, four years later, I look back at an amazing time in which I met many interesting people, visited great places and learned a lot. In this section, I would like to thank those people who played an important role, both directly and indirectly, during the past four years.

First of all I would like to thank my supervisors Holger Schiele and Jasper Veldman. Holger, thank you for introducing me into the preferred customer topic and your guidance throughout the project. You gave me the directions I needed in the beginning of this project and the freedom to develop my own ideas in a later stage. Jasper, you were the critical friend I needed in the writing process. You thaught me the ins and outs of academic writing and challenged me to think critically about my research. We developed a close friendship and I look forward to our future collaboration.

I would like to thank the members of my Promotion Committee: professors Chris Ellegaard, Joop Halman, Koos Krabbendam, Jan Telgen and Arjan van Weele. Chris, my research was greatly inspired by your work. It is a great honor for me that you are part of my committee. Koos, thank you for being in my committee, but also for welcoming me in the OOHR group four years ago and everything you have done for me in the meantime. Joop, four years ago you were in my Master's graduation committee and I am happy that you are present at another important moment in my life. Jan and Arjan, it is great to have two of the frontrunners of the Dutch academic Purchasing and Supply Management community in my committee. I would also like to thank the chairman of the committee, professor Boorsma, for his guidance in the final stage of my promotion.

I would like to thank Lisa Hüttinger especially for her help in the research presented in Chapter 3, but also for the many fun moments during conferences and meetings in Enschede and Wolfsburg. I thank Henk Sierksma for his collaboration in the research that lead to Chapter 5, and Raymond Loohuis for introducing us. I kindly thank Bernd Zunk and his team at the Graz University of Technology and my friends at the University of Missouri - Kansas City for hosting my research visits. I also thank the students and colleagues involved in the Brasilisation study tour for the great time in Brazil.

There are many colleagues at the University of Twente that I would like to thank for their help and collegiality: Petra, especially for your help with statistics but also for many other things; Waling, one of my best friends in the office; Jeroen and André especially for the lifesaving help with AMOS; Marie-Christine and Jeannette for the (in Dutch) gezelligheid; Tanya for being a great colleague, Frederik for the many nice chats, my fellow $\mathrm{PhD}$ colleagues with who I had lots of nice dinners and drinks: Natalie, Arjan, Silvia, Björn, Gabi, Raja, Ellen, Martin. And I thank Adrián, Anna, Erwin, Klaasjan, Matthias, Marco, Michel, Michiel, Sandor, Siraj, Tom and the other (former) BA, NIKOS, IEBIS and UTIPS colleagues for the many great lunches, interesting discussions and pleasant collaboration.

Finally, I would like to thank those who were not directly involved in my research, but who were very important for me. I thank my parents and I am proud that my brothers Sander and Eise will be my paranymphs. I thank "de familie Koopal" and of 
course Sarah, because she is great. I would like to thank my friends from Joure, the TBK-guys, the Alsättersgatan 11B-crew and last, but definitely not least, the various generations of Morshuizers and those who regularly came to visit.

Niels Pulles

Enschede, August 2014 